\title{
Fishing in the Dark
}

\author{
Science, Values and \\ Deep Water Fisheries Research
}

by

Isabella Cawthorn

A thesis

submitted to the Victoria University of Wellington

in partial fulfilment of the

requirements for the degree of

Master of Environmental Studies.

Victoria University of Wellington

2007 



\begin{abstract}
This research sought to assesss the safeguards protecting scientific objectivity in New Zealand deep-water fisheries science decision-making fora. Managing depleted, slowgrowing and poorly-understood stocks demands particularly accurate, objective scientific information. New Zealand's Ministry of Fisheries undertakes deep-water fisheries management in an information-poor, high-stakes context. This context means neither of the two strictly separate policy and scientific advice processes is able, in isolation, to provide advice confidently. Preliminary investigations suggested that to enable the Ministry to meet the ongoing need for management of deep-water fishing, science fora are effectively taking on a quasi-policy role.

This research investigated whether deep-water fisheries science processes have sufficient safeguards to protect the objectivity of scientific decision-making in this difficult climate, thereby ensuring maximum accuracy in their advice. Twenty-two personal interviews were conducted with key informants, and analysed using grounded theory. Themes thus revealed were analysed in light of concepts from economics, philosophy of science and institutional analysis literature. Research suggested that the scientific process is ill-suited for handling non-scientific judgements, and the spread of non-scientific considerations into scientific fora is risking the objectivity of scientific analysis which is critical for fisheries management. Imbalanced stakeholder representation in scientific fora further imperils objectivity in these fora, with potentially significant implications for sustainable fisheries management.
\end{abstract}

Keywords: scientific objectivity, fisheries management, science for policy 



\section{Contents}

1 Introduction 1

1.1 Context of the research $\ldots \ldots \ldots \ldots \ldots$

1.2 Critical role of clean science $\ldots \ldots \ldots \ldots$

1.2.1 Science for fisheries management $\ldots \ldots \ldots$

1.3 Contribution of this research $\ldots \ldots \ldots \ldots$

2 Methodology 17

2.1 Aim and Objectives . . . . . . . . . . . . . . . . 7

2.1 .1 Aim of the study . . . . . . . . . . . . 7

2.1.2 Research question and objectives . . . . . . . . . 7

2.2 Methodological Approach: General Strategy of Inquiry . . . . . . . . 8

2.2.1 Research paradigm . . . . . . . . . . . . . . . . . . . . .

2.2.2 Research design . . . . . . . . . . . . . . . . 9

2.3 Research Processes . . . . . . . . . . . . . . . . . . . . . . 10

2.3.1 Objective 1: Literature review / conceptual framework . . . . 10

2.3.2 Objective 2: Primary data collection . . . . . . . . . . 11

2.3.3 Objective 3: Analysis of data . . . . . . . . . . . . 13

2.4 Limitations . . . . . . . . . . . . . . . . . . . . 15

2.4.1 Limitations of the research approach . . . . . . . . . 15

2.4 .2 Limitations of this study . . . . . . . . . . . . 15

3 New Zealand Context 17

3.1 The Status Quo . . . . . . . . . . . . . . . . . . 17

3.1.1 The Ministry's role and responsibilities _ . . . . . . . . 17

3.1 .2 Fisheries science processes . . . . . . . . . . 20

3.2 A Brief History . . . . . . . . . . . . . . . . . . 22

3.3 Conclusion .................... 30

4 Conceptual Framework $\quad 33$

4.1 Introduction . . . . . . . . . . . . . . 33 
$4.2 \quad$ Scientific Professional Excellence . . . . . . . . . . . . . . 33

4.2.1 Good scientific practice: foundation of science's authority . . 34

4.2.2 Scientific method: the Way to the Truth? . . . . . . . . 35

4.2.3 Science is fallible, but still dominates . . . . . . . . 38

4.2.4 Modernising forces on science . . . . . . . . . . . 38

4.2.5 Fisheries science: Formative decades . . . . . . . . . . 40

4.3 Forces Driving Government Agents _ . . . . . . . . . . . . . . . 42

4.3 .1 Generic drivers for action $\ldots \ldots \ldots 42$

4.3.2 What forces do government institutions exert on their agents? 44

4.3.3 What government agents do, day-to-day . . . . . . . . . . 49

4.3.4 New ways of doing things . . . . . . . . . . . . 51

4.4 Summary of Conceptual Threads . . . . . . . . . . . . . . . 51

4.4.1 The context of fisheries science . . . . . . . . . . 51

5 Results $\quad 55$

5.1 Introduction . . . . . . . . . . . . . . . . . 55

5.2 Government Fisheries Management Role . . . . . . . . . . . . 55

5.2.1 Philosopher kings or voices of the People? . . . . . . . . 55

5.3 Management for All New Zealanders? . . . . . . . . . . . . . 58

5.3.1 Provision for in situ value: policy guiding science . . . . 58

5.4 Potential Threats To Objectivity _. . . . . . . . . . . . . . 60

5.4.1 Money and Efficiency - research and funding . . . . . . 60

5.5 Scientists in Practice . . . . . . . . . . . . . . . . 64

5.5.1 Scientists in action: scientific purity, human frailty, both? . . . 64

5.5.2 Representation of non-scientific views in science fora . . . . 67

6 Discussion $\quad 75$

6.1 Introduction . . . . . . . . . . . . . . . 75

6.2 Science Only in Scientific Fora . . . . . . . . . . . . . . . 78

6.2.1 The gloves are off in meetings, but so are hats . . . . . . . 78

6.3 Meanwhile, Policy Enters Scientific Fora . . . . . . . . . . . . . 79

6.3.1 Pragmatic approach . . . . . . . . . . . . 79

6.3 .2 Effect of the pragmatic approach . . . . . . . . 80

6.3.3 MFish role: neutral and aloof? . . . . . . . . . . . 81

6.3.4 Neutral, or risk-neutralising? . . . . . . . . . . . 82

6.3.5 Scientific or democratic representation? . . . . . . . . 83

6.3.6 Defensive counter-positioning in science fora . . . . . . 85

6.4 Research Funding's Effects on Science . . . . . . . . . . . . . . . 86

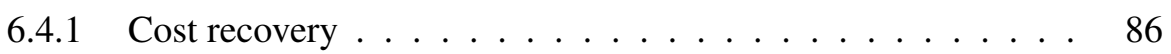


6.5 Summary . . . . . . . . . . . . . . . . . . . 87

$\begin{array}{lll}7 & \text { Conclusions } & 91\end{array}$

$\begin{array}{ll}\text { A Glossary } & 95\end{array}$

$\begin{array}{lll}\text { B Participant Information } & 97\end{array}$

C Interview scheme

$\begin{array}{ll}\text { D Human Ethics Forms } & 101\end{array}$

$\begin{array}{ll}\text { Acknowledgements } & 107\end{array}$

$\begin{array}{ll}\text { Bibliography } & 109\end{array}$ 


\section{Chapter 1}

\section{Introduction}

\subsection{Context of the research}

While New Zealand's seas are relatively unproductive in world terms, its Exclusive Economic Zone (EEZ) is large and hosts a great variety of biota, ${ }^{1}$ with unknown species continuing to be discovered. ${ }^{2}$ The fishing industry earns New Zealand around $\$ 1.35$ billion annually in export revenues. ${ }^{3}$ Both fisheries and marine environments provide considerable benefit to New Zealanders, but are conditionally renewable resources. Good management is the difference between the benefits from marine resources continuing to flow indefinitely, or being reduced or even temporarily or permanently cut off - with potentially enormous losses for New Zealanders. The government's Ministry of Fisheries (MFish) is responsible for managing all fishing within New Zealand's EEZ and extended Continental Shelf (and by New Zealand-flagged vessels outside it), as well as fishing's effects on the marine environment. The Ministry's empowering statute is the 1996 Fisheries Act (the Act), of which the purpose is "sustainable utilisation" of fisheries resources.

QMS: main tool The Quota Management System (QMS) is the principal tool by which the Ministry manages the nation's fisheries, supplemented by regulations to control environmental externalities. The QMS works by allocating property rights (tradeable access and withdrawal rights) to species. Total allowable catches (TACs) identify the fishable component of target stocks based on assessments of their maximum sustainable yield (MSY) subject to risk constraints.

\footnotetext{
${ }^{1}$ Organization for Economic Cooperation and Development (2007)

${ }^{2}$ Ministry of Fisheries (2007g)

${ }^{3}$ Ministry of Fisheries (2007f)
} 
Information needs The QMS relies on a steady supply of high-quality marine research to link its property right structure (quotas and access rights) to the animals in the sea via permissible levels of harvest and associated impacts. TACs are reviewed annually, and set based on two sets of information: scientific advice on the biological and ecological status of stocks and their "fishability", and policy advice on the "human" implications of different levels of fishing. A comparable process produces the less numerous limits on bycatch. Without this information, allowable catches, fishers' quotas and the limits on externalities such as bycatch are arbitrary numbers that could be above or below a safe level of fishing. This would mean either under-utilisation or over-exploitation of valuable renewable resources. New Zealand fisheries management is therefore very information-hungry.

Providing the information: two streams Scientific advice is generated each year through a cyclical process. MFish scientists, in consultation with fisheries stakeholders, form recommendations for what fisheries research the Ministry should purchase that year. MFish scientists use the "best available" scientific information (pursuant to the Act's section 10) to assess the status of target and bycatch stocks and the impacts of fishing activity, also in consultation with representatives of the main fisheries stakeholders. Policy advice, meanwhile, is generated through a linked but separate process, also including consultation rounds, which ascertains the social, economic and cultural effects of various catch-setting options. Based on these two sets of advice, the Fisheries Minister makes fisheries management decisions. The great majority of these are setting catch and bycatch limits.

The processes and people generating the two sets of advice are quite separate within the Ministry of Fisheries. The decision-making mandate of the annual scientific fora is strictly scientific and technological, limited to considering and advising the Minister on the ecological and biological implications of fisheries management decisions. Advice on the allocative and distributive effects of fisheries management decisions - the social, cultural and economic implications - is the domain of policymakers. These are much more subjective phenomena, varying according to people's perceptions and world-views. They are also assessed qualitatively rather than quantitatively (with the exception of financial returns to the fishing industry). In this thesis the terms "science" and "scientific" will be used to denote the natural sciences, the fields in which the Ministry of Fisheries' scientific fora operate. "Non-scientific" research or information will mean social science-based information that may be delivered by expert research but is not from the "hard" or "natural sciences". "Scientific fora" is therefore an umbrella term for FAWG, RPG and RCC meetings 


\subsection{Critical role of clean science}

Accurate scientific information on stocks is what connects the QMS and catch limits to the real animals in the sea, and is critical for New Zealand's fisheries to be properly managed. The idea of science as value-neutral investigation that is society's only reliable route to the "truth" has been significantly eroded in the past three decades. It is now acknowledged in many quarters that it is neither possible nor necessarily desirable that scientists hermetically seal off their work from their values ${ }^{4}$ (see Conceptual Framework). However this thesis' position is that the biota that fishers pursue are fundamentally objective phenomena, existing independently of our awareness or comprehension of them. Fish and other marine biota have certain biological and ecological characteristics that determine the nature of their existence regardless of humans' awareness and understanding of them. However our knowledge informs our actions in exploiting these resources, via fisheries management mechanisms. Scientists' role is to provide society with a picture of marine resources that is as accurate as possible, as closely representing the objective "truth" as possible — in other words, with minimal influence from subjective considerations.

"Fisheries" in this thesis will refer to fish stocks and the ecosystems in which they exist. "Fisheries research" and "deep-water research" therefore means research into fish and other living marine resources, and does not include research into non-living marine resources.

\subsubsection{Science for fisheries management}

Fisheries are socio-ecological phenomena, and New Zealand's fisheries management system, like every other, must simultaneously tackle the issues around both the human and the non-human components. It is difficult for scientific decision-making to operate in this context without being affected by non-scientific, subjective influences. Management decisions for deep-water fisheries, where scientific uncertainty ${ }^{5}$ is very high, yet fished-down stocks and slow-growing target and non-target species demand especially precise management, exhibit "wicked problem" characteristics. They fall into a zone between policy and science where neither process can provide useful information independently, and the boundary between scientific and policy considerations becomes indistinct. Because annual catch limits must be set, decisions must be

\footnotetext{
${ }^{4}$ Popper (1959); Polanyi (1958); Kuhn (1970); Feyerabend (1975)

${ }^{5}$ Wynne (1992) distinguishes uncertainty (knowing a system's parameters but not the quantitative importance of its components), risk (knowing a system's parameters and being able to quantitatively assess probabilities), indeterminacy (a relativist concept of knowledge highlighting the subjectivity of human understanding of phenomena) and and ignorance (essentially not knowing what we do not know) Wynne (1992). "Uncertainty" will be used as an umbrella term encompassing all these types, for they are all frequent features of deep-water fisheries management.
} 
made. In deep-water fisheries, a number of factors have meant that the scientific arm of the fisheries management process has picked up much of the burden of substantive decision-making.

These are not ideal conditions for regularised, robust scientific decision-making, but this alone does not undermine confidence in the process. However the composition of the science fora is additional dimension to New Zealand deep-water scientific decision-making. MFish's stakeholder consultation practices have been extended to the scientific process via "approved parties" (under section 12 of the Act). The scientific and technical function of these meeting rounds means specialist expert representation is needed to participate properly in debates. The cost of engaging expert representation means that the two stakeholders with the clearest interest in the results of deep-water research, environmental groups and fishing industry groups, are very unequally represented.

Without the highly specialised expertise that would permit examination of the scientific decisions themselves, a lay observer such as a taxpayer must look to the decision-making processes and structures for assurance that science is fulfilling its role and providing accurate - i.e. objective - information on what is happening in the seas. That quasi-policy decisions are being made in science-only fora exhibiting sharp disparities in representation suggests that the objectivity and therefore quality of scientific decision-making in those fora may be compromised.

Research question This thesis therefore seeks to investigate the following question:

Are there sufficient checks and balances in deep-water scientific fora such that one can be satisfied that the most accurate and objective picture of the resource is produced from a given amount of research spending?

Methodological issue The thesis was originally intended to provide an assessment of objectivity in research fora from an external vantage point, making only supplementary use of the personal views of individuals who participate therein. However an absence of records of the rationales for decisions to make a first-hand assessment of these questions (see Methodology section) meant that personal interviews became the central data source. Individuals closely involved in deep-water fisheries research were interviewed to gain insight into what goes on in the yearly scientific fora.

Process for examining research questions The unique elements of the New Zealand context were identified, and are found in Chapter Three. An Intellectual Framework was developed to identify the literary and theoretical context for the research, presented in Chapter Four. The main themes are: 
- the "science-related" constraints to which scientists in deep- water fisheries research fora are subject — both those imposed by the scientific community and by their own drivers. These include:

- the importance of objectivity and disinterestedness, and how to react to challenges to these

- how to deal with uncertainty

- the scientific tradition's notions of the truth and the role of the scientific community

- the non-scientific pressures to which these scientists are subject, generated both by the institutions in which they work and by their own personal drivers

- notions of the greater good

- ideas about the role of the private and public sectors

- views of ideal distributions of natural resources, and

- views of the role of science and policy.

Personal interviews lasting around one hour were conducted with key individuals in the Ministry's deep-water scientific decision-making processes, and with key people involved in deep-water fisheries and their management. Interview material was analysed using grounded theory techniques, observing the emergence of themes around:

- the political, economic, social and cultural context of fisheries science

- notions of appropriate and inappropriate subject-matter for scientific fora to consider

- the roles of government and other parties in fisheries science

- perceived drivers of scientific meeting participants' behaviour

- the effects that legal and policy frameworks and science funding structures have on the provision and handling of science.

Revealed themes were then analysed using the concepts in the Intellectual Framework, to give insight into the safeguards operating in deep-water fisheries research fora to ensure objectivity of scientific analysis. These results are presented in Chapter Five. Chapter Six is the Discussion, where the results are examined in light of the Conceptual Framework 


\subsection{Contribution of this research}

The issue of non-scientific influences in scientific and technical fisheries decisionmaking has so far not been examined in New Zealand. New Zealand fisheries science has had some general attention in academic literature since the bureaucratic reforms of the late 1980s and mid-1990s. ${ }^{6}$ Interpretive social-constructivist approaches using grounded theory, similar to that employed in this thesis, have been applied in some fisheries contexts overseas, ${ }^{7}$ but have not been applied to New Zealand.

\footnotetext{
${ }^{6}$ Starr et al. (1998); West et al. (1999); McClurg (2000); Harte (2001); McKoy (2006)

${ }^{7}$ Jentoft (1999); Weeks and Packard (1997)
} 


\section{Chapter 2}

\section{Methodology}

\subsection{Aim and Objectives}

\subsubsection{Aim of the study}

This thesis examines the Ministry of Fisheries' scientific fora, which provide biological and ecological information on New Zealand's deep-water fish and marine resources. It seeks to ascertain whether there are sufficient safeguards operating in these scientific and technical fora to protect the objectivity of their decision-making. This will assist understanding of how New Zealand's fisheries management processes are dealing with highly uncertain decision-making situations, where the boundaries between scientific and policy processes are indistinct.

\subsubsection{Research question and objectives}

This thesis approaches its aim via the following question and objectives:

Are there sufficient safeguards operating in deep-water scientific fora that without understanding the particulars of fisheries science, one can be confident that the scientific process is producing the most accurate and objective possible picture of New Zealand's deep-water biota?

Objective 1: Construct a conceptual framework from literature on the forces and phenomena involved in gathering and using scientific and non-scientific information for natural resource management. This will provide an impression of the different forces operating in the deep-water scientific fora which will inform the gathering and analysis of primary data.

Objective 2: Gather information on the forces and decision-making processes in New Zealand deep-water fisheries science fora. 
Objective 3: Analyse this data using grounded theory processes, and analyse the resulting hypotheses using the conceptual framework. This will place these propositions in the context of what is known about decision-making in similar circumstances, and suggest their implications for the objectivity and accuracy of the scientific information being produced.

Objective 4: Make an assessment of how likely it is that normal decision-making processes in deep-water scientific fora are ensuring the most objective, accurate pictures of deep-water resources are being fed into the fisheries management process. From this information, make recommendations for further research and investigation.

\subsection{Methodological Approach: General Strategy of Inquiry}

\subsubsection{Research paradigm}

As a researcher, openness about one's paradigm ${ }^{1}$ and the values one holds is essential. "Reflexivity" is therefore employed, which recognises the impossibility of conducting value-free research, but attempts to ensure that values do not make untrammelled incursions into the research process. ${ }^{2}$

There are two elements to the author's research paradigm for investigating the handling of science in New Zealand's deep-water fisheries management. It is based on a belief in the objectivity of the natural world, whose phenomena exist independently of human regard, but takes a social constructivist perspective to the human or social world. It draws on Kiser and Ostrom's (1982) "rational institutionalism" model. ${ }^{3}$ Here, individuals' perceptions of the world and their behaviour in interacting with it are determined by a combination of internally-generated motivations, including economic rationalism, and externally-generated world-views, guides and rules instilled by the institutions in which they live. "Institutions" in this formulation denotes "the conventions, norms and formally sanctioned rules of a society". ${ }^{4}$ This includes families, schools and other educational institutions, places of employment, social and cultural groups, and nation states. For this analysis the main institutional drivers of behaviour are governments, the scientific community, environmental non-government organisations (ENGOs), and companies. Their influences are most likely to be identifiable in analysing information about what takes place in fisheries research fora. Individual interviewees' opinions and actions in fisheries science fora are therefore presumed

\footnotetext{
${ }^{1}$ The ontological, epistemological, axiological and methodological assumptions one has about the world Bailey (2007, page 60).

${ }^{2}$ Bryman (2001, page 23)

${ }^{3}$ Kiser and Ostrom (1982)

${ }^{4}$ Vatn (2005, page 60)
} 
to be products of a complex and dynamic web of forces. An investigation of what these forces are, and how they interact to drive individuals' actions in fisheries science fora, must therefore take an appropriate approach. The subjective and highly interconnected nature of behavioural drivers prohibits a positivist or reductionist approach and demands one that is holistic and contextual.

This difficulty in predicting what might inform someone's views of a phenomenon (such as an event or a piece of research) makes it essential that the researcher avoid imposing ideas upon the data (part of reflexivity). An inductive approach within a qualitative and descriptive research design is therefore the most appropriate. Due to the limitations of this thesis' scope, case study research design will be used, with interviews from key informants. While these methodological choices limit the replicability, reliability and validity of the study, the insights gained from the flexibility and contextual holism of inductive inquiry will have greater scope for applicability. ${ }^{5}$

\subsubsection{Research design}

Two major approaches to qualitative research are evident in the literature: analytic induction ${ }^{6}$ and grounded theory. ${ }^{7}$ Analytic induction is unsuited to this thesis' research question, whereas grounded theory allows for ongoing revision of categorisations and theories. ${ }^{8}$ This makes it particularly suitable for studying a dynamic field such as fisheries management. Theory produced by a grounded theory study can be presented in different ways. ${ }^{9}$ In this thesis it will be used to paint a picture of the interplay between scientific and other forces in fisheries science fora, and ascertain the degree to which the objectivity of meetings' decision-making appears to be protected.

\section{Data sources and implications for research design}

The original research question was to assess the objectivity of research-purchasing decisions, based primarily on records of the Ministry of Fisheries' deep-water and aquatic environment research planning meetings. Objectivity would be assessed by comparing research projects' eventual fate with whether participants in research planning processes supported or opposed them. These data would be "triangulated" 10 by comparison with personal interview data from a few key stakeholders to strengthen resulting conclusions. However the Ministry's Chief Scientist, Dr Pamela Mace, advised

\footnotetext{
${ }^{5}$ Malinowski (1922)

${ }^{6}$ The researcher collects data until no cases that are inconsistent with his or her hypothesis are found and a general explanation of the phenomenon is thereby established Bryan (1984).

${ }^{7}$ Glaser and Strauss (1967)

${ }^{8}$ Charmaz (2000)

${ }^{9}$ Cresswell (2007)

${ }^{10}$ Denzin (1978); Hill (1984)
} 
me that it is impossible to ascertain why any research project was approved, adjusted or rejected without attending the meeting in question. This is because record-keeping is somewhat sporadic; with the exception of any personal notes taken by participants, records of research planning group (RPG) meetings are exclusively verbal. Where official records exist for research coordinating committee (RCC) meetings, they are not sufficiently detailed to provide the desired information (Mace pers. comm. 2.10.2006). Tantalisingly, in some years (such as in 2004-05 and 2006-07), the information sought has been recorded and made public, but this has been done too infrequently to provide a usable sample.

Public record-keeping has implications for open government, public participation and democracy, as reflected in the existence of the Official Information Act (1982), ${ }^{11}$ and is therefore an important part of public management. However record-keeping takes resources away from Ministries' core business, so the ratio by which effort should be allocated to record-keeping and to the core business of government is an ongoing issue. $^{12}$

This lack of documentation of the reasons for research planning decisions necessitated that the research shift to assessing the scientific process as a whole via key participants' individual testimonies. More interviews were then arranged, a qualitative research design was constructed, and the reduction in the robustness of the thesis' conclusions was acknowledged. However the focus on procedural robustness as a proxy for the quality (objectivity and therefore accuracy) of scientific outputs remained, as this is one of the few ways a layperson can assess the scientific processes.

\subsection{Research Processes}

\subsubsection{Objective 1: Literature review / conceptual framework}

The New Zealand Context section provides the real-world context for interpretation of the data. It gives a brief history of New Zealand fisheries management, with a focus on recent events in the deep-water fisheries and aquatic environment areas, and outlines the main elements now involved in managing New Zealand's marine resources. Material for this section came principally from books and academic articles, and some information came from research participants during interviews.

\footnotetext{
${ }^{11}$ Shaw and Eichbaum (2005)

${ }^{12}$ Pollitt (2000)
} 


\subsubsection{Objective 2: Primary data collection}

\section{Method and participant selection}

In-depth personal interviews were chosen over other data-gathering methods such as questionnaires and surveys in order to gain a socialised perspective of the subject. ${ }^{13}$ The semi-structured interview style was chosen to allow participants to cover topics that they felt were relevant and thereby ensure that data collection was not unduly constrained by the researcher's own ignorance of the area - the "observer as participant". ${ }^{14}$ The aim was to restrain, to a moderate level, researcher "participantness" where the researcher acts or has the effect of acting as a participant and affects the outcome of the research. ${ }^{15}$

The "key informant" purposive approach was taken to selecting interviewees, ${ }^{16}$ as an individual's "key" status in their field also usually means they have a broad, deep knowledge of the area. ${ }^{17}$ Initially participants were chosen by identifying the major stakeholder groups, ${ }^{18}$ noting who key figures were from relevant organisations' staff lists, and observing the occurrence of names in submissions and conference papers. The major stakeholder groups for deep-water fisheries management are: the Ministry of Fisheries (in its role as representing the interests of the people of New Zealand), the fishing industry (comprising a range of stakeholders from quota owners through skippers to political representatives), environmental NGOs, science providers, and Maori. The absence of recreational and Maori customary fishing in deep water, and the fact that these groups are rarely if ever represented in deep-water research fora renders the "action arena" 19 narrower than for shared fisheries, and therefore these groups were not pursued. Inside these major groups, several sub-groups needed to be represented in the participant sample: present and past Ministry of Fisheries science policy staff (to ensure good coverage of the relevant period), skippers, managers and political representatives from the fishing industry, and both NIWA and competitor science providers. The small number of environmental representatives who regularly attend research meetings, and the paucity of science providers who contest for Ministry and industry deep-water research contracts, both constrained the depth of participant selection.

Once identified, potential participants were then approached by phone (if in or near Wellington) or by email (if overseas), and informal discussions of fisheries manage-

\footnotetext{
${ }^{13}$ Marshall and Rossman (2006, page 133)

${ }^{14}$ Gold (1969)

${ }^{15}$ Patton (2002)

${ }^{16}$ Patton (2002)

${ }^{17}$ Davidson and Tolich (2001, page 123)

${ }^{18}$ Grimble (1998)

${ }^{19}$ Ostrom et al. (1994)
} 
ment often ensued as people suggested areas the study could focus on. From then a "snowballing" approach was used, as during initial informal discussions and later interviews, participants often also recommended other individuals whom I subsequently contacted. Of the 24 people approached, one person refused outright to be interviewed, and two others had to withdraw due to personal and family problems.

\section{Interviewing}

Primary supervisor Cath Wallace stipulated that in order to ensure would-be interviewees felt secure participating in the research, despite her activity as a lobbyist for the environmental movement, provision be made to protect interview material. This was endorsed by the University's Human Ethics Committee, and entailed the maintenance of "Chinese walls" and other provisions (described briefly below) to ensure that no information that was not authorised to go in the thesis' final copy was communicated to Ms Wallace (see Participant Information sheet in Appendix C). Secondary supervisor Richard Willis took on the role of supervising sensitive material.

Performed between August 2006 and August 2007, the semi-structured interviews lasted around one hour and took place in person, by telephone or via Skype. One interview was via email. Participants could choose how anonymously their material would be cited, and could opt to receive a summary of the findings prior to publication. About half the sample took this opportunity. There were many tantalising comments made in informal conversations associated with this study, including in preliminary discussions to interviews, but if official interview questions could not draw these out "on the record", they could not be used.

Interviews were discursive in form, with questions drawn from a series of potential question schedules. These covered the themes of interest to the research and were sent to each interviewee in advance (see Appendix C). Questions' wording was regularly modified to improve clarity and suit each participant's area of expertise. Interviews would begin with Human Ethics approval formalities, and move to an open question that encouraged participants to range over the subject, followed by more directed, probing questions as recommended by Flick. ${ }^{20}$ Clarifying and follow-up questions were both essential and regularly used, in order (respectively) to minimise the need for ex-post-facto interpretation and to ensure interviewees addressed the research focus areas.

Interviews were tape-recorded and transcribed, and both transcriptions and recordings were analysed. While these processes were time-consuming and expensive and recording undoubtedly had an effect on participants' responses,${ }^{21}$ it was important

\footnotetext{
${ }^{20}$ Flick (2002)

${ }^{21}$ Dunn (2005)
} 
to appreciate inflexions and tones (such as sarcasm) in responses and to ensure loss of context was minimised. ${ }^{22}$ The disadvantages of cassette recordings were revealed when two tapes became stretched and damaged. Following this a digital recorder was procured for the remaining interviews.

\subsubsection{Objective 3: Analysis of data}

In accordance with grounded theory, responses were coded at increasing levels of analysis. $^{23}$

\section{Open coding}

Initial ("open") coding was according to the basic subject-matter of the response (which did not always match the question asked, though such non-answers can themselves be data $^{24}$ ). The following are some examples of codes:

- Section 10 / precautionary principle - effect, definitions

- Management for all New Zealanders - (including non-extractive uses)

- Advocacy in science - appropriate and inappropriate matters

- Cost recovery - perverse incentive?

- Commercial science — trustworthiness?

- Macro-scale direction for New Zealand fisheries

- Role of a government scientist

There were 25 different open codes in total, which were numbered for quick reference. Adhesive flags with corresponding numbers were stuck to the pertinent sections of interview transcripts in order to facilitate recourse to the raw data (required by grounded theory's iterative process). Memos were taken from the outset, as recommended by Backman and Kyngäs (1999).

\section{Axial coding}

Secondary ("focussed" or "axial") coding examined the issues participants considered relevant to the question (which revealed what causal connections and relationships they

\footnotetext{
${ }^{22}$ Opie (2001)

${ }^{23}$ Coffey and Atkinson (1996)

${ }^{24}$ Dunn (2005, page 94)
} 
perceived in the issues in question), and the language participants used (which indicated their opinions about these things). For example, part of a participant's response may be initially coded with "Commercial science - trustworthiness?", and might focus on the importance of scientifically-designed, independent research (which is expensive). It would also contain the comment "I hate to say it but a big stumbling block is industry people trying to do cheap and nasty surveys to save money". Therefore this data would receive axial codes identifying independent research, its costliness, and the cost-consciousness of industry, and a memo identifying the participant's reluctance to express the statement and the relative strength of the "cheap and nasty" idiom to describe industry research.

\section{Tertiary coding and theory development}

Tertiary coding sought underlying themes and mental models as signalled by the rhetoric and metaphors participants used. Theory was being developed by this stage (though it was constantly evolving as its relationship with codes and the raw data revealed different themes and trends). This dynamism and iterative process are part of the essence of grounded theory. ${ }^{25}$

Tertiary codes came from the language that participants used, which indicates underlying assumptions about the subject ${ }^{26}$ (though tailoring to the researcher's presence is an inevitable phenomenon ${ }^{27}$ ). For example, participants' use of "we" and "they" indicates a sense of inclusion in or standing outside certain groups, while a participant's use of the language of efficiency (productivity, maximising value, waste) suggests a different view of marine resources from someone who employs the language of assets (guardian, trusteeship, legacy). Memos were used to chart the development of these emerging elements, and to identify relationships and causal links between both different participants' (and groups of participants') perceptions, and between the data and the academic literature in the conceptual framework section.

The conceptual framework was used to place some context around and help describe the observed views, perceptions and relationships. Policy and institutional analysis literature ${ }^{28}$ helped by providing some axial codes which eventually formed the structure of the Discussion.

\footnotetext{
${ }^{25}$ Corbin and Strauss (1990)

${ }^{26}$ Silber (1995)

${ }^{27}$ Fineman and Opie (1987)

${ }^{28}$ Young et al. (1996); Yandle (2001)
} 


\subsection{Limitations}

\subsubsection{Limitations of the research approach}

It is extremely difficult to achieve and maintain the "clean slate" mental state, free from preconceived notions of what might emerge from your data, that grounded theory advocates. ${ }^{29}$ The requirements to present a reasonably well-formulated research question for a thesis proposal force a certain amount of preconception upon the researcher. Indeed, some authors argue that the passiveness of the researcher is over-emphasised in grounded theory; themes do not "emerge like daffodils from the data", but are drawn out by the researcher. ${ }^{30}$ Funder (2005) argues that researchers' institutional experience and context (with institution in its broad sense) play an enormous role in how investigated phenomena are structured and labelled. ${ }^{31}$ He cites Fetterman's (1998) statement that researchers should ideally enter the field "with an open mind, not an empty head".32

A particular pitfall of grounded theory is risk of losing the context of respondents' comments (and misinterpreting them) as coding or categorisation proceeds. ${ }^{33}$ Some participants requested to "vet" any instances where their material would be used, which allowed correct context to be ensured. ${ }^{34}$ However this was time-consuming and relatively onerous given ongoing changes to the writing by the researcher, as well as changes requested by participants, so unless a participant requested "vetting", recourse was made to the raw data rather than the interviewee.

\subsubsection{Limitations of this study}

The small interviewee sample added to the high level of subjectivity inherent in both the data's form and in its interpretation. In particular, the attenuated sample of environmental non-government organisation (ENGO) respondents mean that this group was under-represented. The highly qualitative and subjective approach means that the researcher's subjective judgements are inevitably interwoven from the outset. However, the data collected and approach taken provide a more holistic view of the subject than an empirical approach, and the more contextualised nature of such a methodology makes it better suited to informing practical application.

The conclusions of this study will highlight an area of New Zealand fisheries management that has not yet benefited from having the spotlight of academic and policy

\footnotetext{
${ }^{29}$ Backman and Kyngäs (1999)

${ }^{30}$ Bailey (2007, page 127 )

${ }^{31}$ Funder (2005)

${ }^{32}$ Fetterman (1998)

${ }^{33}$ Jacobs (1970, viii)

${ }^{34}$ Questioning the authenticity of a participants' ex post facto retraction of comments cannot be entertained, as a participant's word is final.
} 
examination trained upon it. While the spotlight approached recently with the Fisheries Amendment Bill 2007's proposal to amend section 10, research purchasing was not directly in its focus. This thesis' conclusions will fall into a largely unstudied area. Even if the recommendations are ignored, the issue of how institutional structure and processes can distort how values and science are used in fisheries decision-making will hopefully be examined by the academic and policy community. 


\section{Chapter 3}

\section{New Zealand Context}

\subsection{The Status Quo}

New Zealand exercises sovereign rights of management under the 1982 United Nations Convention on the Law of the Sea (UNCLOS) over an Exclusive Economic Zone $(\mathrm{EEZ})^{1}$ of approximately 4.2 million square kilometres which descends to depths of 10,000 metres. $^{2}$ The MFish is the principal government department mandated to govern New Zealand's seas, managing fisheries and most of the marine environment under the Fisheries Act 1996 (the Act). The Act's purpose is to provide for the utilisation of fisheries resources while ensuring sustainability (section 8). Several other agencies manage different aspects of the seas under a variety of Acts, ${ }^{3}$ but in terms of area the MFish has by far the greatest responsibility. (For discussions of jurisdictional issues in New Zealand seas, see Weeber (1998) and Peart (2005).)

\subsubsection{The Ministry's role and responsibilities}

Like all Ministries, MFish receives tax funding to conduct its activities, and is obliged to follow traditional processes for budgeting. It requests its yearly funding from Parliament in a process timetabled around the financial year (rather than the October-toOctober fishing year). The Primary Production Select Committee reports to Parliament recommending the Ministry's budget and also financially reviews the Ministry every year. The Office of the Controller and Auditor-General can conduct financial and per-

\footnotetext{
${ }^{1}$ See Glossary of Abbreviations for explanations of acronyms in this text.

${ }^{2}$ Fisheries (2005)

${ }^{3}$ These include the Department of Conservation (which administers marine reserves, marine mammals and threatened species under the Conservation Act 1987, Marine Reserves Act 1971, the Wildlife Act 1953 and the Marine Mammals Protection Act 1978), territorial authorities (which manage coast and inshore waters out to 12 nautical miles (nm) under the Resource Management Act (RMA) 1991, and Maritime New Zealand (Ministry of Transport) which administers nautical travel under the Maritime Transport Act 1994.
} 
formance audits of MFish under the under the Public Finance Act (1989), checking for adherence to its projected output classes. As part of the public service, whose political independence is an important if somewhat theoretical aspect of New Zealand's constitutional structures ${ }^{4}$ ), the MFish must also ensure that its policy is consistent with over-arching government strategies. These are currently articulated in documents such as the Growth and Innovation Framework, Environment 2010 and government policy themes. ${ }^{5}$ Government departments' policy is coordinated by the Treasury, the State Services Commission and the Department of Prime Minister and Cabinet. ${ }^{6}$ The independence of the public service as advisors to Ministers is an important aspect of New Zealand's constitutional structure; its loyalties must be to the government of the day rather than a political party. ${ }^{7}$

MFish sees its purpose as ensuring that fisheries are sustainably used within a healthy aquatic ecosystem. ${ }^{8}$ This entails advising the government on the policy and legal frameworks for the efficient and sustainable use of fisheries, delivering services that support their effective operation, protecting the aquatic environment, managing marine biosecurity risks, maintaining relationships with tangata whenua and supporting the Crown's obligations to Maori for fisheries. ${ }^{9} 130$ species are commercially fished in New Zealand, of which 97 species and species complexes are in the Quota Management System (QMS), the Ministry's principal tool for managing fisheries. ${ }^{10}$ Of these, 55\% are known to be at or near target levels (72 of 130 stocks). 85 stocks have sufficient information to ascertain stock levels. Quota holdings are worth approximately $\$ 3.8$ billion, and the Ministry's budget for 2007/08 is $\$ 93.7$ million excluding GST. ${ }^{11}$ Research budgets average around $\$ 25$ million annually. Around $33 \%$ of the Ministry's costs are recovered from the industry.

ITQs, ACEs, TACs and TACCs MFish manages fisheries principally by setting Total Allowable Catches (TACs) under section 13 of the Act for target stocks. TACs are for all fishing on fish stocks ${ }^{12}$ which include allocations for recreational, Maori customary and commercial extraction (the latter is the Total Allowable Commercial Catch or TACC), including consideration for any illegal fishing. MFish also sets "sustainability measures" to ensure that marine resources are distributed properly over time (sec-

\footnotetext{
${ }^{4}$ Mulgan (2004)

${ }^{5}$ Families: Young and Old, Economic Transformation, and Strengthening National Identity, to which "sustainability is central" Clark (2007, page 6).

${ }^{6}$ Shaw and Eichbaum (2005)

${ }^{7}$ Martin (2003)

${ }^{8}$ Ministry of Fisheries (2007d)

${ }^{9}$ Ministry of Fisheries (2007d)

${ }^{10}$ Ministry of Fisheries (2007a)

${ }^{11}$ Ministry of Fisheries (2007f)

${ }^{12}$ Ministry of Fisheries (2007h)
} 
tion 11). Fishers can hold one or both of a withdrawal right (Annual Catch Entitlement or ACE) and an access right (Individual Transferable Quota or ITQ), which Kerr et al (2003) describe as a right to a perpetual stream of ACEs. These are tradeable rights to a percentage of the TAC for the pertinent stock, with decentralised trading occurring relatively freely in multiple markets ${ }^{13}$. Catches must be matched with quota, and landed fish are tracked through comprehensive reporting requirements (administered since 2001 by an industry-run company, FishServe). The Ministry is responsible for compliance and enforcement, done with a variety of measures ranging from licensed fish receivers to at-sea surveillance by on-board observers and Air Force Orion aircraft. Criminal penalties apply to such behaviour as falsifying records, over-catching and dumping fish. In the QMS' early days research showed signs of improving fisher satisfaction with enforcement, ${ }^{14}$ but enforcement capacity is an ongoing problem. ${ }^{15}$

B $_{\text {MSY }}$ and other obligations Section 13 obliges the Minister to manage fish stocks at or above the biomass that will support the maximum sustainable yield ( $\left.\mathrm{B}_{\mathrm{MSY}}\right)$. While $\mathrm{B}_{\mathrm{MSY}}$ is calculated using fisheries science, the choice of harvest strategy also influences the biomass level to which the stock is managed. MFish describes s13 as prescribing a 'threshold' for ensuring sustainability, with limited scope for management above and below $\mathrm{B}_{\mathrm{MSY}}$ in accordance with the Act's Purpose. This interprets $\mathrm{B}_{\mathrm{MSY}}$ as a target reference point rather than a limit . ${ }^{16}$

Section 5 stipulates that decisions made under the Act must be consistent with New Zealand's international legal obligations for fisheries, and with the provisions of the Treaty of Waitangi (Fisheries Claims) Settlement Act (1992). The Act's s12 and the Ministry's commitment to "open government" in "Towards Fisheries 2010" oblige the Minister, when setting TACs and sustainability measures, to consult with the classes of persons nationally representative of those having an interest in the stock or aquatic environment affected by the fishing in question. This usually includes Maori, environmental, commercial and recreational interests. ${ }^{17}$ The Minister has discretion to determine these classes, ${ }^{18}$ and once determined, the Ministry is only statutorily required to "... consult with the person or organisation who is considered to be representative of those classes of persons". ${ }^{19}$ There is significant case-law on consultation, both gener-

\footnotetext{
${ }^{13}$ Kerr et al. (2003, page 124)

${ }^{14}$ Boyd and Dewees (1992)

${ }^{15}$ Ministry of Fisheries (2004)

${ }^{16}$ Ministry of Fisheries (2006a, 2007h)

${ }^{17}$ The Fisheries Act is relatively unusual in its absence of provision for wider public participation. Other major environmental statutes make such provision, including the Hazardous Substances and New Organisms Act (2003), the Conservation Act (1987) and the Resource Management Act (1991).

${ }^{18}$ Ministerial discretion is a major part of the Act. The highly operational level of research planning and stock assessment decisions, however, means that it is extremely rare than the Minister would ever decide to exercise discretion and depart from the Ministry's recommendations on these matters.

${ }^{19}$ Ministry of Fisheries (2001b, page 4)
} 
ally and for fisheries.

\subsubsection{Fisheries science processes}

\section{Topography of fisheries research procurement}

Each year the Ministry's Science Group runs three interlocking processes which provide the fisheries research that links the QMS to the animals in the sea. A diagram of the science process is shown below (see 3.1). Contestability of government science purchasing, instituted as part of the public sector reforms of the mid-1990s and designed to maximise efficiency of supply, ${ }^{20}$ requires the Ministry to procure fisheries research by competitive tender. For expensive projects, transparency requirements necessitate engaging external experts to assess tenders. While there is a healthy science provider market in most fisheries, independent research capacity in the deep water is chiefly limited to the National Institute of Water and Atmospheric Research, NIWA, which wins the great majority (by value) of deep water contracts. ${ }^{21}$

These processes are broadly guided by the government's priorities as indicated by such documents as the Biodiversity Strategy, "Towards Fisheries 2010", and the Growth and Innovation Framework. ${ }^{22}$ The Science Group runs Fishery Assessment Working groups (FAWGs) which produce scientific information on stocks' status and (via a separate but related process) the sustainability measures needed to maintain stocks in accordance with the Act. Research Planning Groups (RPGs) assess species' research needs, and manage the processes that send a recommendation to the Minister to procure research that produces stock assessments, sustainability research and general public good research. They undertake consultation on research procurement and funding and the means by which it is paid for.

A major feature of the New Zealand fisheries science landscape is cost recovery for fisheries management services. This is explained further below (see "Funding and management reform"). In essence, the fishing industry must reimburse the government for the costs of fisheries management from which it is the principal beneficiary via the Fisheries Services Levy (to MFish) and the Conservation Services Levy (to the Department of Conservation). The Ministry funds research which is deemed to be in the wider public interest, and the industry is cost-recovered for research such as stock assessments (which is of commercial benefit) and for part of the cost of research that benefits both the industry and the public. The latter is calculated on the "attributable costs principle" as laid out in "the Agreement" (the Fisheries Cost Recovery Rules 2001, statutory regulation 2001/299 under section 263 of the Act). The Agreement

\footnotetext{
${ }^{20}$ Cartner and Bollinger (1997)

${ }^{21}$ McKoy (2006)

${ }^{22}$ Ministry of Fisheries (2006d)
} 


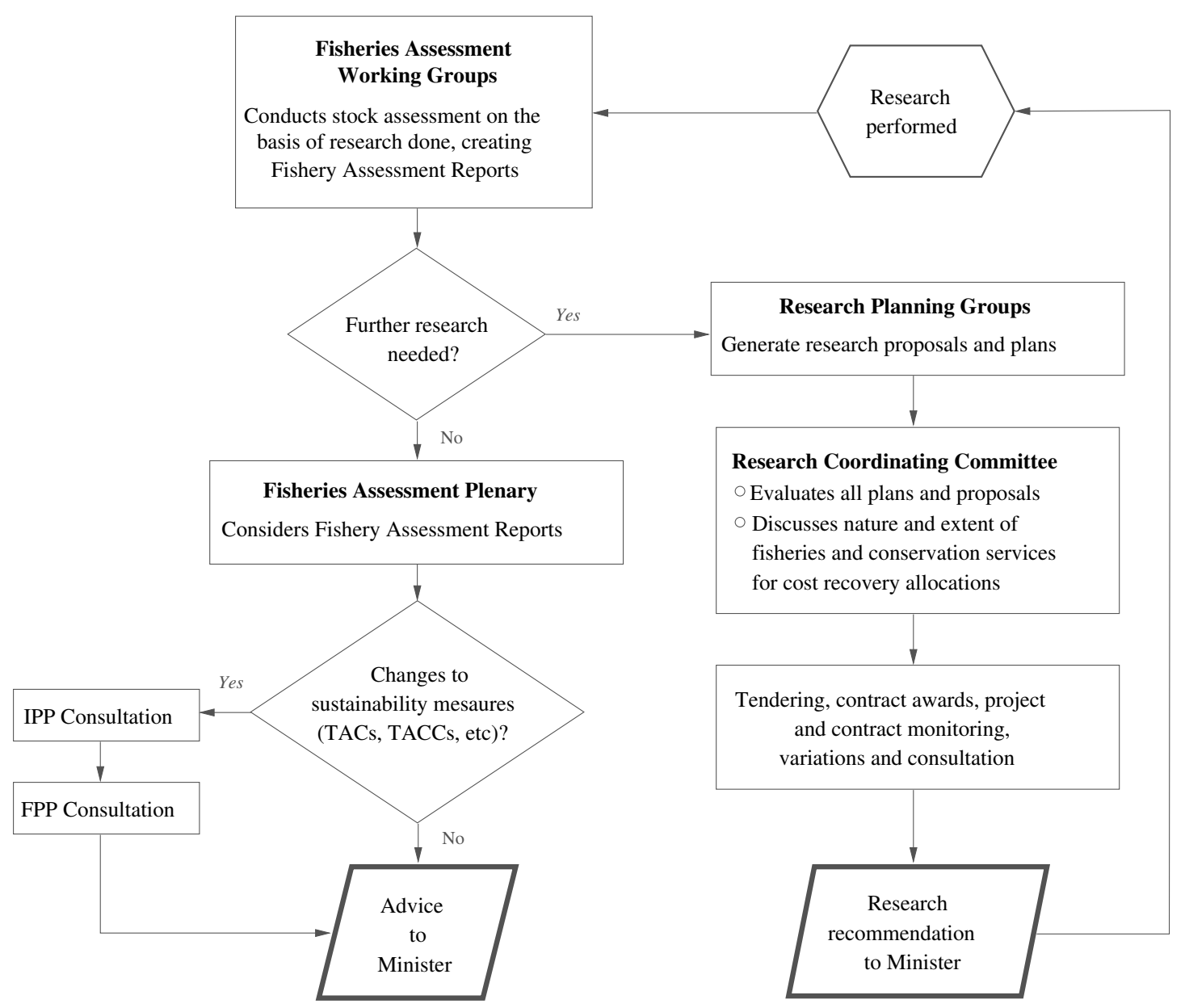

Figure 3.1: A simplified version of the Ministry of Fisheries' decision-making processes. 
dictates inter alia the proportions of costs of fisheries management and conservation services to be borne by the fishing industry, either as a specific percentage or by means of a formula. There is also a "rule of thumb" stating that the costs to be levied on a fishery do not exceed $10 \%$ of the port price of that fishery's fish for that year (Mace, pers. comm 15.10.2006). Consultation on procurement of most marine research is open to all stakeholders, whereas consultation on cost recovery processes is restricted to commercial stakeholder organisations (CSOs) and the Ministry. Stakeholder participation in management fora varies widely, and in research fora it is dominated by scientific representatives from NIWA and the fishing industry. As observed, deep water fisheries are distinct from "shared fisheries" in that they lack recreational and Maori customary extraction. Representation by non-industry interest groups in deep-water scientific fora is usually restricted to occasional appearances by one or at most two ENGO representatives. ${ }^{23}$

\subsection{A Brief History}

Prior to the advent of the QMS, New Zealand's fisheries were managed under a somewhat primitive combination of limited-entry licenses and input controls. ${ }^{24}$ There was little research undertaken, ${ }^{25}$ but when in the 1960s foreign fishing activity alerted New Zealand to its under-utilisation of its offshore fisheries resources the government began encouraging expansion of the fishing industry. ${ }^{26}$ Fisheries management and research became more organised with the creation of the Marine Department and its Fisheries Research Division, but research was restricted by the small size of the Division's research vessel, the James Cook. Government development initiatives saw huge increases both in vessel numbers ${ }^{27}$ and catches, ${ }^{28}$ but particularly in the deep water, research was essentially racing fishing effort to ascertain $\mathrm{B}_{\mathrm{MSY}}$ before the industry fished past it. ${ }^{29}$ However the signs of overexploitation were already unmissable in the inshore fisheries, and by the 1980s over-capitalisation was also evident despite attempts to rein in fishing effort. ${ }^{30}$

\footnotetext{
${ }^{23}$ Anon (2004-2005)

${ }^{24}$ Straker et al. (2002)

${ }^{25}$ Nightingale (1992)

${ }^{26}$ Sharp (1997)

${ }^{27}$ Sharp (1997)

${ }^{28}$ Straker et al. (2002)

${ }^{29}$ (Cullen and Memon, 1990; Johnson, 2004)

${ }^{30}$ (Cullen and Memon, 1990; Ministry of Fisheries, 1996)
} 


\section{Contraction and a new regime}

By 1982 industry over-capitalisation, fuelled by government assistance, was severe The licensing and registry regime was also causing a huge transaction cost burden. ${ }^{31}$ The government seized two main policy tools to remedy the situation: fleet reduction and a new management paradigm of property rights in fish. The fleet reduction policies managed to remove small fishers and reduced the administrative burden, but at significant social and economic cost, particularly to Maori. ${ }^{32}$ The new property rights scheme was successfully trialled as a prototype with a resource rental in the relatively new deep-water fisheries in 1983, with a view to extending it to inshore fisheries. In 1984 the new fisheries policy was announced, based on ITQs and ACEs and designed to promote efficient utilisation, value-maximisation and a stewardship ethic in fishers. ${ }^{33}$ The associated per-tonnage resource rental was also a multi-goal policy tool. It was designed to return some of the economic rent from fisheries to the public, offset the government's fisheries management costs, and buffer the risk burden the government adopted by using quota trading to adjust catch levels. ${ }^{34}$ The government would tender for surrender of quota (and eventually buy and sell them) from industry to effect changes in TACs, which were mostly large reductions due to the extensive over-exploitation. Sharp writes that the period 1983-86, during which the new policies were being debated, saw the original bold reductions in TAC whittled away until "... with few exceptions, the proposed TAC [had] increased over this period". 35 In light of the meager existing science on target species, which was nevertheless able to show over-exploitation of many stocks, the failure to achieve any decreases in catch to accompany the new regime did not bode well for sustainability.

\section{Stumbling blocks}

Catch reductions The need for essential catch reductions quickly made the government's quota trading activity very expensive. ${ }^{36}$ This plus the potential politicisation of TACC adjustments motivated the government to shift the risk burden of fisheries fluctuations onto resource users. The 1986 Fisheries Amendment Act changed ITQs from fixed tonnages to percentages of a stock's TACC, with market compensation for reductions.

\footnotetext{
${ }^{31}$ Straker et al. (2002)

${ }^{32}$ Cullen and Memon (1990)

${ }^{33}$ Straker et al. (2002); Sinner and Fenemor (2005)

${ }^{34}$ Clark et al. (1988); McClurg (2000)

${ }^{35}$ Sharp (1997, page 513)

${ }^{36}$ Sissenwine and Mace (1992)
} 


\section{Maori rights}

The way the new fisheries management policy had sidelined Maori was the source of considerable resentment, and the government's collection of a resource rental for fish (an exercise of sovereign rights guaranteed to Maori under the Treaty) was a particular insult. After two landmark court cases, the Court of Appeal forced the government to halt the implementation of the QMS pending reports on Treaty of Waitangi claims by the Waitangi Tribunal. Further judicial recognition of Maori fisheries rights under the Treaty of Waitangi forced the government to settle Treaty claims in order to complete the QMS's implementation. ${ }^{37}$ This was done via the 1989 Maori Fisheries Act and the ground-breaking settlement deal for indigenous fisheries rights enacted in the 1992 Treaty of Waitangi (Fisheries Settlement) Act. This provided for a transfer of new ITQs to Maori and for development of Maori fishing capacity. ${ }^{38}$ (For a comprehensive examination of the settlement, see Guth 2001).

\section{Science-based management?}

Science-based deep-water fisheries management in New Zealand has had a patchy history. During the late 1980s and early 1990s, the initial huge catches of orange roughy were diminishing fast; the species' "bankrolling of the New Zealand fishing industry" ${ }^{39}$ had come to an end. ${ }^{40}$ The original biological estimates of roughy productivity were flimsy indeed, based on international defaults in the absence of information, but the species' aggregation behaviour had allowed the fact that the estimates were quite inappropriate to remain hidden by high catches. ${ }^{41}$ By 1988 , however, following an experimental rise in one fishery's quota (adaptive management was formally introduced in $1991^{42}$ ), the level of depletion had revealed itself as grave indeed. ${ }^{43}$ When the government moved in 1988 to make roughy ITQs proportional rather than tonnages, proposing significant TAC reductions without compensation, the industry challenged it in court seeking almost $\$ 130$ million in damages. ${ }^{44}$ In order to forestall further litigation, ${ }^{45}$ the government negotiated an out-of-court settlement whereby compensation was payable for TAC reductions for five years, during which time decreases would be effected incrementally in three fisheries while the fourth's TAC would be doubled in

\footnotetext{
${ }^{37}$ Boast (1990)

${ }^{38}$ Memon and Cullen (1996)

${ }^{39}$ Johnson (2004, page 407)

${ }^{40}$ Annala et al. (2003)

${ }^{41}$ Sissenwine and Mace (1992)

${ }^{42}$ Holdsworth (2004)

${ }^{43}$ Clark (2001)

${ }^{44}$ McClurg (2000)

${ }^{45}$ Straker et al. (2002)
} 
an adaptive management experiment. ${ }^{46}$

In 1988, the fishing industry contracted scientists from the Imperial College of London to re-assess the orange roughy stock assessment. In 1990 the University of Washington became the industry's preferred science provider and have produced alternative stock assessments and second opinions ever since. ${ }^{47}$

\section{The QMS: financial burden}

The early 1990s were a difficult period for the new fisheries management system. Orange roughy had shone a spotlight on the scientific foundations of the QMS and found them to be shaky, inshore stocks were not recovering, and recreational fishers had been largely ignored by fisheries policy. ${ }^{48}$ Resource rentals were being vociferously protested by industry groups in court and out, and fundamentally challenged by Maori (who were also legally entitled to a substantial compensation package). The self-funding ability of the QMS had failed to materialise; Pearse wrote in a 1992 review of fisheries policy that fisheries were in fact "... a substantial net loss to Treasury", and recommended cost recovery instead of resource rentals, ${ }^{49}$ a conclusion echoed by the 1991 review of fisheries legislation. ${ }^{50}$ In 1992, Cabinet decided to employ the "avoidable cost" principle to calculate the quantum of costs payable by the industry. This was defined as "[a]ll expenditure that arises purely as a consequence of the existence of commercial fishing should be recovered from the industry. In addition, some nonavoidable costs which are 'jointly' shared by the commercial and non-commercial sectors, such as research, should be chargeable to the industry, in recognition of the degradation of non-commercial values as a result of commercial exploitation". ${ }^{51} \mathrm{En}$ vironmental groups were among non-industry stakeholders who resisted the change to attributable cost, arguing that the "return to the nation" aspect of avoidable cost was essential. ${ }^{52}$ However following vociferous lobbying by industry groups, Cabinet agreed in February 1994 to a reduced version of avoidable cost whereby government would bear a larger percentage of non-avoidable costs. ${ }^{53}$

\section{Funding and management reform}

The 1994 Fisheries Amendment Act provided for cost recovery, abolished resource rentals, and transformed the Ministry of Agriculture and Fisheries (MAF) into a Min-

\footnotetext{
${ }^{46}$ Hilborn (2006)

${ }^{47}$ Maunder and Starr (2002)

${ }^{48}$ Ministry of Fisheries (1997)

${ }^{49}$ Pearse and Walters (page 1992, page 15)

${ }^{50}$ Fisheries Task Force (1992)

${ }^{51}$ Ministry of Fisheries (page 1997, page 14)

${ }^{52}$ Environment and Conservation Organisations of Aotearoa New Zealand (ECO) (2007)

${ }^{53}$ Ministry of Fisheries (1997, page 18)
} 
istry of Fisheries (responsible for fisheries policy) and a CRI (NIWA), with staffing reductions of around $40 \%$ in the latter transition. ${ }^{54}$ Cost recovery was the subject of ongoing skirmishes over the "attributable or avoidable" joint cost issue, ${ }^{55}$ while the quantum of funds recovered gradually dropped. Stokes, Gibbs and Holland (2006) write that it was intended to decrease over time as the efficiency of service delivery improved and industry acquired responsibility for services. ${ }^{56}$ In contrast, Wallace and Weeber (2003) write that "the total to be paid [was being] whittled down under intense pressure from the industry, shrinking well below what the government expected". 57 The new Fisheries Amendment Act (passed in two parts in 1995 and 1996) introduced a sweep of major reforms. One of these was the finalisation of the division of the old Ministry of Agriculture and Fisheries into a policy unit (the modern Ministry of Fisheries) and a separate commercially-driven science provider (NIWA). The 1996 Act also included fisheries management novelties such as "sustainability" (section 8), a requirement to consider the marine environment (section 9), and a version of the precautionary principle (section 10). These were responses to New Zealand's domestic legislative trends in environmental management (such as the Resource Management Act (1991)) as well as new international obligations. ${ }^{58}$ The 1996 Act also provided new rules for cost recovery in Part 14, but the continued lack of “... shared theoretical base or understanding of cost recovery between the Ministry and stakeholders" 59 saw court proceedings initiated to base cost recovery on "attributable cost". This essentially provides that the industry only be charged for services from which they have benefited, rather than for the costs its operation imposes as avoidable cost provides. ${ }^{60}$ A 1996 Select Committee review of cost recovery saw the proceedings (and a later threat to withhold levies) withdrawn but the regime and its uncertainties were the source of ongoing acrimony between industry and government. ${ }^{61}$

\section{Policy development and trends}

New Zealand's marine management has evolved greatly since 1996, but the following developments are particularly significant for this study. The Ministry produced the "Fisheries 2010" document in 1997 to complement the Ministry for the Environment's "Environment 2010", which set overall goals for New Zealand's environmental man-

\footnotetext{
${ }^{54}$ Nightingale (1992, page 241)

${ }^{55}$ McClurg (2000, page 4)

${ }^{56}$ Stokes et al. (2006, page 12)

${ }^{57}$ Wallace and Weeber (2003, page 11)

${ }^{58}$ Including the Convention on Biological Diversity (1992), the Rio Declaration (1992) and the Agreement for the Conservation and Management of Straddling Fish Stocks and Highly Migratory Fish Stocks (1995).

${ }^{59}$ Ministry of Fisheries (1997, page 10)

${ }^{60}$ Ministry of Fisheries (1997, page 6)

${ }^{61}$ McClurg (2000); Wyatt (2000)
} 
agement. ${ }^{62}$ In 1998 the Ministry produced "Strategic Framework and Directions for Fisheries Research Contracted by the Ministry of Fisheries", but it was followed in 1999 by the Office of the Controller and Auditor-General's review of the information requirements for the sustainable management of fisheries, which found the Ministry's information provision lacking in many important respects. ${ }^{63}$ (A followup report in 2005 showed significant efforts had been made to remedy the problems but the QMS still suffers from a chronic information deficit. ${ }^{64}$ )

Devolution Co-management increased in prominence in fisheries policy for three years, culminating in the 1999 Fisheries Amendment Act's proposals for significant devolution of fisheries management responsibility to industry. ${ }^{65}$ The Act also provided for reducing the cost-recovery basis to "attributable cost", both developments that were fought strenuously by non-industry stakeholder groups. ${ }^{66}$ The move towards devolution was halted by a change of government and a Fisheries Minister (Pete Hodgson) who appeared less willing to trust industry to wield devolved management power responsibly. ${ }^{67}$ However the process for devolving fisheries registry services was in train, and continued until "FishServe", an industry-run organisation, took full responsibility in 2001; its success has since been hailed as a triumph for devolved management. ${ }^{68}$ In 2000 the Ministry was continuing to develop fisheries plans and standards for fisheries management (though this was proceeding too slowly for the Auditor-General's office ${ }^{69}$ ). Also in 2000 the Minister declared 18 areas within the EEZ to be closed to bottom trawling and dredging, ${ }^{70}$ and launched the initial phases of the Oceans Policy. In 2001, 12 environmental performance indicators were finalised to assess fish stocks and the state of the marine environment. ${ }^{71}$ Also in 2001, the hoki fishery received Marine Stewardship Council sustainable fishery certification (a development which has sparked both elation ${ }^{72}$ and disappointment ${ }^{73}$ ). In the same year, the government

\footnotetext{
${ }^{62}$ Fisheries 2010's twelve goals are: Inter-generational Equity; Biodiversity; Environmental Bottom Lines; The Precautionary Principle; Research, Science and Technology; Protecting our International Competitiveness; Sustainable Property Rights; Least-cost Policy Tools; Pricing of Infrastructure; Internalisation of External Environmental Costs; Defining the Limits of Fishery Resource Use and Substitution; and Social Costs and Benefits.

${ }^{63}$ Office of the Auditor-General (1999)

${ }^{64}$ Office of the Auditor-General (2005)

${ }^{65}$ Yandle (2003)

${ }^{66}$ Burstall (1998); Environment and Conservation Organisations of Aotearoa New Zealand (ECO) (1999)

${ }^{67}$ The Hon. Pete Hodgson (2000)

${ }^{68}$ Soboil and Craig (2006)

${ }^{69}$ Office of the Auditor-General (2005)

${ }^{70}$ Ministry of Fisheries (2007b)

${ }^{71}$ Office of the Auditor-General (2005)

${ }^{72}$ Clement (2000)

${ }^{73}$ Royal Forest and Bird Protection Society (2004)
} 
published the results of its consultation on the Oceans Policy, which showed that New Zealanders had a strong relationship with the seas and some strong views about marine environmental management. ${ }^{74}$

Section 10 in the courts In 2002 the Minister established an Oceans Secretariat to rejuvenate the Oceans Policy process, instructing it to swiftly deliver a policy. ${ }^{75}$ Also in 2002, the first of a series of legal cases testing section 10(a) of the Act was brought. Misapplication of the MALFiRM bycatch model $^{76}$ and outdated economic information in a Ministry report recommending a regional set-net ban to protect Hector's dolphins meant the decision was returned to the Minister under judicial review. In 2003, the industry won an injunction against a proposed closure of a squid fishery to protect sealions, on the basis that gaps between observed and projected bycatch mortality prevented the Minister from assessing the balance between the Purpose and section 15 (protection of marine mammals). In 2004, the Court of Appeal held that while a precautionary approach to the balancing of utilisation and its effect was reasonable, the Minister must still use the best available information. With a preponderance of evidence in favour of greater utilisation, the MFish's uniquely low sealion mortality threshold for that year breached s10(a).

\section{Environmental developments}

Following its presence at the Reykjavik Conference on Responsible Fisheries in 2001, the Ministry signalled the desirability of ecosystem-based fisheries management, but was very aware of the immediate needs of single-stock sustainability. ${ }^{77}$ This has remained a significant sticking-point, especially given the greater expense of even minimalist ecosystem-based management. ${ }^{78} 2005$ saw the launch of the Strategy for Managing the Environmental Effects of Fishing (the SMEEF) which provides for the setting of environmental standards. However standards must be preceded by "identif[ication] of the New Zealand government's obligations", ${ }^{79}$ and the new higher emphasis on ecosystems requires much more information. ${ }^{80}$ Some draft standards for fisheries management were released for discussion in late 2006 for several sections in Part I of the Fisheries Act; a management goal hierarchy to contextualise the standards is due to be released in November this year. Also in 2006, on the heels of an international conference over bans on bottom trawling, the government accepted a proposal from

\footnotetext{
${ }^{74}$ Ministry of Fisheries (2001a)

${ }^{75}$ Peart (2005)

${ }^{76}$ Maximum Allowable Level of Fishing-Related Mortality

${ }^{77}$ Ministry of Fisheries (2001b)

${ }^{78}$ Mace (2001)

${ }^{79}$ Ministry of Fisheries (2006c, page 7)

${ }^{80}$ Ministry of Fisheries (2006c)
} 
the fishing industry (the Benthic Protection Area Accord or BPA Accord). This provides for closing $30 \%$ of the EEZ's area to bottom trawling to protect the environment, in exchange for a cap on cost-recovery for deep-water benthic research (one-third of the total costs ${ }^{81}$ ) and restrictions on the Ministry's power to institute further closures within the EEZ, ${ }^{82}$ and is now incorporated in a Memorandum of Understanding with the Deep Water Stakeholders' Group. However it was criticised as a missed opportunity to achieve substantial protection of benthic environments. ${ }^{83}$ The Ministry is also in the process of developing a Benthic Impacts Strategy. ${ }^{84}$ Another recent development was the Shared Fisheries proposal, which has elicited active and vocal participation from Maori, commercial and recreational stakeholders over suggested re-allocations of limited inshore stocks. ${ }^{85}$

\section{Fisheries Amendment Bill 2007: precaution realigned?}

The Bill proposes to amend section 10 of the Act, directing decision-makers not to let uncertainty prevent them from taking steps to achieve sustainability (rather than to achieve the Act's purpose of sustainable utilisation). This has been a fascinating showcase of stakeholders' normative and descriptive views of the Ministry of Fisheries' roles and performance. ENGOs support the Bill, seeking to strengthen further the protective nature of the proposed provision. ${ }^{86}$ Industry groups are unanimous in their opposition of the Bill, founded on their opposition to realigning the precautionary direction towards sustainability. They argue that there are sufficient environmental protection provisions in the rest of the Fisheries Act and in international law to inform section 10, and that the proposed principle will be a shield for reduced transparency and a prop for otherwise unjustifiable decisions on the part of the Ministry. ${ }^{87}$ As was reflected in this research, the industry feels that the Ministry already engages in inappropriate environmental advocacy, and changing section 10(a) will only open the floodgates. There were also fears that the seafood industry will be used as a "cash cow" to fill the gaps in the public good science base left by years of under-funding, and that the new provision will be used to justify cutting TACs because of uncertain information while preventing research that would enable gaps in that information to be filled. ${ }^{88}$ Green groups, in contrast, feel that the Ministry is currently too rash in

\footnotetext{
${ }^{81}$ Ministry of Fisheries (2007e)

${ }^{82}$ Ministry of Fisheries $(2007 \mathrm{~b}, \mathrm{c})$

${ }^{83}$ Leathwick et al. (2006, page 28)

${ }^{84}$ Ministry of Fisheries (2006b)

${ }^{85}$ Hapi (2007); Option4 (2007)

${ }^{86}$ Environment and Conservation Organisations of Aotearoa New Zealand (ECO) (2007); Greenpeace (2007)

${ }^{87}$ New Zealand Seafood Industry Council (2007); Ltd (2007)

${ }^{88}$ New Zealand Seafood Industry Council (2007)
} 
its marine management decisions, and that changing the law can only improve those decisions. ${ }^{89}$ The Minister himself stated: "I want to amend the Act so it is absolutely crystal clear that sustainability is the priority and no lawyer or court can cast any doubt on it. Sustainability is too important for us to be in any doubt about its priority. What I want is for us to agree that sustainability is the bottom line and to make this clear in section 10 so the lack of information is not used as a reason to delay taking measures to protect fisheries." 90 This "environmental bottom line" attitude was also expressed from a Maori perspective by the Greens' fisheries and Maori affairs spokeswoman, ${ }^{91}$ but contrasts with the Maori perspective presented by the Maori Party's co-leaders which was consistent with the fishing industry's view. ${ }^{92}$

\subsection{Conclusion}

To conclude, New Zealand's marine resource management is in a state of flux. Some believe the QMS has actually become the management system for New Zealand's marine resources. ${ }^{93}$ The legislative framework for transferable quota has many aspects in need of policy and statutory development, notably the environmental principles. The New Zealand public has not had enough opportunity (and perhaps lacks the volition) to express its preferences for the long-term, large-scale management of the nation's marine resources. Meanwhile, the policy framework itself sports a number of initiatives which have had a visible effect on practical management (such as the SMEEF and the BPA Agreement), but also has many measures which are in their early developmental stages. These have the potential to make a great contribution to improving cohesion and coherence of marine and fisheries management, but they are not sufficiently advanced to contribute at present.

The QMS has expanded to include 97 of the 130 commercially-fished species, and the Act's environmental principles require the effects of fishing these species on the wider marine environment to be reduced or avoided. However fisheries research budgets have not expanded in harmony, so many of the species are managed under section 10's precautionary approach as information (scientific or otherwise) is deficient or absent. This provision is the source of great contention, and has been earmarked by the Minister for amendment to push management under uncertainty in favour of sustainability rather than sustainable utilisation.

Meanwhile, fisheries research is procured by the Ministry for deep water species

\footnotetext{
${ }^{89}$ Environment and Conservation Organisations of Aotearoa New Zealand (ECO) (2007); Greenpeace (2007)

${ }^{90}$ The Rt Hon Jim Anderton (2007)

${ }^{91}$ Turei (2007)

${ }^{92}$ Sharples and Turia (2007)

${ }^{93}$ Johnson (2004, page 370)
} 
via a combination of cost-recovery and government funding, with a near-monopoly on independent research provision and a duopsony for its purchase. In the fora where research decisions are made, scientific representatives from the fishing industry, who (along with NIWA and MFish scientists) comprise the great majority of representation. One or at most two lay representatives from ENGOs are occasionally present, (in the deep water fora non-commercial Maori interests are almost never represented). In these fora, decision-making (particularly under uncertainty, which is omnipresent in the deep water arena) is characterised by a shifting frontier between hard-sciencebased and value-based decisions. Where hard science is dominant, scientists debate the validity of assumptions and conclusions drawn from the limited data available. As values become more influential in decision-making, the legitimacy of these determinations is often disputed by industry and ENGO representatives. 


\section{Chapter 4}

\section{Conceptual Framework}

\subsection{Introduction}

This section is the conceptual framework in light of which interview results will be examined. To understand how normative and positive information, science and policy, and individual and institutional elements interact in New Zealand fisheries science fora, an awareness is necessary of the different forces to which the scientists in these fora are subject. The focus of the non-scientific drivers is on government agents because of the New Zealand government's ultimate responsibility for sustainably managing the country's fisheries, and its mandate to run processes procuring and using fisheries science to that end.

This chapter is therefore divided into two sections, canvassing the pressures exerted on the different scientists, particularly fisheries scientists, and the pressures on government agents.

\subsection{Good Scientific Practice: Professional Excellence}

For a scientist acting in his or her professional capacity, professional standards (what constitutes being a good scientist) are the primary consideration for guiding decisions. These are defined principally by the scientific method, the series of founding principles that distinguishes science as a way of acquiring and refining knowledge about phenomena. The provision of scientific information ("these are the characteristics of this phenomenon") is clearly distinguished from the provision of any subsequent policy information ("this is what should be done about it"). New Zealand's scientific and policy advice processes for fisheries management are in this mould. Policy-making, via the "sustainability rounds" of meetings, involves assessment of factors such as economic, social and cultural value, subjective considerations which (while assessed via professional analysis) are deliberately excluded from pure scientific investigation. 
The literature distinguishes scientific methods from other methods of inquiry as being based on collection of measurable, observable evidence by repeatable, documented observation and experiment, and on analysis of this evidence according to certain principles of reasoning. ${ }^{1}$ The essential value of this approach is its minimisation of subjectivity in the conclusions: the results of a good scientific investigation will theoretically be the same regardless of who performs the research. A scientific conclusion is therefore interpreted as being objective, accurately describing a phenomenon and being the "truth" — or at least as close to all these as it is possible for society to come. ${ }^{2}$ The scientific community advances knowledge by building on the conclusions of past research in an iterative process of critique, discussion, and extension in pursuit of originality. ${ }^{3}$

\subsubsection{Good scientific practice: foundation of science's authority}

The scientific community plays a critical role in quality-checking, via peer review, scientists' procedural and analytical robustness. The considerable expertise required to assess scientific performance means laypeople must put their trust in the scientific community as a reliable judge of analytical quality. ${ }^{4}$ Non-scientists trust that this community's dedication to professionalism will uphold and enforce the canons of scientific practice, so that scientists' pronouncements on issues are the products of scientific and technical opinion rather than non-scientific considerations such as personal norms. Peer-reviewed journals and their various reputations are used as indicators that research has met certain technical standards, and that scientists are held in regard by their peers.

\section{The weight of scientific numbers}

The role of scientific "consensus", or majority scientific opinion, is a critical concept. In Western society generally, laypeople take an overwhelming majority amongst relevant, respected scientific experts in support of a certain scientific hypothesis to mean that this statement is, for practical purposes, "the truth" or as near to it as society can reasonably get. ${ }^{5}$

Scientists' professional opinions on the degree to which the results of study A mean that conclusion Y is the "truth" vary because of their different stances on technical components of the issue. For example, Study A (which might be sampling a population of fish) returns a result that suggests the total population has biomass of

\footnotetext{
${ }^{1}$ Newton (1972); Veblen (1906)

${ }^{2}$ Godfey-Smith (2003); Nola and Sankey (2007)

${ }^{3}$ Polanyi (1962)

${ }^{4}$ Merton (1973); Bloor (1976)

${ }^{5}$ Godfey-Smith (2003)
} 
size $y$. Depending on relevant population scientists' views of the accuracy of the sampling method, and of the relative influence of the population variables (such as predation, habitat conditions, food availability, the previous year's recruitment), they might interpret Study A's result as showing a total population size of anywhere from comparatively small $(y-1)$ through to comparatively large $(y+1)$. Disagreement will likely ensue as the various experts critique the original Study A conclusion of population size $y$, arguing the relative merits of their interpretive approaches. This is the qualitychecking role of the scientific community - to test from every angle the robustness of the conclusion claimed from Study A. Scientific pluralism is useful here, as many scientists' different critiques can highlight the different areas of potential weakness in the original analysis. (By informing further iterations of the technique, methodologies are improved via gradual minimisation of subjective influences.)

However, a non-expert who wants to know what Study A means cannot distinguish the merits of the different positions across the interpretive spectrum. ${ }^{6}$ A flat "population distribution" of the experts across the spectrum of views from $y-1$ to $y+1$ without any clustering around one conclusion (lacking any consensus) means that science provides little additional information, because the layperson is left with several apparently equally valid but very different conclusions. For practical purposes, therefore, it is necessary to have the largest possible population of expert scientists critiquing and expressing their views on a study's conclusion, so that a normal distribution can be discerned, the extreme "tails" discounted, and the expert population's clear mean for interpretations of Study A (for example at "total population $=(y+0.2)$ ") can be identified and taken as the "truth".

\subsubsection{Scientific method: the Way to the Truth?}

However there is a significant element of faith in this assumption. The relationship between adherence to scientific method and the discovery of "the truth", or knowledge and understanding of the world's phenomena as they "really are", has long been passionately debated. The controversy over the inductive reasoning that allows a tested hypothesis to be accepted as universal (always holding true under those circumstances) intensified in the 1960s. Karl Popper's (1959) position that scientific methods falsify rather than verify hypotheses ${ }^{8}$ (as the logical positivist tradition espoused ${ }^{9}$ ) joined that of Michael Polyani, Thomas Kuhn, Paul Feyerabend and Imre Lakatos ${ }^{10}$ in fuelling the debate over the scientific method's status as the only pathway to objective "truth".

\footnotetext{
${ }^{6}$ Weber and Word (2001)

${ }^{7}$ Fleck (1975)

${ }^{8}$ Popper (1959)

${ }^{9}$ Suppe (1977)

${ }^{10}$ Polanyi (1958); Kuhn (1970); Feyerabend (1975); Lakatos (1976)
} 
The ongoing conflict, flaring in the 1990s in the "Science Wars", ${ }^{11}$ was (and remains) a reaction to the epistemological hegemony that pure science has enjoyed since the Enlightenment, to the detriment of other academic disciplines and non-scientific forms of knowledge. ${ }^{12}$

\section{Limitations on truth-finding power}

This debate helped to articulate the limitations on the natural sciences' usefulness for describing objective phenomena, and those most relevant to the fisheries management problem are as follows.

The scientist's disinterestedness is a cornerstone of objectivity and therefore of science's status as a pathway to the truth. Merton (1973) described it as one of the five fundamental principles of science. ${ }^{13}$ However, disinterestedness has two significant limitations. The first is the impossibility of scientists, as human beings, being able to exclude entirely their personal world-views, values, hopes and other subjective, normative influences from their analysis. ${ }^{14}$ This was a strong theme in the Science Wars' debates, ${ }^{15}$ which drew on a rising tide of sociology- and philosophy-based thought (see below) examining the interplay between innate and socially-acquired components of individual people's preferences and behavioural motivators.

The second limitation is that scientists need to be paid, and funding is a powerful challenge to disinterestedness. While at the extremes it is clear where science is being subsumed beneath a non-scientific interest, ${ }^{16}$ it is difficult to discern the boundary between legitimate scientific and technical positions on an issue and illegitimate ones driven by non-scientific considerations such as money (for convenience, labelled "positioning" in this thesis). This is particularly so under uncertainty, where a wide spectrum of equally legitimate scientific conclusions can be drawn from the same data. Establishing whether a scientist is biased (his or her professional opinions show "a [...] persistent discrepancy in a politically relevant direction" ${ }^{\prime 17}$ is particularly difficult where scientific uncertainty is high.

Government-funded science is acknowledged as being less vulnerable to resultsdriven commercial pressures, ${ }^{18}$ in recognition of governments' obligation to pursue the

\footnotetext{
${ }^{11}$ The Science Wars was an intellectual conflict fought in the 1990s in the academic literature between two groups, one questioning the objectivity of the scientific method from a wide variety of angles (including post-modernism, feminism, ethnology, sociology), and the other arguing that objective knowledge exists and the scientific method is the best approach to it. (1996) for a contemporary overview.

${ }^{12}$ Ravetz (1979); Hill (1984); Ravetz (1990); Gross and Levitt (1994); Sokal and Bricmont (1998)

${ }^{13}$ Merton (1973)

${ }^{14}$ Brown (1995); Charles (1998); Ihde (2002)

${ }^{15}$ Parsons (2001)

${ }^{16}$ Aron et al. (2002)

${ }^{17}$ Roll-Hansen (1994)

${ }^{18}$ Easton (1989); Ministry of Research, Science and Technology (1992); Callon (1994); Hammond and
} 
greater public interest (which includes full accountability and disclosure of spending). New Zealand's public service restructuring in the late 1980s and early 1990s in pursuit of greater efficiency decreased the ratio of government to "user pays" funding in the science system, a move that many felt compromised its ability to produce good-quality, objective science. ${ }^{19}$

\section{Effects of context on science}

Another caution against believing science to be entirely value-free is that the ends to which scientific research will be used often mean that ostensibly value-neutral scientific technicalities can have significant distributive effects. Given the scientific method's preference for Type I over Type II errors, ${ }^{20}$ the placement of a heavy burden of proof is very important in situations where potential harm would be wide-spread but potential benefits would be concentrated. ${ }^{21}$ Environmental impacts from industrial technologies are an example. Scientists' extreme specialisation, and their common demographic characteristics, may mean they are generally less able to see their subject area in a wider societal perspective. ${ }^{22}$ Because of their more generalist view, those seeking to use science in policy have a significant responsibility to account for burden of proof influences when commissioning scientific inquiry.

A final caution against expecting too much from science for practical decisionmaking is the aforementioned effect of high uncertainty. A population of relevant experts scattered across the spectrum of interpretive positions regarding the same data prevents non-scientists from identifying a majority expert opinion that can be taken as the "truth" for practical purposes. In such situations science therefore fails to contribute significantly to society's understanding of the phenomenon, because nonscientific considerations must be employed to choose what the "truth" will be taken to be. It also means that it is extremely difficult to distinguish a scientist's position on an issue is based solely on scientific and technical preferences or partially on nonscientific bases, such as norms generated by the individual scientist's values or by an institution such as an employer company. Scientific pluralism provides a useful contribution to understanding an issue if the population of relevant experts describes a normal distribution, which covers a wide spectrum of views but most importantly has an identifiable "majority" position.

\footnotetext{
Devine (1994)

${ }^{19}$ Easton (1989); Cartner and Bollinger (1997); Edmeades (2004)

${ }^{20}$ Scientists are more willing to make false negative mistakes (variable A has no effect on variable B) than false positives (variable A has an effect on variable B).(Lemons, 1998)

${ }^{21}$ Lemons (1996); Shrader-Frechette (2006)

${ }^{22}$ Dahl (1966)
} 


\subsubsection{Science is fallible, but still dominates}

The issues at the root of the Science Wars' conflicts - how objective science can genuinely be, and the role of social construction of knowledge - remain unresolved. Authors such as Bent Flyvbjerg (2001) have offered reconciliations emphasising the different strengths of scientific and non-scientific analysis, and the necessity of both for advancing societies' knowledge of the world. ${ }^{23}$ This is slowly becoming acknowledged, particularly in policy circles, ${ }^{24}$ and some blending is visible in the boundaries between the disciplinary territories (discussed further below). Amongst the general public, the mystery and authority of science has been somewhat eroded in recent decades, particularly by the politically motivated cultivation of high-profile scientific dissent on issues such as climate change, ${ }^{25}$ and the social sciences are experiencing an associated increase in exposure.

However, the natural or "pure" sciences' epistemological dominance persists, particularly in fields such as fisheries which have an acknowledged objective component to the information required to deal with them. ${ }^{26}$ This hegemony is partially perpetuated by academic journals' inherent conservatism and the way they provide society with an easily-interpreted signal of scientific professional achievement. ${ }^{27}$ The much more regularised and institutionalised nature of biologists' and ecologists' contributions to fisheries knowledge make it much easier for decision-makers to find "reputable" information than for the social sciences (see Fisheries science section), and New Zealand is no exception.

\subsubsection{Modernising forces on science}

However, the dynamism of modern society may force acceleration in the paradigm shift towards a new multi-disciplinary approach to gathering knowledge of the world. The development of industrialised societies has created situations where uniquely large risks, for which responsibility has become difficult to attribute, are a feature of everyday life - Ulrich Beck's "risk society". ${ }^{28}$ "Manufactured risk" ${ }^{29}$ in natural resource management means human activities court far-reaching consequences such as species extinction and climate change, ${ }^{30}$ while uncertainty ${ }^{31}$ and ignorance are both rife. ${ }^{32}$

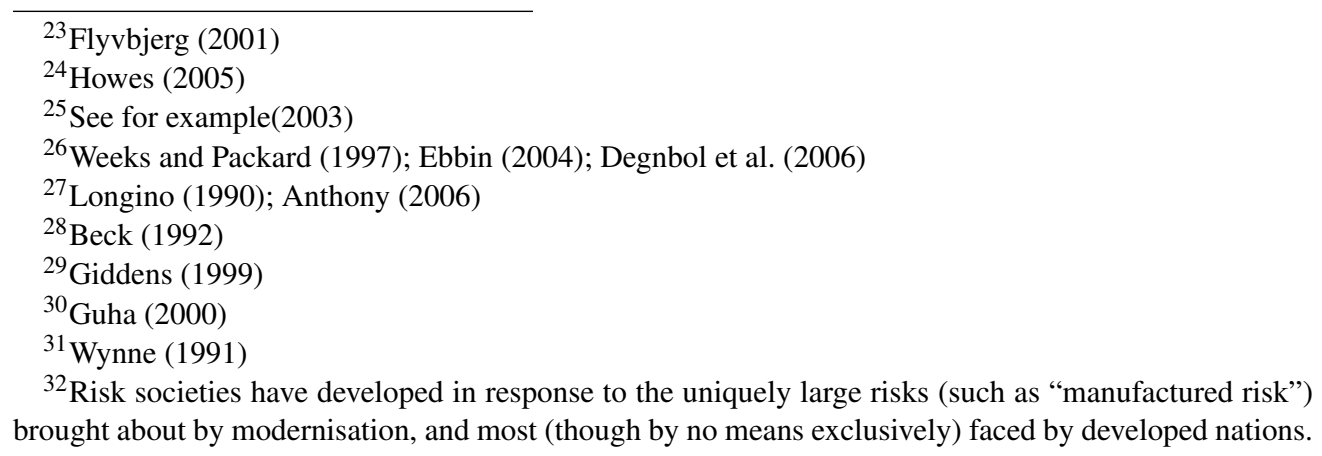


Where complex natural phenomena are crucial to human life, gravely threatened by ongoing human action and persistently under-valued by both leaders and the public in general, society's information-gathering and decision-making systems are acid-tested. Scientists are being increasingly called on to provide some solidity and objectivity in politically fraught situations where decision-makers see an objective component such as an environmental bottom line contrasting with an intimidating tangle of subjective positions. Scientists then come under pressure (often from themselves ${ }^{33}$ ) to step outside the pure science domain and give policy advice. ${ }^{34}$

However, orthodox scientific training focuses on excluding subjective influences as completely as possible from one's professional purview, ${ }^{35}$ and this means scientists are particularly likely to handle poorly the more subjective elements of policy decisions such as social, cultural, economic and political considerations. ${ }^{36}$

\section{Attempted "fixes" for orthodox science}

The desire for the unequivocal solidity of traditional "hard" science, coupled with steadily increasing acknowledgement of its limitations for solving increasingly difficult real-life issues, has seen the development of some new types of science and new approaches to using it. ${ }^{37}$

While there is intense debate over the operational detail and merits of interdisciplinarity $^{38}$ the arguments from the sociologists, political scientists and philosophers of science inspired by Popper, Kuhn and their intellectual descendants have taken root.

In the policy arena, best practice pushes for multi-disciplinarity of informationgathering to improve both the substance and the democratic credentials of the resulting policy decisions. ${ }^{39}$ Decision rules such as the precautionary principle are becoming widespread, as policy-makers attempt to ensure scientific inquiries are pointed in the

Giddens 1999 describes risk societies as "increasingly preoccupied with the future and ... safety", and struggling to cope with the fact that many of the risks they face have been brought about by people rather than by natural forces. Ulrich Beck 1992 uses the term "crisis of responsibility" to describe how the insulation of human activity from its effects (such as those on the environment) has led many manufactured risk to be seen to be no-one's fault in particular.

${ }^{33}$ Ehrlich and Ehrlich (1996); Myers (1999); Winterton (2003)

${ }^{34}$ Brouha (1993); Meffe et al. (1998); Senkowsky (2004)

${ }^{35}$ Wagner (2001); Aron et al. (2002); Hilborn (2006)

${ }^{36}$ Bowen (1997); Ebbin (2004); Lach et al. (2003); Taylor (2004)

${ }^{37}$ Salwasser (1993); Gibbons et al. (1994); Weible et al. (2004); Younger et al. (2005). One of the most significant trends is inter-disciplinarity, where both natural and social scientists are influenced by each others' methodological strengths and the resulting research has positive emergent properties. (Klein, 2007) Practically, inter-disciplinarity (and even the less merging multi-disciplinarity (Tress et al., 2006)) demands significant changes to traditional scientific practice, extending to institutional and social structures. (Metzger and Zare, 1999; Lattuca, 2001)

${ }^{38}$ Brewer (1999); Garrett-Jones et al. (2005)

${ }^{39}$ Stone (1989); Rochefort and Cobb (1993) 
right direction ${ }^{40}$ so that the policy they inform is "roughly right rather than precisely wrong". ${ }^{41}$ This will be discussed further below. One vehicle for effecting this change is "post-normal science", ${ }^{42}$ which will be a useful concept for this analysis. Adaptive management is an example of a practical (though limited) tool for dealing with uncertainty, though as yet it does not take post-normal science's strong inter-disciplinary approach. $^{43}$

Inter- and multi-disciplinarity have been argued to constitute a significant paradigm shift for science, but one which different disciplines and institutions are embracing with varying enthusiasm. ${ }^{44}$ Kuhn's examinations of paradigm change in science ${ }^{45}$ argue that in the transition period between paradigms, where the new and the established temporally overlap but are both structurally weak, a sort of paradigmatic vacuum is created. At such a time, scientists are subject to a wide variety of forces. The following section looks at fisheries science and identifies the paradigmatic conditions currently operating.

\subsubsection{Fisheries science: Formative decades}

In fisheries science, the objective characteristics of the subject-matter mean that the field has traditionally been dominated by natural sciences (principally biology, zoology and ecology). During the first, formative decades of its history, as MSY was generated with its roots in the fisheries theories of the $1930 \mathrm{~s}^{46}$ and fish stock modelling flourished in the post-war period, ${ }^{47}$ fisheries science was the domain of biologists and mathematicians. Some authors argue that the 1950s have had a lasting reductionist influence on fisheries science, resulting in fisheries managers clinging to single-stock management and fisheries scientists being preoccupied with MSY. ${ }^{48}$

The human element of fisheries began to be considered in the 1950 s, as "bioe-

\footnotetext{
${ }^{40}$ Beck (1996)

${ }^{41}$ Myers (1997)

${ }^{42}$ Post-normal science, a term coined by Funtowicz and Ravetz in the early 1990s, draws on Kuhn's 1970 notion of paradigm shifts (when it becomes clear that "normal science" is gravely insufficient for solving real-world problems and its underlying rules are called into question). Post-normal science is designed for dealing with situations where the stakes are high and decisions are a one-shot game (each choice will have significant consequences), values are in dispute, and facts are uncertain, of which climate change is the primary example. An extended peer community is a key aspect of post-normal science, where those in the traditional scientific community recognise that orthodox science cannot fill the information gaps preventing society from tackling the problem at hand. They therefore engage with experts from outside the traditional scientific community whose information is necessary to solve the greater problem at hand (Funtowicz and Ravets, 1990, 1993).

${ }^{43}$ Walters (1986); Guerin (2007)

${ }^{44}$ Yager (1996); Harriss (2002); Bruun et al. (2005)

${ }^{45}$ Kuhn (1970)

${ }^{46}$ Russell (1931); Graham (1935); Hile (1936)

${ }^{47}$ Ricker (1954); Schaefer (1954); Beverton and Holt (1957)

${ }^{48}$ Larkin (1977); Smith and Link (2005)
} 
conomics" factored fishers' profits into analysis of stock sizes ${ }^{49}$ according to mainly individual-based approaches. ${ }^{50}$ Trends in other fields, such as sociologically-driven interest in societal institutions ${ }^{51}$ and citizen participation in politics ${ }^{52}$ caused ripples in fisheries science. Two examples of this are Optimum Sustainable Yield (a short-lived MSY with social objectives ${ }^{53}$ ) and adaptive management. ${ }^{54}$ However these were but ripples, and by 1980 Francis lamented that “... over the past two or three decades most of the advancement in fisheries science has occurred in the branches of this scientific discipline rather than at the roots". He prophesied danger if fisheries science continued to put the mathematical modelling "cart" before the fish stock and ecosystem "horse'. 55

\section{Rude awakenings and methodological self-doubt}

This prophesy seemed to be realised in the dramatic fish stock crashes of the $1980 \mathrm{~s}$ such as Atlantic cod and Pacific sardines. The crises "spawned a feeding-frenzy of introspection" amongst fisheries scientists, ${ }^{56}$ who were joined by sociologists, economists and other academics, as the crashes' socio-economic fallout focussed political attention on fisheries management and thereby on fisheries science.

This coincided with a trend of increasing academic attention to small communitybased resource management, including successful fisheries examples. ${ }^{57}$ These stood in stark contrast to the fresh memories of centrally-managed fisheries crashes, and began a strong literature stream advocating management devolution to fishing communities. ${ }^{58}$

\section{Turning a few points on the ocean liner's wheel}

The late 1980s and early 1990s also saw the entry of "sustainability" into the international political lexicon, via the 1987 Brundtland Report and the United Nations' 1992 Rio Declaration. Sustainability advocated policy pursuit of balance between human and natural systems, and included a distinct participatory democratic theme. It coincided with the growing trend in the natural sciences towards more holistic analy-

\footnotetext{
${ }^{49}$ Anderson (1987)

${ }^{50}$ such as Gordon (1954); Scott (1955); Turvey (1964); Smith (1968)

${ }^{51}$ Scott and Coustalin (1995)

${ }^{52}$ Arnstein (see for example 1969); Frankena (see for example 1987)

${ }^{53}$ Larkin (1977)

${ }^{54}$ Holling (1978)

${ }^{55}$ Francis (1980, page 94)

${ }^{56}$ Longhurst (2006, page 107)

${ }^{57}$ McCay (see for example 1980); Ostrom (see for example 1990, 1992)

${ }^{58}$ Jentoft (1986); Berkes (1987); Pinkerton (1989); Vedsmand and Nielsen (1995); Sen and Nielsen (1996)
} 
sis, emphasising ecosystem research, interconnections and emergent properties. ${ }^{59}$ The field of fisheries management responded, if slowly, and ecosystem-based management appeared in international agreements, such as the UN's 1995 Straddling Stocks Convention. ${ }^{60}$

In fisheries science, new models of fisheries analysis have also been developing, such as ecosystem-based management, ${ }^{61}$ though this growth has still been in Francis' branches of the discipline rather than its roots. ${ }^{62}$ Meanwhile, the spread of new technology has enabled fishing to extend into hitherto untouched areas such as the deep ocean, which has created significant "manufactured risk" for both target stocks (such as New Zealand orange roughy) and bycatch species.

Fisheries science is acknowledged as an essential input for governments that must manage fisheries and other marine resources, particularly for those subject to manufactured risk. Fisheries scientists' decisions in scientific fora are an integral part of the New Zealand fisheries management process which is relied upon to produce the most accurate picture of marine resources that can be achieved with available funding. The following section looks at what particular additional pressures are exerted on government agents in the execution of their role, which will inform examination of how New Zealand's fisheries management processes handle and digest science.

\subsection{Forces Driving Government Agents}

This section canvasses the kinds of forces driving government agents' decision-making. The pressures on government agents are canvassed both generally and specifically. General pressures are the complex combinations of internally- and externally-generated forces that drive individual humans' behaviour, which apply equally to any person (including scientists), while the specific pressures are those to which government agents are subject in the course of their work.

\subsubsection{Generic drivers for action}

The question "what makes people behave as they do?" has inspired millennia of thinkers and writers to investigate these phenomena, and to hotly debate their conclusions. A wide range of investigative approaches has generated similarly diverse results, varying according to the relative influence they accord to individuals' internallygenerated drivers and to exogenous externally-sourced motivations.

\footnotetext{
${ }^{59}$ Grumbine (1994); Norgaard (1994); Simberloff (1998); Peuhkuri and Jokinen (1999)

${ }^{60}$ Convention on the Law of the Sea relating to the Conservation and Management of Straddling Fish Stocks and Highly Migratory Fish Stocks.

${ }^{61}$ Link (2002a,b); Hall and Mainprize (2003); Pickitch et al. (2004)

${ }^{62}$ Anderson (1987); McGlade (1989); Caddy and Seijo (2005); Garcia (2005); Heron et al. (in press)
} 
Approaches emphasising the individual's endogenous preferences as the key driver of human behaviour owe much to economic theory, particularly neo-classical authors such as Arrow (1951), Coase (1960), von Hayek (1960), Demsetz (1967) and Posner (1977). Drawing on philosophers such as Locke (1690(1994), Smith (1776 (1937), Bentham (1776 (1948) and Ricardo (1821), these approaches share an underlying conception of society as composed of individuals pursuing innate or "natural" preferences.

In contrast, other schools of thought postulate that the greatest causative influence on people's behaviour is the institutions in which they live and operate, and any investigation of the drivers of an individual's actions must focus on these institutions and the forces they exert on people. "Institutions" in this sense uses Vatn's (2005) defini$\operatorname{tion}^{63}$ which includes government bodies (and government as a whole), universities, families, tribes, clubs, NGOs, companies and professional associations. The scientific community, governments and companies are key institutions for this thesis. Tracing their roots to philosophers such as Durkheim (1895 (1938), Marx (1867 (1970), Veblen (1906) and Weber (1922 (1947), institution-centred schools of thought have more recently drawn on sociology and psychology. ${ }^{64}$ The interplay between an individual human's autonomy and institutions' authority has been heavily studied. ${ }^{65}$ Scott (1995) provides an accessible history. ${ }^{66}$

\section{Individual and institutional drivers}

Untangling the multiple institutionally-generated and internally-generated forces driving a person's actions can be a Herculean task. This thesis' position is that a person's actions at any given point are directed by subtle combinations of the two, but that the behavioural directions generated by some institutions (such as the scientific community and the agency one works for) are more easily identifiable. The small size of the New Zealand deep-water scientific fora means participants' reactions to each other's behaviour vis-à-vis shared institutions will likely be more visible. ${ }^{67}$ The literature that looks at the variables determining whether people operating under an institution choose to abide by its rules rather than pursuing a more individually-favourable path (cooperate or defect) applies to a wide range of situations, including fisheries. ${ }^{68}$ Furthermore, fisheries are inherently institutional phenomena at any scale, ${ }^{69}$ and the New

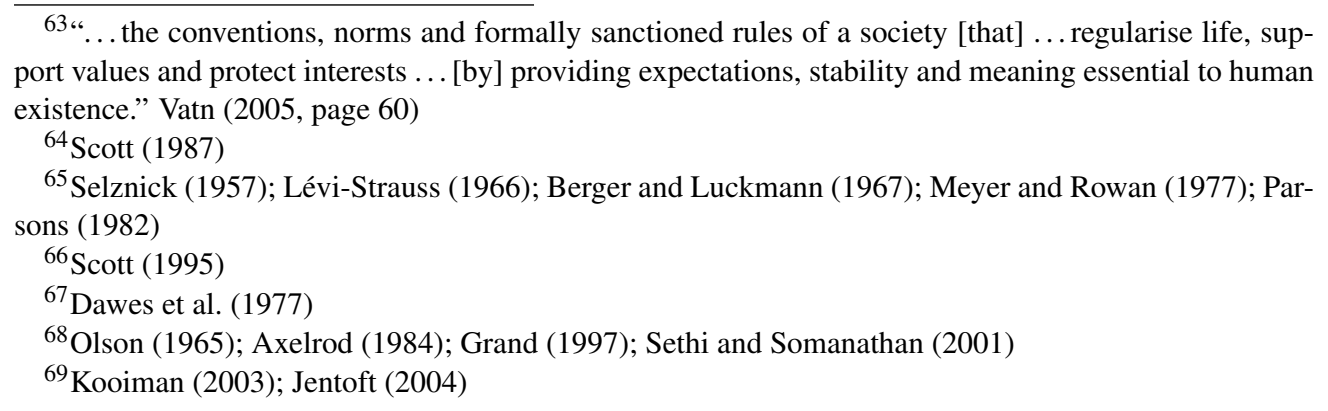


Zealand deep-water fisheries that are this study's focus are managed by nested institutions with government as the over-arching unit.

\subsubsection{What forces do government institutions exert on their agents?}

Governments - large, powerful, enduring institutions - have been the subject of much analysis, providing many models of the government / citizen relationship. Many of these focus on the ways the power imbalance between the parties is maintained once it is established. ${ }^{70}$

This thesis uses the "social contract" concept, acknowledging its underlying, subconscious influence in modern democracies. With its roots drawing on philosophers such as Hobbes, Locke, Jean-Jacques Rousseau and Emmanuel Kant, and rejuvenated more recently by Rawls, ${ }^{71}$ its essence is that citizens obey their government's laws and rules (including paying taxes) "in exchange" for the government performing vital services. ${ }^{72}$ The idea of the vote as the ultimate tool for "punishing" a government that fails to perform its social-contractual duties is an important one, despite the theoretical status in of citizens' rights to withhold civil obedience. ${ }^{73}$ (Interestingly, "user pays" structures for public services (that featured conspicuously in the "new public management" reforms of the late 1980s and early 1990s) have created a visible "user says" mentality in a relatively pure social-contractarian mode. ${ }^{74}$ ) It is at the root of the professional obligations stipulated by public sector ethics, such as the State Services Commission's State Services Code of Conduct, recognising governments' responsibility to govern well. ${ }^{75}$

Citizens' obligations to government are clearly identifiable, specified in minute detail in the letters of the law and enforced with the considerable coercive power of government. What it means for the government to keep its side of the bargain is much less clear, and even general rules (such as "do what's best for everyone overall") are contested territory. Would a good government and a good government agent employ a utilitarian, Bayesian approach ${ }^{76}$ or a Rawlsian "maximin" approach ${ }^{77}$ to assessing "best"? Public sector ethics uses "the public interest", which is itself a fraught term. ${ }^{78}$

\footnotetext{
${ }^{70}$ See for example Foucault (2000), Arendt (1958), and Habermas (1973).

${ }^{71}$ Hobbes (1651(1968); Locke (1690(1994); Rousseau (1762(1968); Kant (1784(1965); Rawls (1971)

${ }^{72}$ Boucher and Kelly (1994)

${ }^{73}$ Riley (1982)

${ }^{74}$ James (1991); Cartwright (2003)

${ }^{75}$ State Services Commission (2007)

${ }^{76}$ Harsanyi (1985)

${ }^{77}$ Rawls (1971)

${ }^{78}$ Dewey (1960); Flathman (1966); Meyer (1975)
} 


\section{What should a government do vis-à-vis natural resources?}

Much of a government's obligation revolves around distribution of the nation's natural resources amongst its citizens. Many valuable natural resources — including oceanic fisheries - are non-excludable goods, and if they are used rivally equitable intragenerational distribution is problematic. For conditionally renewable goods ${ }^{79}$, rival extractive use can exhaust them and causes inter-general inequity. The "tragedy of the commons" is where in the absence of use management, individuals exhaust a shared natural resource. ${ }^{80}$ It is difficult for a manager to ensure that individuals' uses of a natural resource (such as marine species) achieve a socially-optimal distribution. ${ }^{81}$ The interconnectedness of natural resources means the indirect impacts of use, on assets such as functional ecosystems, ${ }^{82}$ are also non-excludable. Property rights, the management tool used in New Zealand, most often cover specific uses of a resource rather than the full spectrum of effects, ${ }^{83}$ and environmental externalities ${ }^{84}$ are caused by the exercise of the right. ${ }^{85}$

General obligations Management of people's natural resource use, correcting the market failures to which it is prone and effecting socially-desirable distributions of natural assets, is a public good. ${ }^{86}$ There is considerable literature on the way people weigh the transaction costs of management against its benefits, ${ }^{87}$ and choose management institutions such as various kinds of property rights. Distributive justice arguments hold that where a management system causes the benefits of an activity are enjoyed by a few and the costs (negative externalities) are borne by society, the burden of proof to continue that activity should rest with the beneficiary. ${ }^{88}$ (In fisheries, the working presumption is usually that the burden of proof is on those opposing fishing; fishing can continue unless proven otherwise. ${ }^{89}$ )

General principles such as equity and efficiency therefore provide some very broad

\footnotetext{
${ }^{79}$ These are only renewable if certain limits to renewal, such as minimum biological requirements for reproduction, are respected. They cease to be renewable and will be exhausted if these limits are surpassed.

${ }^{80}$ Hardin (1968)

${ }^{81}$ Leach et al. (1999)

${ }^{82}$ Holling (1978); Folke et al. (2002)

${ }^{83}$ Edwards and Steins (1999)

${ }^{84} \mathrm{An}$ externality is an unintended and uncompensated effect on a third party to the use of the resource Tietenberg (2000). This is also called "cost shifting", where the benefits and costs of an activity are felt by different groups of people.

${ }^{85}$ Daly and Farley (2004)

${ }^{86}$ Pigou (1920); Anscombe (1978); Sartorius (1981)

${ }^{87}$ Ostrom (see for example 1990); Bromley (see for example 1991); Schlager and Ostrom (see for example 1992), and Feeny (1994); Hall (1998); Edwards and Steins (1999); Knight (2002); Libecap (2003)

${ }^{88}$ Johnston (1994); Shrader-Frechette (2006); Leach et al. (1999); Caino and Niemann (2006)

${ }^{89}$ Dayton (1998); Campbell et al. (2000)
} 
rules of thumb for government agents seeking to do what's best in natural resource management. However beyond this there is considerable debate over "what's best to do". Policy rules of thumb such as efficient use of effort and funding ${ }^{90}$ guide how governments pursue desired outcomes (and are assessed by watchdog agencies such as New Zealand's Auditor-General, ${ }^{91}$ but give little guidance on how to set policy goals. $^{92}$ For a government agent seeking to fulfil their professional responsibilities by making fisheries management policy that pursues the public interest, there are two sources of information to which they can turn to define what fisheries management outcome would be "best": they can turn to the citizens themselves, or they can turn to a few experts. For convenience, these will be respectively labelled the "vox populi" (voice of the people) and the "philosopher king" approaches, and will be examined in turn.

\section{The vox populi}

The underlying notion of democracy, legitimising the coercive power that governments exert over citizens, is that the elected government represents the "voice of the people" and enacts their wishes; in other words, "what is best" is what citizens want. ${ }^{93}$ Economics has contributed much to this debate, by arguing that the best approach a government can take is to set conditions that enable individual citizens to pursue what they want (generally in the free market), which will most efficiently achieve optimal ("the best") resource distribution. ${ }^{94}$ Neo-classical economics inspired influential arguments that government agents' nature as individuals, motivated by the same rational self-interest as any other human being, ${ }^{95}$ and emphasising the deleterious effects of presuming that bureaucrats are possessed of any superior power to discern and effect "what is best". 96

The legitimising power of participatory democracy — where citizens are involved in the processes of government beyond simply voting — is testimony to the persistent power of the vox populi as mandate. ${ }^{97}$ While for decades the "representative government" notion has been subject to trenchant deconstructions and theoretical siege has been laid to it, ${ }^{98}$ it is still the most advertised source of governments' mandate to rule, particularly in election years. ${ }^{99}$ Public sector ethics holds that a government

\footnotetext{
${ }^{90}$ Young et al. (1996); Boston and Pallot (1997)

${ }^{91}$ Longstaff (1994); Sampford (1994)

${ }^{92}$ Ubel et al. (1996)

${ }^{93}$ Pitkin (1972); Grillo (1998); Urbinati (2006)

${ }^{94}$ Smith (1776 (1937); Libecap (2003); Stathakis and Vaggi (2006)

${ }^{95}$ Barnes (1995)

${ }^{96}$ See for example Buchanan and Tullock (1962); McKean (1965); Buchanan (1980)

${ }^{97}$ Smith (1993)

${ }^{98}$ Aleshire (1972); Hoggart (2000)

${ }^{99}$ Fredrickson (1994); Denhardt and Denhardt (2000)
} 
department's mandate to make binding decisions is its manifestation of the vox populi, expressed via an elected government's policy, and pursuit of that policy must therefore override any individual bureaucrat's normative notions. ${ }^{100}$

Human limitations on the vox populi However the three-yearly vote is an extremely blunt instrument for expressing what citizens want for specific issues such as natural resource management, ${ }^{101}$ and "the people" rarely speak with one voice. While in some situations, well-designed participation in rule-making procedure can legitimise the eventual outcomes regardless of their consistency with interest groups' wishes ${ }^{102}$ high-stakes decisions need specific information on what it is people want. ${ }^{103}$ However, populations' heterogeneity, and the multifarious ways people value natural resources, ${ }^{104}$ produce many diverse expressions of "what the public wants" for managing natural resources. (This is leaving aside the notion of intrinsic value in biota, as discussed in Singer and Regan (1989), Nash (1989), Gregory et al (1993) and Routley (1995).) People's values in natural resources are communicated by a wide variety of voices, which penetrate into the ears of government with varying success. ${ }^{105}$ Attempts to improve government decision-making by increasing participation must take account of the variables affecting this communicative success. ${ }^{106}$

Resources, rights and representation There are potential downstream consequences of involving certain groups, such as the risk of government capture. ${ }^{107}$ Jean Tirole's "revolving door" between government and the main interest group, enabling government capture, ${ }^{108}$ is relevant for small "action arenas" such as New Zealand fisheries management. ${ }^{109}$ Participation activity is often determined by interest groups' different "resource mobilisation" ${ }^{110}$ ability. ${ }^{111}$ Resource mobilisation (being able to deploy funding and human resources) is heavily influenced by the type and distribution of benefits from natural resources. For example, the wide, shallow distribution of the benefits from public goods contrasts with the highly concentrated distribution of private goods, particularly if (as is often the case) there is a private property right enabling

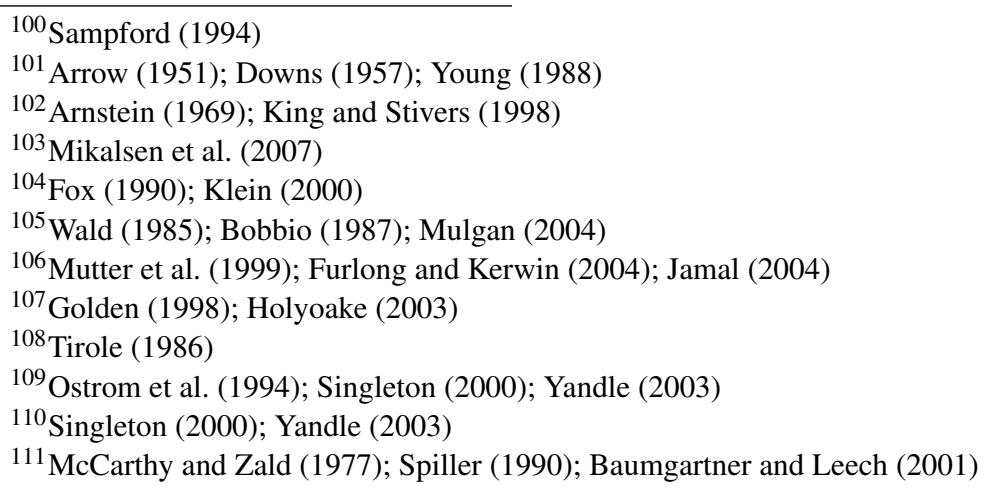


easy transformation of the fruit of a natural resource into money. ${ }^{112}$

The "silent constituency" (or "missing market") status of future generations ${ }^{113}$ is a difficult issue for vox populi approaches to directing government agents' decisionmaking. The concept has been extended to non-human species, ${ }^{114}$ asking for example how non-human species' existence rights (inherent value) and option value for future generations should be accounted for. The sustainability literature provides insight via the notion of capital (natural, human and manufactured), and the substitutability (and non-substitutability) of the elements in the capital portfolio that each generation receives from its antecedents and passes to its descendants. ${ }^{115}$ (Lags in the manifestation of environmental externalities are another dimension of challenge. ${ }^{116}$ ) However modern government structures make little formal provision for such intergenerational decision-making, leaving government agents to use their discretion to balance missing markets' anticipated needs against those of the more clamorous present generation.

\section{The philosopher king}

Plato's "philosopher king" (the benevolent, omniscient autocrat ${ }^{117}$ ) provides the label for this information source for "what is best" to do for government problems such as how to manage fisheries. Taking this approach, a leader essentially claims that he or she "knows best" what to do - better than the wider public — and, thus directed, the outcomes of government will therefore be better than if the citizens were to direct them. A variant on the philosopher king notion is the benevolent "king" drawing omniscience from expert advice, an arrangement that Svein Jentoft (adding to Weber's three types of authority for rulers ${ }^{118}$ ) calls "the authority of expertise". 119 Here, the "king" is a sort of colonial organism whose "brain" includes expert advisors and knows better than the citizenry "what is best" because it has uniquely good information supplied by experts.

Intense debate continues over the idea that governments, by their very nature, define "what is best" less myopically and in a more public-spirited way than individuals, resulting in policy that is better for the nation than that which citizens would call for.

Saving us from ourselves? Regardless of the shortcomings of bureaucrats, the complexity and "public good" characteristics of many shared natural resources make it

${ }^{112}$ Landell-Mills (2002); Mansfield (2004); Goble (2006)

${ }^{113}$ Broome (1994); Bhat and Stamatiades (2003)

${ }^{114}$ Dobson (1996); Saward (2006)

${ }^{115}$ D'Amato et al. (1990); Taylor (1998); Kysar (2007)

${ }^{116}$ Carpenter and Gunderson (2001)

${ }^{117}$ Sprague (1962)

${ }^{118}$ Weber (1948)

${ }^{119}$ Jentoft (2000) 
unlikely that anything even approaching a socially-optimal distribution of them will be achieved by people acting in isolation, pursuing individual desires on the basis of their own information. ${ }^{120}$ Human individuals' observed tendencies to temporal myopia, ${ }^{121}$ susceptibility to issue framing effects ${ }^{122}$ and media manipulation, ${ }^{123}$ and inability to objectively judge risk ${ }^{124}$ are the reason for the "paradox" of environmental democracy. ${ }^{125}$ It is difficult indeed to find expression of Rousseau's volonté générale, a "general will" that is immune to these handicaps and taps into the true greater good. If natural resource managers seek increased public participation and the benefits of "communicative rationality" 126 this seems to militate for increased effort in science communication. Until such time as the benefits of this manifest itself in a public more attuned to a volonté générale, there is a clear natural resource management role for government: preventing "wasteful exploitation of Nature's resources"127 and "saving people from themselves". 128

To a point, advice from experts can inform government agents about biological and ecological complexity, thereby making decisions better-informed and arguably improving the content of decisions - imparting the "authority of expertise". But a fundamental and omnipresent question remains: does being part of an institution called government somehow better enable an individual human being to compare the incommensurable, know the social discount rate ${ }^{129}$ and otherwise transcend the inherently human limitations listed above?

\subsubsection{What government agents do, day-to-day}

Where "what is best" can be defined in several mutually exclusive ways, how should government make tradeoffs? This is often the case in marginal decisions, such as where fishing unavoidably depletes a rare bycatch species or where the target stock may be at a critical minimum threshold.

In practice, governments make use of both the vox populi and philosopher king methods to define the goals for policy to manage natural resources. To maximise both the substantive quality of policy decisions and their perceived mandate, policy-makers combine tools such as stakeholder consultation with advice from specialist experts. Meanwhile, the exigencies of the political and budgetary processes often exert con-

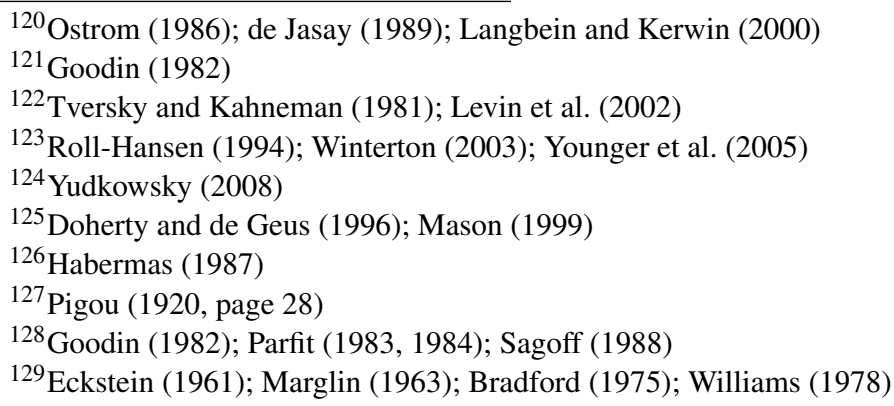


trary influences on this activity. The policy process has been heavily studied, with the literature moving from simpler models of decision-making ${ }^{130}$ through to more sophisticated models of the complex decision-making processes. ${ }^{131}$ However this wealth of literature allows insight into how governments make policy, but do not shed much light on how to tackle fundamental, substantive demand-for-government problems such as oceanic fisheries management.

\section{International law principles}

In recent decades the precautionary principle has appeared as a more substantive guide for the outcomes of natural resource management policy, though its varied manifestations in domestic and international law hinder practical interpretations. ${ }^{132}$ Sustainable management is another guiding principle, whose future element suggests avoiding irreversibility in natural resource management policy, ${ }^{133}$ but it is open to interpretation on the issue of substitutability of capital. ${ }^{134}$ Both these principles are common features in modern natural resource management law and policy, including the New Zealand Fisheries Act, but provide limited assistance government agents making on-the-ground marginal decisions. Government agents know well that in situations of conflict, duty to their employer institution - the government of the day as a representative of the public — precludes their personal norms from driving their professional behaviour. However where there is little information on what their government actually means by requiring precautionary decision-making, where can one turn for guidance?

Legacy systems often limit the option sets of contemporary governments, particularly given the need to avoid antagonising voters. Governments inherit established resource-distributing structures, such as property rights in fisheries, which have become cemented in social, economic and political structures along with their attendant effects on power distributions. ${ }^{135}$ They also inherit the ecological legacy of historical resource management, which for New Zealand fisheries includes a set of deep-water stocks that have been heavily fished-down but are still poorly-understood. Many decisions are therefore potentially marginal ones, with consequent distributive effects that raise the ecological, economic, social and sometimes political stakes. These are key characteristics of "wicked problems"136 which modern risk society is creating more of

\footnotetext{
${ }^{130}$ Downs (see for example 1957); March and Simon (see for example 1958); Lindblom (see for example 1959); Stigler (see for example 1971); Buchanan (see for example 1980)

${ }^{131}$ Stone (1989); Sabatier (1988); Rochefort and Cobb (1993); Kingdon (1984); Ostrom (1986); Wildavsky (1987)

${ }^{132}$ Cameron and Abouchar (1991); VanderZwaag (2002)

${ }^{133}$ Norgaard (1992); Tacconi and Bennett (1995); Goodland and Daly (1996)

${ }^{134}$ King (1994); Prugh (1995); Sands (1995)

${ }^{135}$ Pateman (1976); Bromley (1991); Kysar (2007)

${ }^{136}$ citetRittel1973
} 
than at any other time in human history. ${ }^{137}$

The demand-for-government problem of fisheries management, especially in the highly complex and poorly-understood deep-water context, means government agents receive limited information about "what is best" to do from both the vox populi and philosopher king sources. Science can seem to be an oasis of objectivity and solidity in the shifting sands of risk society policy-making. However, the quality-assurance of scientific best practice is still our best tool for ensuring we have the most accurate possible picture of objective phenomena. Incautious leaps by science into the policy domain - and decision-makers incautiously dragging scientists into the policy domain — have the potential to jeopardise the operation of this valuable tool.

\subsubsection{New ways of doing things}

Cognisant of this risk, there are increasing arguments that the unique conditions of the modern world demand new types of science ${ }^{138}$ and wholly new approaches to policymaking. As a starting point, these approaches have awareness of the gaps in society's understanding and the limitations of the tools at our disposal for filling them. They deliberately combine scientific and non-scientific disciplines in awareness of risk and uncertainty and the need for holism when predicting consequences of policy choices. ${ }^{139}$ Such approaches would help "re-embed" economic activity in society, reconnecting humans' actions to their consequences - particularly their impacts on nature. ${ }^{140}$ Notions such as Lubchenco's (1998) "new social contract for science" demanding greater policy involvement by scientists, ${ }^{141}$ are useful to help identify the terms of this more intimate engagement. Such a formalised approach is a critical step to allow integration of science into policy while protecting its ability to provide its unique contribution.

\subsection{Summary of Conceptual Threads}

\subsubsection{The context of fisheries science}

Objectivity is the link between the practice of scientific research, and the authority of science rests on its objectivity as a scout or messenger, going forth into unknown areas and reporting back to the rest of society on what is out there. This objectivity in turn rests on the checks that the scientific method has built into itself over centuries, which seek to remove human subjectivity from the analysis so that a plain, unfiltered, untainted picture of the subject phenomenon is presented.

\footnotetext{
${ }^{137}$ Wright (2004)

${ }^{138}$ Funtowicz and Ravets (1993); Lee (1993); Wagner (2001); Barry (2005)

${ }^{139}$ King (1994); Jentoft (2000); Hughes et al. (2005); Mayumi and Giampietro (2006)

${ }^{140}$ Lash et al. (1996); Saward (2006)

${ }^{141}$ Lubchenco (1998)
} 
The disinterestedness (objectivity) of the individual scientist as a professional, achieved and assessed through the scientific method, is a (if not the) crucial component of this link. The philosophy of science and the arguments seen during Science Wars continue to deconstruct and dispute, from a variety of angles, the nature and validity of the link between scientific method and "the truth" about the world. The impossibility of entirely removing subjectivity and influences of individual scientists' non-scientific views is widely acknowledged.

However the natural sciences are still able to argue that they are the best means humanity has for getting accurate descriptions of the world's objective phenomena. Decision-makers in fisheries management (and those subject to the decisions) accept the authority imparted by science. In other words, management decisions that can show they have used good science are more legitimate than those that cannot.

\section{Scientific objectivity: a difficult climate}

Natural science is the best tool we have for getting "the truth" about fisheries, human beings make the decisions that produce scientific advice about the status of New Zealand's marine species. Scientific experts are a key part of this, for they are trained to be better than laypeople at excluding subjectivity from their thinking. However, the New Zealand fisheries management context makes it difficult to be a pure scientist. Many generic natural resource management issues and deep-water-fisheriesmanagement issues are constantly pushing their way into the scientific decision-making process. Some have already shaped the fisheries management landscape to the extent where they affect the components of decision-making fora before meetings even begin.

High uncertainty in deep-water fisheries research means that fisheries scientists' decisions in the science meeting rounds can have a significant non-scientific component which threatens their objectivity. ${ }^{142}$ This uncertainty, plus the complexity of deep-water fisheries and the scarcity of information on the wider public's value in deep-water biota, means scientific decisions have an unintendedly large influence on deep-water fisheries policy. These lack mandate because they are being effected by scientists rather than those charged with policy-making, and are likely to be made poorly because scientists are professionally ill-equipped to weigh non-scientific considerations.

Operating strictly and solely in the scientific-technical mode in RPG, FAWG and RCC meetings is therefore difficult. However they are key to the process designed to provide the objective information on New Zealand's deep-water biota so critical to fisheries management, and the scientific process is "the only game in town" for acquiring that information.

${ }^{142}$ Clark (2003) 


\section{How the Conceptual Framework will be used}

There are certain issues that are perpetually omnipresent in fisheries management, of which some are thrown into sharper relief by the unique conditions of New Zealand deep-water fisheries management. These are all non-scientific considerations, which clamour at the metaphorical gates of the scientific decision-making process. The "guards" at these gates are the motivations that push scientists to restrict their analytical decisions and behaviour to scientific and technical considerations only, in accordance with the norms common to the scientific community and with the acknowledged role of the scientific fora. The conceptual framework will be used as a taxonomy of infiltrating forces and the scientific defenders, functioning as a spotter's guide to inform interpretation of interview data.

The infiltrating forces are a combination of "big picture" notions about how fisheries management should be done ("what is best" for the public, what is fairest, what is most efficient), and more personal responses to perceptions of other people's behaviour. If interview data and analysis shows that these are present in scientific meetings despite the procedural mandate that specifically excludes them, it can be presumed that they may be having an impact on the objectivity of the meetings' analysis. Once a non-scientific issue appears to be regularly present on the decision-making stage in scientific fora, the thesis will attempt to ascertain whether it is having an effect on the objectivity of scientific advice, and if so what that effect is.

Qualifier This research freely acknowledges the difficulty of identifying what drives a person's actions. Not being present in deep-water science meetings, nor having any quantifiable record of the rationales for decisions, means relying on meeting attendees' subjective assessments of other meeting attendees' behaviour and what drives them, and then making a further subjective assessment (though this latter is more signposted).

\section{Likely candidates for threatening scientific objectivity}

The nature of complex public goods (marine environments) versus private goods (captured and sold fish) affects how easily value in these can be communicated and expressed as the vox populi. The distribution of fisheries rents (from the operation of private property rights) has an impact on significant influence on the scientific "firepower" representing different interest groups. (This is an example of a non-scientific issue that affects scientific meetings before they even begin.) The depleted, slowgrowing nature of many deep-water stocks and the scarcity of information raise the spectre of at least local extinctions as a potential consequence of fishing activity. This would have major consequences for future generations, for the public good and for option value, and for distributive equity. The issue of the interplay between efficiency and 
effectiveness in science (particularly science for policy), highlighted by questions of funding, makes regular appearances due to shortages of funding for research into target and bycatch stocks, and the monopoly provider market for independent deep-water scientific research.

\section{What could guide next steps?}

The literature analysing how science is operating in modern societies, which need policy decisions made for wicked problems, provides clues to how New Zealand might proceed in deep-water fisheries management given the issues with the status quo. This will inform the conclusions and recommendations section of the thesis.

The following chapter presents the results of interviews, where key people involved in deep-water fisheries science and management were interviewed to elicit information on what goes on in the yearly scientific fora. 


\section{Chapter 5}

\section{Results}

\subsection{Introduction}

This section presents the results of interviews that sought to provide insight on the decision-making process in these meetings. They focus on whether and how the participants ensure that the scientific and technical analysis (that is the meetings' entire raison d'etre) is insulated from the non-scientific issues that loom large in the wider fisheries management landscape. This would provide reassurance that the scientific analysis from these meetings is objective as possible, and gives the most accurate picture of the state of deep-sea resources that New Zealand can afford.

This section first maps this landscape with reference to the scientific advice process, identifying the features of NZ fisheries management that "clamour at the gate" of the scientific fora. It will then look at how scientific analysis operates in this environment, with a view to assessing whether a lay observer can be reassured as above.

Material from interviews will be cited according to how participants indicated on consent and waiver of confidentiality forms their material could be attributed (see Appendix C). Further details of interviews may be found in Appendix B. Brief summaries of interviewees' involvement with fisheries management in New Zealand, as described to the author, can be found in Appendix D.

\subsection{Government Fisheries Management Role}

\subsubsection{Philosopher kings or voices of the People?}

While there was general agreement that MFish must manage New Zealand's fisheries resources in the public interest, the actual form of that interest was hotly contested. Interviewees felt in general that there has been no large-scale, comprehensive research into the wider New Zealand public's macro-level wishes for fisheries and marine man- 
agement that could set an overall direction for the government. Initiatives such as public consultation for the Oceans Policy were acknowledged to be the right type of remedy for this problem, but had not gone far enough to significantly improve on the status quo.

\section{Satisficing but losing scientific accuracy?}

Complaints about fisheries policy mis-firing on scientific issues occurred relatively frequently throughout interviews, which is perhaps not surprising given the scientistheavy interview sample. A wide range of interviewees felt that policy-makers seem to understand neither science nor the practice of fishing (Carey, Clement, Courtney, IP, McKoy, Sullivan, Weeber). An industry interviewee opined that MFish policy staffers are trying to correct for deficiency of fisheries policy, but are generating large quantities of inferior-quality material (Starr).

Several participants (NIWA, industry and ENGO) felt that a general deficiency of communication between MFish policy and science staff causes the perceived scientific inadequacy of much Ministry policy, or at least allows it to persist (McKoy, Starr, Stokes, Weeber). While observing that it is scientists' responsibility to ensure that their results are communicated intelligibly to non-experts, an industry respondent saw an unusual degree of scientific illiteracy in MFish's policy department, particularly compared to European equivalents (Stokes).

One industry participant attributed policymakers' science failures to a tendency to simply ignore the results of research (Courtney), while others (from the industry, NIWA, and MFish) believed scientific shortcomings in policy are due to policymakers' failure to participate in scientific processes or engage sufficiently with the scientific community (Courtney, McKoy, Sullivan). The ENGO interviewee noted that there is variation in different policymakers' level of engagement with science processes, observing that the deep-water group is one forum where policy staff make an effort to participate (Weeber).

\section{Policy vacuum: contested resource allocation decisions}

Interviewees argued that MFish is chronically late delivering on promises to create policy, and when policy eventuates it is too superficial. One participant cited the SMEEF as an example which took five years "... and you could've done it in three months if that was all it was going to be" (Weeber). An industry respondent and the ENGO respondent both cited fisheries standards as another example, expressing cynicism about fisheries standards' potential while they remained without legislative incorporation (Clement, Weeber). 
Research participants made particular mention of the fact that it is not the ITQ itself (which is legislatively articulated in great detail) but rather the deficiency or absence of legal and policy context for the property right that is causing problems (IP, Participant, Stokes, Weeber). An underlying question, rooted in the dual "philosopher king / vox populi" role of government, is whether it is desirable to ask the New Zealand public what it wants or if clear, comprehensive, macro-scale management directions can be set by MFish without the significant expense of this exercise. (More detail can be found in "Providing for in situ value" below.)

Several participants (MFish, industry and ENGO) stated that large-scale public debate over the overall direction for New Zealand's fisheries management is urgently needed to be able to set major fisheries management objectives (Crothers, IP, Stokes, Weeber). The absence of such a vision leaves day-to-day fisheries management more open to conflict, especially decisions allocating fisheries resources between extractive and non-extractive uses. One industry-affiliated interviewee stated that industry stakeholders swiftly contest allocative decisions because they see them as being made in a policy vacuum, and resent what they see as arbitrary imposition of one set of values and priorities upon another (Harte).

An absence of information on New Zealanders' fundamental values in fisheries means different fisheries stakeholders can attack management decisions that disadvantage them on the basis that they represent the interests of New Zealand's "silent majority", or the wider public. For example, industry-affiliated and former Ministry interviewees felt that if forced to choose between environmental preservation and maintenance of current living standards (supported by economic contributions from the fishing industry), most New Zealanders would opt for the latter (Clement, Major). In contrast, an industry-affiliated participant and a former Ministry respondent argued that the fishing industry's incentives fundamentally diverge from wider social objectives, and the government should manage New Zealand's fisheries because they can properly represent the greater public interest (Harte, Cornelius).

\section{Policy vacuum II: practical management moves ahead}

Interviewees noted that absent or insufficient fisheries policy leaves day-to-day management (including fisheries science) to move ahead of it. Industry-affiliated, former and current MFish interviewees cited cost recovery as an example, noting that despite its important distributional ramifications, it was simply adopted without any public discussion as a replacement source for the $\$ 30$ million the disestablished resource rentals had provided (Allen, Annala, Sullivan).

The role of the Act's section 10 (requiring caution and consideration of uncertainty in fisheries management), and particularly 10(d) (stipulating that insufficient informa- 
tion cannot justify failure to act in pursuit of the Fisheries Act's purpose) was an interesting element in interviews. When asked directly, most participants stated that the advent of section 10 had not had a significant impact on how information is handled in fisheries management. However, a prominent feature of interviews was the issue with section 10(d) - its failure to stipulate whether to err in favour of the utilisation or the sustainability elements of the Act's purpose when making decisions under uncertainty, allowing it to be interpreted in mutually exclusive ways. Interviewees who perceived a policy-maker consistently erring in favour of one purpose or the other saw this as evidence of "capture" by interest groups. Interview respondents who saw participants in scientific meetings consistently erring towards sustainability or towards utilisation interpreted this as inappropriate policy-making behaviour.

Interestingly, there was little direct mention of the influence of RPGs' decisions in setting the distribution of research effort and thereby the distribution of scientific information - and uncertainty — between stocks. One exception was the former Ministry respondent who emphasised the importance of keeping an eye on the bigger picture, because decisions (in RPGs) over which questions to address with research and which to put in the "too hard basket" have far-reaching implications (Cornelius).

\subsection{Management for All New Zealanders?}

Fisheries management policy is relevant for people operating in a strictly scientific, technological environment because it can guide technical decision-making where scientific uncertainty is high.

\subsubsection{Provision for in situ value: policy guiding science}

Discussion of providing for in situ value in marine resources such as intrinsic and option value showcased this phenomenon. It was particularly evident in the issue of whether such value justifies restricting fishing beyond the level needed to minimise the risk of inducing critical depensation ${ }^{1}$ in a target stock. This is uniquely starkly illustrated in deep-water fisheries contexts, where there is a strong dichotomy between stakeholder groups.

\section{Is in situ value worth the bother?}

Three participants (former Ministry, industry and unaffiliated) felt that practically providing for in situ value in fisheries management was a Herculean task but one nonetheless worthy of attention (Annala, IP, Participant). Others (former MFish, science

\footnotetext{
${ }^{1}$ Critical depensation is where a population is so small that under natural conditions (with normal background levels of predation, sickness, emigration and so on) it cannot maintain its size by reproduction
} 
provider-affiliated and two industry-affiliated) felt that attempting to provide practically for the exercise of non-extractive value would open a Pandora's Box. Therefore if provision for in situ value is to be embarked upon, it must be strictly controlled (Allen, Clement, Hilborn, Stokes).

Discussing the use of area closures as a marine resource management tool, two participants (NIWA and MFish) felt that the public interest in avoiding losses of deepwater coral and sponge species merits implementing zero-fishing areas (McKoy, Sullivan). Two industry-affiliated participants questioned the rationality of closing large areas of the EEZ "just 'cause" and noted that the public would never see (and by implication not value) deep-water species if they were not fished (Harte, Starr). Three interviewees (former Ministry and industry) posited that the public interest in nonextractive value can probably be fulfilled by preserving a minimal quantum of biota (Allen, Hilborn, Stokes). Several industry participants nevertheless highly praised the fishing industry's sustainability initiatives such as the BPA proposal (Courtney, Clement, Harte, Hilborn, Starr). The ENGO respondent felt that BPAs without scientific support as being ecologically representative are not useful (Weeber).

On the issue of quota cuts to preserve non-target species, two industry-affiliated participants argued that the greater public does not understand the notion of fish-down to $\mathrm{B}_{\mathrm{MSY}}$, nor why it is not necessarily better to manage at higher standing stocks (Hilborn, Starr). One questioned the rationality of economically painful quota cuts whose only benefit would be slightly more security and a slightly higher standing stock (Hilborn).

Interestingly, there was unexpected accord between a Ministry respondent's and an industry-affiliated respondent's discussions of protecting bycatch species. Their statements suggested that they had respectively interpreted section 10's "precaution" as meaning protection for deep-water benthic biota (Sullivan), and for vulnerable, "unique" marine environments (Harte). They felt that when these phenomena are identified, there is no point in further research, for in most cases protection is automatically required. Some industry-affiliated interviewees argued that in being made to constrain its resource use to rehabilitate already-modified productive terrain, the fishing industry is being singled out from New Zealand's primary industries, particularly when compared with the environmentally destructive dairy industry (Clement, Stokes). 


\subsection{The Context For Fisheries Science: Potential Vehicles For Threats To Objectivity}

\subsubsection{Money and Efficiency — research and funding \\ Efficiency and financial risk in research provision}

Several industry-affiliated and science provider respondents felt that MFish's research procurement process is run by scientists for scientists, and combined with an "open chequebook" attitude, this results in MFish condoning exorbitant charging by NIWA (Clement, Hilborn, Starr, Stokes). An industry participant cited an example of NIWA quoting the Ministry around 50\% more than it quoted an industry group for the same job (Clement), while an SP participant described it as very competitive, where it actually has competition (Hampton).

For a variety of other respondents, a long-standing market failure - the monopoly for independent deep-water research provision - is the dominant feature of New Zealand's deep-water science landscape (Crothers, Hilborn, IP, Participant, Sullivan), and NIWA's commercial imperative determines its pricing behaviour (Clement, Hampton). MFish, NIWA and unaffiliated interviewees argued that the contestable contract approach to government fisheries research introduces significant transaction costs. For deep-water research these are largely formalities, yielding dead-weight losses rather than the benefits of genuine competition (Crothers, McKoy, Participant, Robertson, Sullivan).

Responses varied over what should be done about this situation. Some industryaffiliated interviewees argued strongly that devolving deep-water research procurement to industry (or at least contracting industry boats to perform stock assessments) would be much more efficient and effective than the status quo (Carey, Clement, Courtney). For other respondents, the competitive system's market failure in deep-water research is an unfortunate fact of life, and some inefficiencies must be borne for the sake of maintaining a flow of independent, high-quality research to use in management (Crothers, Sullivan). Ministry, former Ministry and unaffiliated respondents readily acknowledged the inefficiencies of the status quo but emphasised the need for the government's research to be seen to be independent. The "fox in the henhouse" presumption means the burden of proof rests with industry to prove their fisheries research is comparable with the heavily peer-reviewed MFish research before significant moves to using industry-collected science will be made (Allen, Annala, Crothers, Participant).

NIWA, unaffiliated and industry participants cited examples of skippers unwillingness or inability to collect worthwhile series of good-quality data (SF, McKoy, Participant, Robertson). One Ministry respondent's experience was that despite the best 
intentions and all the promises in the world, industry "get bored and uninterested and their programmes never happen, or run for a year and then fall over — they're not even bothering"(Sullivan).

\section{Funding, science and uncertainty, and the best science?}

Participants' comments about efficiency and waste in research provision revealed differing views of the nature of science.

NIWA, Ministry, unaffiliated and former-Ministry-affiliated interviewees felt that the fundamental unpredictability of scientific research (which is even greater for deep water science) means that a certain amount of "wasted" effort and funding (that fails to yield a useful result) is unavoidable. However this does not render that piece of research unworthy of funding nor necessarily inappropriate for cost-recovery (Annala, Cornelius, Participant).

This contrasted sharply with an industry participant's view (see below):

You would go to the science service providers and say "Can you please provide me with an answer to this question?" and you wouldn't accept "Well maybe if you give me a research contract I could", you'd say ....'I'll have a commercial contract, I'll contract you to answer this question. If you don't give me an answer I can use, then you don't get paid" .... It's no good me going to someone and buying a boat to go fishing and they won't guarantee it floats! [...] Put the risk on the service provider not on the Crown! "but nobody would bid for the work!" Well can't you see who's taking the risk? We're buying something that even the people providing it aren't prepared to take the risk. (Clement)

Two industry-affiliated participants argued that NIWA's status as an effective monopoly provider in deep-water science had materially affected the quality of its analysis. They perceived a degree of complacency in NIWA scientists' work (Starr) which made industry scientists' second opinion on research results all the more important (Clement). The role of industry scientists as a "watchdog" over MFish and NIWA science was clear, as was the notion of industry scientists' own science being particularly conscientious to rebut the "fox in the henhouse" presumption (both discussed below). Several participants remarked that becoming a CRI seemed to make NIWA scientists feel obliged to present a united front, reducing their willingness to engage in robust scientific debate (Major, Harte, Hilborn, Allen) and reducing willingness to engage in collaborative research (Hampton). 


\section{Overall fisheries management efficiency}

Interviewees' discussions of cost recovery's effect on fisheries science were largely negative, with the exception of a handful of statements. Three interviewees saw benefit in the way cost recovery causes the wider industry to discuss the merits of fisheries research and understand the back-stage costs of fisheries management (Major, Starr, Stokes), and of the discipline it imposes on government spending (Clement). There was also conditional support for the cost-recovery notion provided government-funded research and innovation were sufficiently funded (Harte, Sullivan).

The project-by-project, stock-by-stock approach to cost recovery and its transaction costs engendered widespread frustration amongst interviewees, who used language such as "bloody stupid", "ridiculous" and "goddamned" to describe it. One interviewee expressed frustration with the amount of MFish staffers' time that cost recovery transactions take up (Participant). Two respondents expressed sympathy with fishers' resistance to paying for research that did not benefit them (McKoy, IP), and as one stated: "the whole [quota management] system's oriented around quotas for particular species and stocks" (McKoy).

Several interviewees noted that cost recovery creates a perverse incentive, whereby the fishing industry advocates against research on the basis of its expense or commercial consequences rather than on its merits for overall fisheries management (Allen, Crothers, Hilborn, IP, McKoy, Participant, Starr, Stokes, Weeber). Most non-target species research is not commercially valuable and may in fact be commercially detrimental if it leads to catch limit reductions. Two industry participants were pragmatic about the industry being cost-recovered for research into charismatic and rare bycatch species such as Maui's dolphins, resigned to the fact that there is strong public pressure to manage such species conservatively (Carey, Courtney).

Several interviewees argued that stock-by-stock cost recovery also fails when fish stocks are depleted, because the industry can least afford to pay for it. As noted, this is in fact when stock assessments and other research are most needed as management must be particularly precise. This system essentially deadlocks non-fished stocks (non-target species and closed fisheries): because no revenue is coming out of them, no research can be funded to assess reopening the fishery (Allen, Hampton, Hilborn, McKoy, Participant, Sullivan, Robertson, Weeber).

Squeezing fisheries research purchasing into the financial year was seen to cripple New Zealand's long-term research ability. Research is usually confined to short projects, and long-term studies are extremely difficult to arrange, causing a deficiency of good long-term information on New Zealand's marine resources (Hampton, McKoy, Participant, Starr, Weeber). One industry participant commented that one of SeaFIC's roles is to convince the industry to pay for important research (IP), with which it has 
some success. However major one-off research projects, which may occur only every five or six years, are unattractive prospects for industry funding as the benefits accrue over a long period of time (and are often not guaranteed), and bank loans would be required to fund such projects up-front (Sullivan, Weeber).

\section{Better alternatives? Public funding}

An industry-affiliated interviewee felt that these problems are a reason for greater flows of government funding (Harte), whereas unaffiliated, ENGO, NIWA and SP respondents saw them as arguments for a more broad-brush cost recovery system more akin to a resource rental (Hilborn, McKoy, Participant, Weeber).

The "attributable cost" principle for cost recovery "totally ignores the public interest in having fisheries ... and the general public interest in sustainability and biodiversity and having it there" (McKoy). Three interviewees similarly argued that government funding for the QMS should reflect the long-term value that a well-managed fishery posed to New Zealand (Carey, Courtney, Stokes). Several industry respondents stated that research into the biology of non-target species, and research to ascertain whether fishing is having an adverse impact on the environment, should be funded by the government and not cost-recovered. Once an adverse impact has been identified, research to investigate and mitigate it can fairly be charged to the industry (Clement, IP, SF, Stokes).

An unaffiliated interviewee and the ENGO respondent observed that MFish's 20062007 fisheries research budget was 57\% of its 1991-1992 level, a shortfall of around $\$ 10$ million accounting for inflation (Participant, Weeber). New Zealand's science funding in general (and fisheries in particular) was described as paltry by international standards (Harte, Stokes), and one argued that the QMS is so data-hungry that even to manage target stocks with precision (let alone bycatch species or the marine environment) simply cannot be done without subsidies (Stokes).

Industry, NIWA, unaffiliated and SP interviewees observed that the number of species in the QMS has tripled since 1991-1992, and the addition of a suite of farreaching environmental principles to the Fisheries Act has imposed a considerable additional research burden (Allen, Hilborn, IP, Major, McKoy, Participant, Stokes, Weeber). ENGO and industry-affiliated participants argued that the largely policyless, "clip-on" (Weeber) nature of the Act's environmental principles means that implementing them demands a huge amount of scientific research. As this straddles the boundary between "public good" and "internalising externality" science, it falls into a funding "black hole" between cost-recovery and government resourcing (Harte, Stokes, Weeber).

Two Ministry participants hinted at a paradigm shift in fisheries science, feeling 
that New Zealand must admit that "OK, we're not going to research our way out of diminishing stocks" (Sullivan), and must instead manage our way out: "perhaps mov[ing] from a reasonable risk, high information, high cost approach to managing ... to a very low risk, low information approach" (Crothers).

Summary While it is clear that the context in which deep-water science fora operate is perpetually controversial, this is not necessarily cause for concern. Marine fisheries management is an inherently complicated and difficult process, requiring science to feed into policy that is inevitably politically charged. The question is whether the decision-making processes of New Zealand fisheries science can be relied upon to deliver the best - i.e. the most accurate - statements about deep-water stocks so that the QMS can function properly and marine resources be utilised sustainably.

The role of the science fora is to provide statements of the status of deep-water marine resources that are as accurate as possible. The proxy assessment of accuracy being used is objectivity of the analytical and decision-making processes. If therefore it appears that the objectivity of scientific analysis in scientific meeting rounds is being shielded against the various subjective forces of the political, economic and social context, we can be relatively satisfied that the scientific process is doing its job.

\subsection{What Happens in Science Fora: How Scientists Act in Practice}

In order to understand how MFish and non-MFish scientists manage the interplay between "objective" science and "subjective" policy at a practical level in the yearly science fora, interviewees were asked about the roles and risk management behaviour of different participants in FAWGs, RPGs and RCCs. Questions were aimed at eliciting information on how the participants in these fora ensure the meetings' outcomes — scientific advice to the Minister - are risk-neutral or objective, and scientifically robust.

\subsubsection{Scientists in action: scientific purity, human frailty, both?}

Several respondents shared the view that because FAWGs, RPGs and RCCs are strictly scientific and technical fora, participants should conduct themselves as pure scientists. The successful functioning of a scientific forum is therefore measurable by how closely its participants' behaviour matches expectations of scientific comportment. For interviewees whose views fell into the "pure science" category, it is simply not appropriate to consider equal representation of all fisheries stakeholder positions in RPGs, RCCs and FAWGs because these are scientific and technical fora. If scientists are acting 
as "pure" scientists, the positions they take on a particular technical issue should be independent of their normative ideas about fisheries management.

While this is a pure Mertonian view of scientists, this position was argued as one which should guide scientists' behaviour in RPGs, FAWGs and RCCs. Sitting alongside these was a distinct but related issue of the degree to which MFish scientists, by virtue of their status as government scientists, had a special and unique role in meetings.

\section{Pure science in action}

Participants were unanimous in generally praising the pure scientific performance of FAWGs as fora for robust and vigorous scientific debate. Industry, NIWA and Ministry respondents particularly approved of FAWGs' strictly scientific and technical tenor, which they felt facilitates discourse largely independent of participants' affiliations (Annala, Harte, McKoy, Sullivan). Two NIWA and ENGO respondents hailed the vigorous scientific debate over alternatives that a large varied gathering of scientists can achieve (McKoy, Weeber). An industry-affiliated interviewee emphasised that the scientific scrutiny goes both ways: "I stand up and they rip me to shreds too. [...] You live by the sword, you die by the sword" (Starr). One former Ministry participant recalled that industry representatives used to engage in considerable positioning during consultation rounds, where they would be represented by their lawyers, but MFish had tried hard - and largely successfully — to remove this (Annala).

An SP and a Ministry interviewee felt that interpersonal forces also operate in scientific fora to constrain improper behaviour. Long-standing personal relationships with other FAWG and RPG participants were believed to have this effect, as does the empathy that present opponents feel from having been "on the other side of the table" in previous professional lives (Hilborn, Sullivan). Interestingly, one MFish respondent said that in research fora NIWA scientists "just try to play the field, flatten the plain", but also noted that they "... do support the Ministry [in its efforts to risk-neutralise meetings] because they're ex-Ministry staff" (Sullivan). (This latter observation was interpreted by some industry scientists as evidence of positioning by NIWA and MFish scientists (see below).)

There was considerable confidence expressed by current and former Ministry, SP and industry interviewees that the behavioural and ethical parameters set by scientific norms would be respected, and that the value individual scientists placed in their professional reputations would restrain them from indulging any desires for advocacy (Annala, Hilborn, Major, Participant, Stokes, Sullivan).

Several respondents stated that every scientist, without exception, is affected by values and has some form of proverbial barrow to push (Crothers, Hilborn, Starr). The 
question is whether scientists can act objectively (as measured by adherence to scientific protocols and reflected in their standing in the scientific community) to ensure their analysis is shielded from those values.

Commissioned science One respondent recalled that fisheries scientists firmly resisted attempts in the 1990s by the industry to hire scientists "who would help them in terms of quota" (Stokes). Similarly, a NIWA interviewee stated that NIWA representatives' only advocacy is in defence of their work (McKoy). Industry-affiliated scientists particularly pointed out that their reputations are all of the highest calibre and their independence is carefully protected, citing the fact that they regularly tell the industry things it does not want to hear (Hilborn, Starr, Stokes). Another stated that the "fox guarding the henhouse" presumption that hangs over industry-affiliated scientists means that industry-commissioned stock assessments must adhere especially strictly to the letter of scientific protocols (Harte). For current and former Ministry-affiliated participants, this means that a burden of proof rests with the industry's scientists to prove their mettle as providers of scientifically sound research before MFish would be willing to devolve responsibility for stock assessments (Allen, Sullivan). (See also Funding, science and uncertainty: what yields the best science? above.)

For one industry participant, encouraging the industry to accept short-term pain where appropriate is a major part of SeaFIC's role; it does not advocate for the industry but rather represents for them, a role akin to a government scientist or policy-maker freely and frankly advising a senior bureaucrat or minister (Stokes). The ENGO representative expressed some surprise at the amount of research that SeaFIC had been able to persuade the industry to pay for over the years (Weeber). These generally favourable views of the scientific purity of analysis and behaviour in scientific fora were articulated despite widespread acknowledgement that significant scientific uncertainty opens the door to advocacy, and criticism elsewhere in interviews of other stakeholders' advocacy behaviour in research fora (see below).

\section{Slightly less pure science in action}

Unaffiliated and Ministry respondents said that industry scientists' contribution to the scientific pluralism of research fora was valuable if it was "expertise, not advocacy" and sought to "collaborate rather than capture" research (Crothers, Participant).

Others (industry-affiliated and former Ministry) cited the advantages of another expert to 'check your sums', an important role when million-dollar quotas are at stake (Clement, Hilborn, Major, Starr). Some saw evidence of some monopoly-induced complacency in NIWA deep-water science that contrasted with industry scientists' attitude (see interviewees' treatment of efficiency and science in Funding, science and 
uncertainty below.)

Some industry participants felt that this "sum-checking" means acting as a sort of watchdog over scientific decision-making processes, and reassuring the industry that the science informing fisheries decision-making is sound and provides the best basis for management decisions. This, they felt, is a particularly important role for industry scientists given the Ministry's and NIWA's conservatism and the cost-recovered nature of much of the research (Clement, IP, Stokes). One can presume from these statements that the scientists concerned would first try to ensure that the science was in fact sound before they reassured the industry about it, a presumption supported by another industry participant's emphasis of the importance of the "second opinion" role of industry-commissioned science. Interestingly, the same participant gave no credence to the notion that positioning occurs in pure scientific fora, saying that "Green science ... is about as spurious as Maori science" (Clement).

A Ministry interviewee pointed out much of the confidence in FAWGs' and RPGs' scientific and technical objectivity rests on faith. He observed that because there is no statutory obligation to publicise privately-funded research, in contrast to publiclyfunded research, one cannot be certain if a study cited to support a particular conclusion is from the extreme "tail" of a distribution of many such studies, or represents the mean. "You've got to hope that the honesty is there, that they'll also show both ends of the spectrum but you don't know. You can't even suspect that they've done the added work [the other studies]" (Sullivan).

\subsubsection{Representation of non-scientific views in science fora}

A major feature of interviews was the subtle distinction between general (typically non-expert) representation of the openly values-based positions of interest groups, and commissioned scientific representation that more or less often aligns with the interests of that group. It is extremely difficult to define where in practice to draw the line, and (as noted in the conceptual framework) this is an issue that scientists and the scientific literature have struggled with for decades. This was reflected in interviewees' responses, which showed the contrasting opinions and degree of confusion on the issue.

\section{Stakeholders' views - appropriate in science fora?}

Participants' opinions differed on the decision-making level where full stakeholder representation should be pursued. They touched briefly on the procedural level at which uncertainty and value-based considerations (the policy or human element) should be tackled in fisheries management processes. This fed into a range of views of MFish scientists' role as government representatives, which are presented below. 
Some interviewees felt that uncertainty in fisheries management was best dealt with in technical fora, where knowledge was most concentrated, and interest groups should engage there by hiring scientists to balance the representative field (Harte, Hilborn, Starr). However two industry-affiliated interviewees and one NIWA-affiliated respondent argued that since ENGOs' modus operandi is advocacy (rather than scientific involvement) their participation is best suited to a policy level where, they felt, value judgements are most appropriately handled (Clement, IP, McKoy).

Observing that hiring expert scientists is beyond the means of most ENGOs, one interviewee was in favour of assistance to such under-represented groups to help them surmount general participation barriers in fisheries management decision-making (Weeber). An industry interviewee recognised that ENGOs represent a broader public interest than recreational fishing groups, for example, and could therefore merit governmentindependent financial assistance with the expenses of participation in fisheries management (IP). However IP also argued that a group's willingness to pay for a professional representative is a good indicator of a critical constituency mass (see quote), as shown by the increasing professionalisation of fisheries management.

“...that environmental constituency needs to think about how much it values the outcomes it could get from actually funding those kind of positions. The industry pays for people like [us] because they think it's worthwhile to employ us. And it is. I don't see why other groups who, if they truly want to be stakeholders and claim to represent a legitimate interest in these things which we are talking about, do it on a professional basis! Brutal!" (IP)

Insufficient scientific representation of other interest groups is not industry scientists' problem to deal with (IP, Harte, Starr), and does not oblige industry to cease its own representation. A different industry interviewee felt that it is particularly important that industry's views are represented in science decision-making processes because their support of cost recovery for fisheries research ("users pay") is conditional on "users say" (Clement).

A Ministry participant said MFish is aware of the lack of expert scientific representation for ENGOs, and in pursuit of the Act's environmental principles, MFish has expanded the Science Group and provided a wider perspective on science (Crothers). The ENGO representative praised the Aquatic Environment Working Group's scientific view as being generally wider than that FAWGs exhibit, due to the broader range of scientific institutions that participate in the Aquatic Environment meetings (Weeber). This pluralism led an industry respondent felt this pluralism made that working group's analysis "especially woolly" (Clement), suggesting a perceived conflict be- 
tween more complete representation of the scientific opinion distribution and quality (or at least clarity) of analysis.

One industry-affiliated respondent suggested that greater social embedding of the fishing industry (such as seen in many Scandinavian countries) would have greater benefits for fisheries management than attempting to scientifically educate the wider public so that they can participate in the scientific component of fisheries decisionmaking (IP). Two industry-affiliated and one NIWA respondent commented that it is difficult to identify the "green constituency" or environmental stakeholder that ENGOs represent (Harte, IP, McKoy).

A feature of interviewees' discussions was the distinction between representing a distribution of strictly scientific opinions (scientific pluralism) and representing a values-based opinion distribution in FAWGs and RPGs. However it was a shifting frontier, and sometimes disappeared altogether when discussions turned to the day-today reality of participating in scientific meetings.

However, it was possible to discern two themes in interviewees' views of the appropriateness of values-based (rather than scientific) positioning in science fora. Once again, whether a respondent took a normative or a positive attitude to scientists' behaviour in meetings significantly influenced their feelings about the role of valuesbased representation. Those who took the normative, "pure science" position felt scientists in meetings should always ignore opportunities to influence wider fisheries management and refuse to engage in positioning. Those who took the more positive view argued that advocacy and values-based decision-making were going to happen anyway, and would likely have an impact on fisheries management because of the greater influence of scientific advice given the way scientific fora are exercising a quasi-policy function. Scientists should therefore take the opportunity to have a beneficial influence on deep-water fisheries policy.

\section{Scientific pluralism and advocacy}

Positioning for science Two interviewees (science provider and industry-affiliated) observed that the point of a science contract with an interest group is to supply information that assists the client with its goals (Hilborn, Starr). The science provider respondent acknowledged the fact that no interest group will pay for science that does not support its cause, and the science provider concerned will simply not get a contract or a contract renewal (Hilborn).

A NIWA and an MFish interviewee argued that such industry "scientist-shopping" for sympathetic providers undermines scientific disinterestedness (McKoy, Sullivan). Two Ministry respondents stated that industry scientists actively try to influence the consensus in FAWGs (Crothers, Sullivan). NIWA and ENGO interviewees described 
industry scientists' conspicuous silence where tabled research errs in the industry's favour, and energetic critique of equally robust or ambiguous research that would disadvantage the industry (McKoy, Weeber). They felt that presence of a vested interest in the science's outcome nullified the potential benefits that industry scientists' participation could provide through increased scientific pluralism (Crothers, McKoy).

In contrast, other respondents (industry-affiliated and science provider) argued that industry scientists' contributions have significantly improved the quality of the scientific analysis in meetings, by redressing imbalance caused by MFish and NIWA positioning. They gave the introduction of Bayesian analysis to FAWGs and the cessation of cost-recovered flat area surveys as examples of improvements industry scientists' participation had made to the scientific advice process, in the face of considerable Ministry and NIWA resistance (Clement, Hampton). One interviewee felt that NIWA scientists consistently favour the cautious option when assessing the highly uncertain results of acoustic sampling, and are extremely suspicious of science suggesting otherwise (Hampton). NIWA scientists' long resistance to using industry boats for stock assessments was also given as an example of unreasonable conservatism regarding research methodology, and two science provider interviewees argued that industry scientists' efforts had improved the fisheries science provision process by overcoming this (Hampton, Hilborn).

A NIWA participant felt that NIWA is insufficiently consulted in terms of the planning process for fisheries science, which he saw as problematic given that it is "... the major source of knowledge about what's going on in fisheries sciences" (McKoy). In contrast, several other participants (industry- and SP-affiliated) complained of an excessively proximal relationship between NIWA and the Ministry science group, founded on scientists' status as ex-colleagues, which means amongst other things that NIWA influences research purchasing decisions and thence science policy (Hampton, Stokes, Clement, IP, Hilborn, Starr, Carey).

\section{MFish positioning — legitimate?}

Strong opinions were evident in interviewees' discussions of whether MFish scientists' role as government representatives gives them a unique licence to consider nonscientific factors in FAWGs and RPGs. Respondents' views here showed evidence of two underlying issues. The aforementioned dissension over the appropriateness of scientists representing stakeholders' or other value-based positions combined with an additional layer of disagreement over the role of a government scientist.

This latter conflict was interestingly presented in that all respondents initially articulated a very "pure science" view of the MFish scientists' role, linked to similar views of the role of the scientific meeting process (see "Pure science" above), which would 
theoretically preclude any positioning of the kind that both MFish and non-MFish interviewees later described in their discussions.

Policy is forbidden There was relatively wide agreement across the interview sample that MFish scientists' role does not extend to shaping policy. Eight interviewees stated that Ministry scientists should not engage in policy-making because their role is to be scientists and as a rule, the normative value-based considerations of policy are outside scientists' purview (Allen, Clement, Crothers, Harte, Hilborn, McKoy, Participant, Sullivan). One research participant stated categorically that the Science Group has no input into allocation and other such value-based decisions unless asked to scientifically assess particular management options by the MFish policy group or Ministry leaders (Participant).

More specifically, several respondents (former and current Ministry, unaffiliated and industry) stated during interviews that the MFish Science Group's role is to conduct a fair and proper research-generating and research-assessing process, impartially transmit stakeholders' views to the Minister, objectively weigh up available research, and provide free and frank advice on that basis to the Minister (Allen, Crothers, Participant, Stokes, Sullivan). In practical terms, there was general consensus that it is important that RPG, RCC and FAWG meetings are as "clean" - i.e. as scientifically objective - as possible, and MFish scientists (notably each meeting's chairperson) therefore have an arbitrator and referee role. This seemed to mean arbitrating each meeting's discussions towards consensus (or at least a large majority), which decision MFish then receive, take away and transmit as advice to the Minister. Unaffiliated and Ministry respondents raised the concept of risk-neutrality (where meeting participants' risk tendencies balance out overall) as requisite for achieving consensus (Participant, Sullivan). For former and current MFish interviewees, achieving this usually means being "stuck in the middle", getting "hammered from all sides", and occasionally "play[ing] the bad guy" (Annala, Crothers, Sullivan). One participant felt that the experienced and somewhat battle-hardened nature of Science Group staff means they are better able to withstand pressure from meeting attendees than less experienced or younger staff would be (Sullivan).

\section{Not policy-makers, but quasi-policy-makers?}

Despite this, however, there was acknowledgement amongst the interview sample that high uncertainty in scientific research, coupled with the need to keep on managing fisheries, inevitably pushes management decision-making into a difficult area. The need for each year's catch limit decisions to be made requires that someone step into this area. Interviewees acknowledged that the precautionary approach stipulated in the 
Fisheries Act is designed to guide decision-makers in this zone, but leaves much open to interpretation. One respondent particularly lamented the vague and unhelpful state of this legislative directive and the international agreements that inspired it (Participant). Industry, SP and NIWA interviewees all felt that the absence of a macro-scale policy framework for fisheries management causes Ministry scientists to engage in policymaking, particularly under uncertainty (Hilborn, McKoy, Starr, Stokes).

Interviewees differed on whether or not this aroused concern for fisheries management overall, or for the quality of scientific decision-making. There was a certain degree of pragmatism expressed by some interviewees (Ministry, former Ministry, industry and unaffiliated), who felt that while MFish scientists may act ultra vires and effectively make policy, on the whole they are simply doing their jobs. In general they enable the science processes to maintain a flow of robust and accurate research from which appropriate management decisions can be made, in a difficult political, economic and institutional context (Allen, Crothers, Harte, Participant, Sullivan).

Another respondent felt that New Zealand's fisheries management would essentially be improved by scientists having greater policy-making influence, while still others thought there should be considerably less policy influence by MFish scientists in particular. The ENGO interviewee suggested that New Zealand model its fisheries management on the CCAMLR ${ }^{2}$ regime, a science-driven approach to precaution where scientists have considerable policy-making influence (Weeber). In contrast, industry participants saw MFish scientists to be essentially writing fisheries policy by being excessively conservative, a dangerous "philosopher king" tendency that they felt the proposed changes to the Act's section 10 would only exacerbate. Two respondents (industry and science provider) told the interviewer that they are convinced that Ministry scientists believe orange roughy are irrevocably overfished and would be happy to see the fisheries closed (Clement, Hilborn).

Policymaking via conservative science One industry respondent felt that Ministry scientists have a propensity to filter off all but the conservative management options when formulating advice for the Minister (IP), while another described MFish scientists' tendency under uncertainty to emphasise the pessimistic interpretations of data to drive down catch-limit decisions (Stokes). Another described Ministry scientists taking the conservative option on each one of a model's variables, in the name of precaution (on that occasion leading, he argued, to a totally inappropriate threshold for sealion bycatch (Harte)). One SP participant recounted how only after lengthy lobbying by industry-affiliated scientists, the deep-water FAWG "grudgingly" adopted the working hypothesis whereby $\mathrm{CPUE}^{3}$ declines faster than biomass (Hilborn). On that

\footnotetext{
${ }^{2}$ Convention for the Conservation of Antarctic Marine Living Resources

${ }^{3}$ Catch Per Unit Effort, or the ratio of fish secured to each unit of fishing effort.
} 
occasion the industry's and MFish's different stock assessment calculations arrived at the vastly different conclusions that the particular orange roughy stock was (respectively) at $40 \%$ and at $10 \%$ of $\mathrm{B}_{0}$. This event and industry scientists' arguments have led to the FAWG adopting a process whereby two parallel stock assessments are conducted, and the average of the two is taken as the final figure. This was seen as a significant improvement on the status quo, but one for which the industry scientists had to fight vigorously (Hilborn).

Two industry-affiliated interviewees attributed this conservatism to the fact that government service inevitably attracts command-and-control personality types (Clement, IP), while another attributed it to the natural conservatism of scientists in general (Stokes). Industry-affiliated participants felt that MFish scientists engage in policymaking because they see themselves as a special case - as "guardians of the fish" (Stokes), who "... have this idea that their bias is a good bias," despite the fact that they are not elected representatives (Starr).

In contrast, a NIWA participant felt that MFish scientists, as government scientists, are indeed a special case. He stated that industry make "the ongoing mistake" of presenting the Ministry as "just another interested party with a particularly conservative view [instead of] representing the public interest" (McKoy). Interestingly, the quantity of MFish's consultation with stakeholders - the vox populi element of democratic responsibility - was never criticised, though the quality, particularly around cost-recovery, was complained about (see Cost recovery section above). Two interviewees felt that in general terms MFish's careful and comprehensive consultation process fulfils the government's democratic responsibilities for stakeholder consultation (SF, Participant).

Interviewees' language gave some clues to their positions on the public interest, independently of their direct statements about it. Terms such as "using efficiently", "productive" and "investment" were notable in industry participants' discussions of fisheries and value, (Clement, IP, Stokes), while in MFish interviewees' responses language such as "the family silver", "national assets" and "not their fields [but] our seamounts" (Crothers, Sullivan) were noteworthy. 


\section{Chapter 6}

\section{Discussion}

\subsection{Introduction}

A clear signal from interviews confirmed the suspicion that had attracted this thesis to New Zealand deep-water fisheries: they exhibit wicked problem characteristics that are stronger even than those common to oceanic fisheries, which mean the latter are an institutional challenge for management. Manufactured risk is strongly evident due to the heavy fish-down of the 1970s and 1980s. Some orange roughy stocks remain very vulnerable, and deep-water bycatch (non-target) species such as gorgonian corals and sponges are likely to be in an equivalent vulnerable position compared to their shallower-water bycatch counterparts.

\section{Cash-starved marine science}

New Zealand's fisheries science funding has been either static or decreasing in real terms for several years, while the inherently information-hungry QMS has expanded over dozens of species. The QMS' well-articulated property rights rely entirely on fisheries science to connect them to the animals in the sea. Deep-water stocks are particularly information-hungry, as the possibility that they are close to critical depensation thresholds, and their ecosystems at risk of associated deleterious effects on functionality, means they need precise management. Government research funding falls far short of what is needed, and industry are unlikely to be a source of significant additional resources. ${ }^{1}$ Besides government, the only interest groups in the deep-water arena are the commercial fishing industry and ENGOs. Both groups lay claim to representing silent majorities of the wider public, and Oceans Policy surveys of the public's views on marine resources are too general to provide a clear direction either way.

Sustainability, environmental principles (including a version of ecosystem-based

\footnotetext{
${ }^{1}$ The combination of the $10 \%$ of port price rule of thumb plus low TACs meaning little value in quota.
} 
management), information principles and the precautionary principle have been incorporated into the Act, signalling recognition of a paradigm shift in fisheries management. However they lack the clear policy development to direct on-the-ground decision-making. The precautionary principle (section 10 of the Act) in particular is notably vague, merely forbidding paralysis under uncertainty rather than stipulating action in a particular direction.

Distributing uncertainty: research planning and section 10 Research planning decisions play a significant role in the distribution of uncertainty (which activates section 10) by distributing the limited fisheries research funding and thereby distributing information and uncertainty across species and stocks from year to year. For deepwater stocks which are very expensive to research, not being researched in a particular year can mean they are managed under significant uncertainty, opening the door to conflict in scientific decision-making. (Interestingly, while dedicating considerable "airtime" to section 10, interviewees made little mention of the role of the RPGs' decisions.) An attempt at amending the section to direct action towards environmental protection (following many international articulations of the principle) seems to have stalled, and the provision remains unchanged.

\section{Keep on satisficing}

The existence of a robust property right in fish seems to mean an effective (though perhaps slowly changing) presumption that the right can continue to be exercised that fishing continues until proven otherwise rather than vice-versa. Keeping up with the demands of information-hungry TAC-setting, along with high transaction costs from stock-specific cost-recovery, consume significant amounts of MFish time.

"[P]eople that think that writing a piece of paper is going to change people's behaviour are really a little bit silly ... I just don't know they're coming from. I think, yes it would be nice if fisheries management in New Zealand was organised enough to come up with good fish plans that covered all the fisheries and they were documented and we did review them and see what the management objectives were, but without them, the way we've been for the last 30 years, we're still managing fisheries! There's a load of fish out there and we're still trying to do the job." (Sullivan)

Interviews confirmed indications in the literature: in deep-water fisheries the cost recovery regime's transaction cost burden weighs heavily. Feeling these costs acutely but failing to see the benefits of the contestable research system, interviewees felt "there's got to be a better way". One potential opportunity cost of this expenditure is structural 
self-examination that could lead to the kind of institutional changes needed for handling the unique characteristics of deep-water fisheries.

In the meantime, while significant scientific uncertainty looks to persist, we must try to ensure that the existing system does not make any major mistakes with deepwater fisheries management. It was clear from the research that regardless of how well the QMS and the fisheries policy framework are managing other New Zealand fisheries, they are not dealing well with deep-water fisheries.

\section{Is satisficing safe?}

The Ministry's strictly separated process for policy and science advice separates off scientific decision-making from other advice processes in fisheries management, setting it to generate its advice in glorious isolation and epistemological purity. As almost all interviewees stated, the job of a scientific-technical forum such as a FAWG is to focus on the research in front of it, to discuss its strengths and weaknesses, and produce a statement of what the research says about its subject for the policy process to use. The decision-making structures established for the scientific advice process work on the presumption that this will be the way it operates. Because participants will be adhering to the rules of behaviour (of which a principal one is disinterestedness) set and enforced over centuries by the scientific community, the fisheries scientific process will not need the kind of highly transparent, discursive checks and balances now increasingly commonplace in policy processes.

The "black box" of the fisheries science advice structure can be argued as an anachronism. The philosophy of science has urged greater acknowledgement of scientists' human nature and of the futility of attempting to hermetically seal off scientific inquiry from subjective influences. Meanwhile, swiftly-developing theories of participatory democracy have seen decision-makers pursue the aforementioned discursive approaches and greater transparency in decision-making. In the Fisheries Act 1996, this has been manifested in section 12 of the Act, requiring consultation of stakeholders, and has also made its way in to the scientific decision-making processes. While a seemingly counter-intuitive move for pure-science fora, this latter is not unexpected: the introduction of user pays for fisheries science also introduced its corollary "user says", and the realisation that (for deep water at least) scientific decision-making is indirectly shaping policy has made stakeholders want to have a say.

These conditions do not instil confidence in the observer hoping to see processes guaranteeing production of objective, accurate scientific information. 


\subsection{Science Only in Scientific Fora}

\subsubsection{The gloves are off in meetings, but so are hats}

Encouragingly, during interviews some respondents argued that there was no need for "safeguarding" objectivity as the scientific-technical status of meetings was appreciated and respected. Interviewees lauded the scientific meeting rounds (FAWGs in particular) for their strict scientific and technical operation, which was seen as a great improvement on the lawyer-riddled meetings of yore. Some interviewees clearly relished the way scientific forum participants could have heated technical disputes ("ripping one another to shreds") while putting aside their various interest-group affiliations.

Comments from several different quarters reinforced this impression of a clear distinction in interviewees' minds between values-based and scientific representation, and what is therefore appropriate comportment for a science-only forum. Respondents noted the science-only mandate of Ministry scientists, which particularly precluded policy-making. There were also comments that as ENGOs' modus operandi is currently values-based argument (being unable to hire scientists to represent them with technical argument), their participation would be most appropriate in policy rather than scientific meetings. This suggests that research participants believe in the value of scientific information and the importance of keeping it as free as possible from values-based, subjective influences.

\section{Personal relationships: virtuous cycles}

Interviewees made several comments about interpersonal relationships influencing meeting participants' behaviour. They generally saw New Zealand's small and somewhat incestuous fisheries management climate, where many key individuals have worked for several stakeholder groups, as an advantage rather than as the government-capturing negative influence of the "revolving door" theory. Meeting participants apparently feel that as other scientists have been in their shoes at some point in their careers, they can empathise and will behave with integrity ("play it straight" and science-only) even if they are currently in opposing "camps".

However there was also interview evidence (though much less) of the opposite effect. Some NIWA and MFish participants were quite frank about NIWA supporting MFish arguments because the individuals concerned were former colleagues, consistently with industry interviewees' suspicions of mutual complicity in NIWA pricegouging and MFish hyper-conservatism. Even if the positive forces of interpersonal relationships are stronger than the cynicism and second-guessing of the negative influence, one should be concerned if this is the only safeguard for objectivity in science meetings. 


\subsection{Meanwhile, Policy Enters Scientific Fora}

Concern is raised because interviews showed clearly that those involved in deep-water scientific meetings are aware that an unfortunate artefact of New Zealand's fisheries management structures allows (or forces) decisions made in deep-water science fora to substantively affect policy. This provides an opportunity for those involved to indirectly shape policy, and while it can be an expensive one requiring expert representation, it can be very effective.

\subsubsection{Pragmatic approach}

Seeing an opportunity to shape policy, scientists in deep-water fora react pragmatically, in accordance with four genres of drivers. These include: notions of "what is best" for fisheries management according to their employer institutions' norms and aims for the world; personal norms of "what is right" for fisheries management; behavioural norms set by the institution of the scientific community; and personal views of what constitutes proper behaviour (and how to respond to perceived "cooperative" or "defective" behaviour in others). There was wide variation in interviewees' responses (both inter-respondent and intra-respondent), indicating that the perceptible influence of these drivers (as acknowledged, a subjective analysis by the researcher) seems to ebb and flow significantly.

The high uncertainty in many pieces of deep-water research leaves room for significantly different interpretations within the bounds of respectable, legitimate scientific practice, making it extremely difficult to discern the boundary between scientific and non-scientific drivers for any individual's opinion regarding a study's conclusions. Nevertheless, interviews gave evidence of all four genres of individual and institutional drivers interacting to determine meeting participants' behaviour.

\section{Opportunistic positioning in science fora}

Non-government scientific forum participants seemed to be taking a pragmatic view of scientific meetings. They saw the fisheries management system's failures forcing the deep-water science fora into a confused quasi-policy zone, thereby providing an opportunity to influence policy, so they want to ensure that any policy-shaping heads in a good direction. At times, interviewees argued that the behavioural norms of the scientific community are holding strong, vociferously denying any persistent, politically relevant discrepancy in industry-affiliated scientists' contributions to scientific fora. Respondents pointed out that scientists whose professional reputations are tarnished by being seen to be prone to such bias are of little use to the industry (or anyone), as everyone second-guesses their views in light of this reputation. Industry scientists reg- 
ularly tell the industry what it does not want to hear, which contributes to reassuring them that the former are reputable professionals whose independence is intact.

Hired guns? Other research participants' views of industry-engaged scientists also varied, but these were largely disapproving variations. These ranged from relatively cautious statements about "expertise, not advocacy" being a valuable industry contribution to meetings, through to describing "conspicuous silences" where pieces of research are erring in the industry's favour while vociferous scientific critique is levelled at studies erring against it.

At other points during interviews, industry-affiliated interviewees expressed the influence of their employer institutions' drivers. They were frank about the nature of contracts: a scientist who too often tells the client what they do not want to hear will not get their contract renewed. If there was any persistent discrepancy in industry scientists' contributions to science fora, which is having the desired effect in shifting the analytical direction in their favour, this means they are doing their job well.

\subsubsection{Effect of the pragmatic approach}

\section{Legitimate activity in a polarised context}

It appeared that this is sometimes the case: interviews indicated that industry scientists have been effective in shifting the mean of the scientific forum on at least one occasion. The key example was a debate over the relative decline speeds of CPUE and stock biomass, where two calculations off the same data produced widely varying estimates of the population size. Scientifically-legitimate representation by industry scientists positing and effectively arguing a different interpretation of the salient data (suggesting the stock in question was at $40 \%$ of $\mathrm{B}_{0}$ rather than the Ministry's $10 \%$ of $\mathrm{B}_{0}$ ), was argued to have adjusted the FAWG's research interpretation practice.

Shifting the mean of the forum's decision-making Two parallel interpretations of such data are now run, and the mean is used as the consensus result. ${ }^{2}$ To a point, this is an example of beneficial scientific pluralism: a variety of scientific and technical viewpoints debating the merits and shortcomings of studies, and quality-checking the analysis by identifying points of weakness (i.e. where it is vulnerable to subjective influences).

However, the key point is that industry scientists' activity was effective in shifting the FAWG's interpretative approach towards the less conservative, "bigger population" end of the spectrum. Even if it was a one-off and has not been accepted as a working

\footnotetext{
${ }^{2}$ Unfortunately the interview that yielded this information occurred near the end of the interview period, which meant there was no opportunity to cross-reference with current MFish interviewees.
} 
hypothesis by the deep-water FAWG (as claimed), successive achievements of this kid by industry scientists will undoubtedly have an effect on the scientific advice the forum produces.

Shifting the mean: in one direction The nature of industry engagement - something industry-affiliated scientists were quite upfront about in interviews - means the scientists would be doing their clients a disservice to lobby as hard for an interpretative approach that moved the forum's consensus towards the more conservative, "smaller population" end. This is a role for scientists engaged by ENGOs, who would do exactly as their industry-engaged colleagues but in the "opposite" direction. However there are no such scientists present in deep-water scientific meetings, primarily because of the high cost of hiring stock assessment specialists of the calibre of those engaged by industry. Industry-affiliated interview respondents rightly observed that it is not the industry's responsibility to make sure that the counter-argument to theirs is presented. Ministry interviewees felt that it is the government's role to ensure science fora are risk-neutral overall, observing the thick skin Ministry scientists need to play this role.

\subsubsection{MFish role: neutral and aloof?}

Several respondents described the MFish scientists' role as "sitting above" the disputes that might occur in science fora, and almost passively receiving and transmitting to the Minister the scientific consensus at which the meeting participants arrived. Interestingly, one unaffiliated and one MFish participant stated that an important MFish role is ensuring meetings are risk-neutral. This suggests recognition of the fact that the neutral arbitrator role requires the MFish chair to receive the meeting's consensus view (or at least the mean position of the meeting's population) and transmit it as the truth.

\section{Effect of unequal firepower}

However at present the highly-trained, specialised experts in meetings represent the Ministry and the fishing industry. If MFish seeks risk-neutrality, the opposite end of the interpretive spectrum should be presented via legitimate technical argument by scientists of equivalent "firepower" to those currently advising and representing for the fishing industry. This is not happening because the best candidate for engaging scientists and getting this done - ENGOs - cannot afford to do so. New Zealand green groups are affected by the suite of well-documented barriers to political participation that affects ENGOs worldwide. One SeaFIC interviewee canvassed the issues succinctly. While acknowledging the broad "constituency" that green groups represent, s/he suggested that public apathy towards most marine environmental causes is 
reflected in ENGOs' cash-strapped nature. The contrast in ENGOs' and the fishing industry's resource mobilisation ability is due largely to the nature of the goods for which they advocate. In deep-water scientific fora, the classic representation issues in environmental management are thrown into sharp relief: the representatives of a small, distinct, self-identifying constituency with a pecuniary interest in the resource (pursuing fish as private goods) are pitted against the representatives of an almost indefinitely large, indistinct constituency that cannot (or fails to) self-identify and fund representation of its (public good) interests in the resource. This phenomenon's consequences for funding and participation in science fora is why, despite being an allocation issue, it is affecting the scientific and technical deep-water fora.

The SeaFIC interviewee's statement finished with the comment that while funding to assist ENGOs with expert representation is an option, for addressing the balance of scientific "firepower", such funding would have to be independent of government. This links us to the role of the fora and those chairing it — government fisheries scientists.

\subsubsection{Neutral, or risk-neutralising?}

It is possible that Ministry scientists, who are fisheries experts, could themselves provide the scientifically-informed counter-arguments to scientifically-informed industry arguments. In the absence of scientific representation of ENGOs, it is difficult to see how MFish scientists might go about ensuring risk-neutrality in a forum without themselves wading into the debate and providing the counter-balance to a well-articulated industry argument. This could be argued to be to the substantive benefit of a scientific forum's discussion, for it would mean the full spectrum of scientific positions on a question is being presented and the salient hypothesis is being challenged from all angles. However if MFish are supposed to take a neutral arbitrator role in meetings, passively receiving the scientific consensus position at which the meeting arrives on each research question, this raises some issues.

Interviews provided evidence both ways. Industry-affiliated and science provider interviewees' statements that where uncertainty is high MFish consistently take a conservative position could be interpreted as MFish being a scientific "devil's advocate" against industry arguments. A Ministry respondent stated that the government, cognisant of the implications of the Fisheries Act's environmental principles and aware of the lack of expert representation for ENGOs, had expanded MFish's Science Group to improve scientific pluralism. One MFish respondent's comment that NIWA representatives help MFish in their efforts to risk-neutralise meetings by "flattening the plane" suggests that it may be NIWA scientists who are trying to ensure the scientific counter-argument to the industry case is presented. 


\subsubsection{Scientific or democratic representation?}

However, this taps into a significant issue: the distinction between representing the spectrum of interest groups and representing the spectrum of scientific opinions. Traditional scientific principles would argue that the latter should have nothing to do with the former, which is the premise behind the dual branches of New Zealand's fisheries management advice process. However, New Zealand's legal, economic and social landscape has inevitable implications for resource mobilisation and thereby for participation with good scientific firepower.

There was significant disagreement over the degree to which conservatism by the statutory managers of New Zealand's marine resources could or should be legitimately manifested in the scientific decision-making that goes on in these fora.

\section{Government: special licence to position in science fora?}

Analysis of interviews revealed a government variation on the pragmatic argument: while the fisheries management system's dual-branch structure continues to fail deepwater fisheries and push policy-shaping influence into their science fora, MFish scientists should actively ensure that any policy-shaping that occurs there is consistent with or at least does not undermine government policy direction.

This means being cognisant of the flow-on effect a scientific decision may have (which given deep-water species' slow growth and the uncertainty common in deepwater decision-making, could potentially include distributing a species through time) and ensuring it is consistent with what they see government policy to be. This is clearly another example of an employer institution's non-scientific drivers directing scientists' behaviour, potentially in contravention of the ostensibly science-only status of the fisheries science fora.

\section{Evidence of wielding the special licence?}

However the government is not just another stakeholder, and as an institution has a clear obligation sourced in the social contract to pursue the wider public's best interests. When put in the unfortunate position where it seems necessary to act as a government scientist instead of a pure scientist, should a member of MFish's Science Group be guided by some expression of the vox populi such as an Oceans Policy survey, or an interest group's wishes? Or should he or she act on a more "philosopher king" awareness of people's perennial failure to express the kind of value in public good natural resources (particularly complex, un-charismatic ones such as deep-water bycatch species) that would result in a more socially-optimal investment in natural capital? 
Conservative research purchasing decisions, for The Nation One situation where the public does rise up and express its value for a natural asset is rare charismatic megafauna, recently sealions and Maui dolphins. When discussing the issue of research purchasing and the philosopher king / vox populi dilemma of government, respondents' comments about research into dolphins and sealions showed the legitimising power of a loud expression of the vox populi. There was relatively wide agreement across industry, science provider and government interviewees that there was a "public interest" in such biota, even to the point where industry respondents were resigned to being cost-recovered for research into these species which would inevitably lead to further cost (curtailment of fishing activity). Interestingly, there was wider than expected agreement that as government agents responsible for ensuring a continued flow of unimpeachable, accurate science into the QMS, MFish scientists are obliged to be conservative regarding the providers of taxpayer-funded fisheries research. This legitimises some (though, for industry participants, not all) MFish conservatism: wariness of contracting industry to undertake research, and the view that the burden of proof rests with the fishing industry to prove that their commissioned research is as objective as the heavily peer-reviewed, fully-disclosed government-purchased research. However the extent to which risk to un-charismatic deep-sea biota in situ should be traded off against risk to fishing was the source of much conflict, reflecting how deeply values are embedded in this "wicked problem". Some views were expressed very strongly, and it is difficult to see how these opinions could be easily put aside and a solely scientific and technical position taken when assessing the funding merits of or analysing research aimed at such values.

Conservative research interpretation, for The Nation For research interpretation, interviews provided some evidence that MFish scientists are consistently conservative in their analysis. Industry interviewees described MFish scientists emphasising pessimistic interpretations of stock data; taking the most conservative position on each of a sea-lion population model's multiple variables (leading to the bycatch mortality threshold being dismissed in court); and having to be dragged into accepting methodological improvements (the aforementioned CPUE / biomass example). They complained of the arbitrariness of MFish scientists, lacking the mandate to make policy decisions, engaging in non-scientific positioning in meetings (effectively taking a "philosopher king" role) in contravention of the scientific behavioural norm. Some MFish interviewees' description of marine resources in language such as "the family silver" and "national assets" suggests they see a trustee element to their role, guarding both target and non-target natural assets for future beneficiaries against the short-term greed of present generations, though these were general statements. 


\subsubsection{Defensive counter-positioning in science fora}

Even if its overall impact on scientific advice is hard to predict, this type of positioning seems likely to have a major impact on the perceived objectivity of science fora by generally destroying their atmosphere of scientific austerity. It was described by all genres of interviewees, both in accusations levelled against other meeting participants and in describing their own behaviour. Defensive counter-positioning is a manifestation of several drivers: scientific, political and very personal. It stands in interesting contrast to interviewees" statements that personal relationships between scientific forum participants mean they "play it straight" for the sake of their colleagues and old acquaintances (see below). It is also an example of a cascade or spiral of reciprocal defection, which suggests that any heroic efforts by participants to maintain cooperative adherence to the science-only behaviour norm will be swimming against the flow. Strong engagement by participants with authority (potentially a Chair) could possibly turn this tide, particularly if they can draw on a personal connection with the defectors, or otherwise rally a critical mass of "cooperators". However acknowledgement that one's actions in a science forum are being driven by illegitimate (non-scientific) motivations is highly unlikely, so any remedial action would have to be subtle and would be vulnerable to being mis-interpreted (or missed altogether).

\section{A vicious spiral}

Defensive counter-positioning was described by industry interviewees who perceived MFish and NIWA scientists as taking overly conservative positions in meetings. They saw this as illegitimate policy-shaping by government scientists who lack the mandate to do so, and as bad scientific practice (they saw a persistent, politically-relevant discrepancy). The effect on other participants seemed to be causing a choice to defect rather than cooperate ("well, if you're not playing it straight and keeping it scienceonly I don't feel so bad about not playing straight either"). Meanwhile, industryaffiliated interviewees saw the scientific effect of MFish and NIWA positioning as shifting a meeting's mean towards a more conservative interpretation of research, an effect that industry respondents argued needed to be balanced off to bring the meeting back to a value-neutral position. This is exactly the same view as that presented by some Ministry interviewees, except that their positioning was redressing the effect of industry arguments shifting the meeting's mean to an overly risky position. Both groups therefore justified their counter-positioning as entirely reactive, in pursuit of scientific risk-neutrality in meetings. Interestingly, none of these interviewees mentioned ENGO representatives as contributing to mean-shifting in meetings' decisions, which supports the contention that ENGOs' typically generalist representation in meetings is not seen as influencing outcomes. 


\subsection{Research Funding's Effects on Science}

\section{Fisheries science: starved of funding}

A strong impression was gained that New Zealand fisheries research is underfunded. While good arguments can always be made for more science, several interviewees commented on the paucity of government funding for fisheries research in general, especially when compared to other OECD nations, and particularly given the QMS' heavy dependence on scientific information. The funding situation seems particularly poor for public good research to inform management of non-target marine biota. Again, in the deep water area this is particularly grave, as the research is inevitably expensive. However the 1980s' and 1990s' public service reforms, which heavily reduced government science funding in favour of user pays, are undoubtedly a contributing factor. Respondents noted that such limited funding essentially ignores the public good in having sustainable fisheries, and forces worthy public good projects to try to obtain industry research funding. Interviews revealed that this causes a significant level of seemingly avoidable frustration and bad feeling across the interview sample, which contributes to broader, more substantive conflicts over the macro-scale goals of fisheries management.

\subsubsection{Cost recovery}

The final section discusses the effect of cost recovery on the scientific objectivity of deep-water scientific fora. The influence of funding in science, and the degree to which government-sourced funding (given governments' transparency requirements and "public good" mandate) can avoid this, inspire ongoing debate. From interviews, one immediately obvious effect of cost-recovery on New Zealand's fisheries science is the engendering of great frustration amongst all those involved.

\section{Double-edged benefits}

There were some exceptions, notably that cost recovery makes the industry aware of the behind-the-scenes costs of fisheries management and makes government more careful about its expenditure. Interestingly, one product of this was industry arguments for using industry vessels for research instead of the Tangaroa, and both industry and non-industry interviewees side cited anecdotal evidence for other parties' unwillingness to genuinely commit to collaborative government-industry provision of high-quality stock assessments. Industry respondents highlighted cost-recovery for expensive deep-water research as another reason for checking the Ministry's and NIWA's sums ("if we have to pay for it, it's got to be good quality"), citing anecdotes where mistakes had been discovered in government-purchased research that would have lead 
to significant unnecessary loss for the industry. The extra industry scrutiny thus attracted to research, particularly projects which seem likely to lead to financial loss, is a feature of the New Zealand cost-recovery system with its "user pays" approach. Rigourous testing and challenging of scientific studies is an important part of the scientific process, but the way cost recovery directs this to projects according to their cost implications means the benefits to New Zealand deep-water fisheries research are a fraction of what they could be if equal scrutiny was applied across the board. The second-guessing problem and disparity of scientific firepower between stakeholder groups are also relevant. Cost recovery's effect on science thus links to the issues of participation and thereby to the question of distributing rents from fisheries.

\section{Crippling science?}

Interview questions about cost recovery's effects on science elicited overwhelmingly negative reactions. The transaction cost burden of project-by-project, stock-by-stock accounting weighed heavily on MFish respondents. Several participants discussed the aforementioned perverse incentive (making industry judge projects on their cost impacts, not their merits, and therefore sometimes oppose good research initiatives). Public good research into the marine environment in general was widely seen as an important government responsibility, but there was conflict over the rules apportioning funding responsibility for research into the environmental externalities of fishing (which is partially cost-recovered and can result in TAC and bycatch limit reductions). In part this reflects different views over the costs of extracting fish (capture of natural resource rent), and whether the fishes' transformation into different forms of capital and (eventual) return to the nation balances out the present-day cost of the research necessary for TACs to be set and this fishing to occur. This is also an illustration of the pervasive downstream effects of establishing a property right to a shared, multipleuse resource, particularly without putting equivalent effort into establishing the policy and regulatory framework to allow it to operate without externalities and other market failures. If a natural resource management system is expected to operate at a constant extreme information deficiency, it needs decision rules appropriate to a context of high uncertainty.

\subsection{Summary}

Analysis of interview material in light of the conceptual framework paints a less-thanpromising picture of the safeguards for objectivity in New Zealand's deep-water fisheries science processes.

However, the key point is that the shifts towards a new, modern approach to gov- 
ernment decision-making (discursive, participatory, drawing on a wide range of information) have been made for the fisheries science processes in a spirit of optimistic naïveté. This has great faith that while the "black box" of fisheries science decisionmaking will be cracked open to get the legitimising benefits of participatory democracy through stakeholder involvement, the canons of traditional scientific objectivity will nonetheless be respected by all participants because, after all, this is a pure-science process. All the decision rules and protocols needed are those of orthodox science, since people participating in these scientific decision-making meetings are all scientists in whom respect for these canons has been deeply engrained by their training.

This seems to put considerable pressure on the processes we rely on to produce accurate information on New Zealand's deep-water biota. This role is critically important for the information-hungry QMS, and (as observed) especially so for poorlyunderstood, depleted, slow-growing deep-water stocks. Where there is more sufficient scientific information this is less problematic, but in the deep-water arena uncertainty and the stakes are so high that neither process can provide adequate information in isolation. Deep-water fisheries management decisions fall into the gap between the two processes, and there is no combined science / policy structure to deal formally with its decision-making needs.

The acknowledged importance of hard-science information for linking the QMS model to reality adds to the strong "authority of science" basis of government fisheries management. The result is that the scientific arm of the fisheries management process picks up the day-to-day decision-making needs, and thereby steps into the no-man's land between the policy and science processes where policy elements infiltrate scientific decision-making. (It should be noted that this investigation would be complemented and rounded out by investigation of the policy arm of deep-water decision-making, but scope and time forbade this.)

The quasi-policy activity occurring in deep-water fisheries scientific fora, ultra vires its scientific-technical mandate, is a pragmatic reaction to the need for deepwater fisheries management to keep operating, and is an artefact of the New Zealand fisheries management system's structural unsuitability for risk society contexts. It is an unfortunate situation, for which no single person can be blamed. The question is whether under these difficult conditions the scientific process is continuing to do its fundamental job: produce clean accurate pictures of the submarine situation. It is particularly essential that this keep happening in the deep-water context because the most serious consequences of getting management decisions wrong - potential local extinctions of slow-growing species, for example - fall on the biota, and the science process is the only source of information we have on this ecological component of fishery. 
In the absence of policy direction that could provide some guidance for this suboptimal situation, the uncertainty more or less ubiquitous in deep-water fisheries research opens the door for the effects of policy-oriented positioning by science forum participants to have a potentially significant impact.

If all those involved were "playing it dead straight" and refusing to entertain any thoughts of influencing policy, scientific decisions would still be having an impact on policy but in a much more haphazard and arguably weaker way than they seem to be. Positioning seems to be occurring on several fronts, driven by a wide variety of interrelated motivations and - somewhat surprisingly - coexisting with scientific drivers which might be expected to curtail the effects of the non-scientific imperatives.

While this is the result of different groups of people doing what they think is best, the net effect appears to be to place the objectivity of deep-water science decision making in jeopardy. There does seem to be having a noticeable effect on scientific outputs. Interviews revealed that the mean of the scientific opinion distribution in meetings, taken as the "truth" for practical purposes in accordance with traditional science principles, has been shifted on at least one occasion. This is likely to effect a permanent shift in the FAWG's interpretation of such research. Were such shifts as this happening in both the "riskier" and the "more conservative" directions, a layperson may feel reassured that overall these phenomena were unlikely to have a significant effect on deep-water fisheries management.

However the distribution of scientific firepower in meetings indicates that this will not happen. ENGOs, the most natural candidate for an equivalent opposite to the fishing industry, cannot afford to hire scientists of the calibre necessary to affect the scientific mean in research fora. Ministry scientists cannot take this role without being seen to be engaging in positioning, which is precluded by their ostensible role as neutral arbitrators of meetings who receive and transmit each forum's decisions to the Minister as scientific advice. While there is an argument that such positioning would fulfil the wider public interest protection role of government, it is dangerous to have specialised scientists making quasi-policy decisions without either the training or the mandate. 


\section{Chapter 7}

\section{Conclusions}

New Zealand's fisheries management structures are subtly failing deep-water fisheries. Deep-water species' and ecosystems' unique characteristics and their proven vulnerability to manufactured risk make them demanding management subjects, arguably the most difficult of New Zealand's fisheries. However our ignorance of them, added to their slow-growing nature, means there is potentially much to lose by getting it wrong. The separate science and policy components to New Zealand's fisheries management, a phenomenon by no means unique to this country and recommended by traditional approaches to both disciplines, has here been taken to an extreme. New Zealand's policy and science components seem to be so strongly divided that they cannot come together in a way that would allow the wicked problem deep-water fisheries management to be tackled in a regularised, transparent way.

\section{Starting at a disadvantage}

The year-on-year demands of the QMS for scientific information, administrative effort and catch level decision-making, with very limited science funding, mean it is difficult for the Ministry to catch its breath and undertake the self-reflexive exercise that a concerted post-normal science approach to deep-water fisheries management would require. The acknowledged importance of hard-science information for linking the QMS model to the reality in the sea adds to the strong "authority of science" basis of government fisheries management. The result is that the scientific arm of the fisheries management process picks up the day-to-day decision-making needs, and thereby steps into the no-man's land between the policy and science processes where policy elements can easily infiltrate into scientific decision-making. (It should be noted that this investigation would be complemented and rounded out by investigation of the policy arm of deep-water decision-making, but scope and time forbade this.) At the same time, scientific decisions that have to be made are being made - the system is func- 
tioning for deep-water fisheries - but the objectivity of the science being fed into this system is highly vulnerable. This is because scientific decisions with significant policy implications are being made in a forum that is not designed to handle them; in fact it is designed for a policy-free decision-making context (and highly valued as such).

The quasi-policy activity of the deep-water science fora is a pragmatic reaction to the need for deep-water fisheries management to keep operating, and is an artefact of the New Zealand fisheries management system's structural unsuitability for risk society contexts. It is an unfortunate situation, for which no single person can be blamed. The question is whether under these difficult conditions the scientific process is continuing to do its fundamental job: produce clean accurate pictures of the submarine situation. It is particularly essential that this keep happening in the deep-water context because the most serious consequences of getting management decisions wrong potential local extinctions of slow-growing species, for example - fall on the biota, and the science process is the only source of information we have on this ecological component of fishery. The different stakeholders in deep-water fisheries appreciate the importance of high-quality, accurate science for fisheries management, and ascribe to the principles of objectivity that scientific practice sets out to ensure this.

\section{Scientific objectivity is at risk}

However, while the forces of interpersonal relationships and individuals' dedication to "playing it straight" are undoubtedly helping to preserve some objectivity in science fora, a much more significant force is the various positioning activities of meeting participants revealed in interviews. Whether it be positioning in the cause of valueneutrality to redress a perceived imbalance in a meeting's scientific opinion distribution, positioning to ensure the greater good is pursued, or positioning to "do right by" those whom one represents, deep-water scientific meetings are very far from clean, technical fora.

This does seem to be having a noticeable effect on the scientific outputs. The mean of the scientific opinion distribution in meetings, which for practical purposes is taken as the "truth" (in accordance with traditional science principles), was shown to have been shifted on at least one occasion. This is likely to effect a permanent shift in how the forum handles CPUE research, a major proportion of stock assessment information.

While the limitations of this study are significant, a layperson would be far from satisfied that New Zealand's deep-water science processes are providing and will continue to provide objective scientific information. As observed, objectivity is the best measure the scientific process can offer for the accuracy of the information it provides on any phenomenon. The natural sciences, in turn, are despite their shortcomings the 
best tool at society's disposal for gaining an accurate picture of the world. Without accurate scientific information about what is going on in our deep seas, New Zealand's fisheries management structures risk being an elaborate and well-constructed house of cards, with the distinction that houses of cards do not potentially court significant ecological risk or economic harm.

\section{Further research}

Contemporary New Zealand has to deal with a legacy of manufactured risk in its deep sea fisheries. The wicked problem of deep-water fisheries and marine resource management needs management structures that acknowledge its wickedness. This means approaching our policy and scientific advice structures with an awareness of their limitations and those of the information they provide. A significant contribution would be made by a stocktake of the different information sources on which New Zealand deep-water fisheries managers can draw, an unflinching assessment of their different strengths and weaknesses, and identification of the conditions under which they can (or fail to) provide the most robust information possible. This would provide the basis for looking at establishing a special deep-water fisheries management forum that combines scientific and non-scientific advice in a regularised, transparent way, acknowledging openly where the scientific contribution ceases and where more subjective considerations must take over. Without this, we will continue trying to navigate a wicked environmental problem with a highly specialised and unsuitable vessel, rather than the post-normal science and policy vehicle which could enable genuine sustainable fisheries management. 


\section{Appendix A}

\section{Glossary}

ACE Annual Catch Entitlement

B $_{\text {MSY }}$ biomass producing Maximum Sustainable Yield

$\mathbf{B}_{0}$ "virgin", unfished (natural state) biomass

BPA Benthic Protection Area

CCAMLR Convention for the Conservation of Antarctic Marine Living Resources

CPUE Catch Per Unit Effort

EEZ Exclusive Economic Zone

ENGO Environmental Non-Government Organisation

FAWG Fisheries Assessment Working Group

ITQ Individual Transferable Quota

MALFiRM Maximum Allowable Fishing Related Mortality

MSY Maximum Sustainable Yield

NIWA National Institute of Water and Atmospheric Research

QMS Quota Management System

RCC Research Coordinating Committee

RPG Research Planning Group

SeaFIC the New Zealand Seafood Industry Council

SMEEF Strategy for Managing the Environmental Effects of Fishing

TAC Total Allowable Catch

TACC Total Allowable Commercial Catch 


\title{
Appendix B
}

\section{Participant Information}

\section{Participant Information Sheet for "Fishing in the Dark: Information Flows and the NZ Orange Roughy Fishery"}

\author{
Isabella Cawthorn \\ Institution: School of Geography, Environment and Earth Sciences, Victoria Univer- \\ sity of Wellington \\ Supervisors: Cath Wallace \\ Senior Lecturer, School of Government \\ Richard Willis Senior Lecturer, School of Geography, Environment and Earth Sciences \\ Duration of research: March 2006-September 2007 \\ I am a student researching for a thesis to complete a Masters in Environmental Studies.
}

My research has two objectives:

- Using economic, political and institutional theories and literature, I will develop a framework through which I can examine how New Zealand's approach to fisheries management and fisheries science has developed

- Using deep-water fisheries research forums' documents and personal interviews, I will analyse whether there are any trends visible in the fisheries researchhandling process.

I'm focussing on deep-water fisheries, specifically orange roughy, for purposes of simplicity. To supplement the data I get from research coordinating forums, I would like to interview individuals from the groups involved - the industry, the Ministry of Fisheries, environmental groups and science providers - to learn their views and gain an appreciation of the different perspectives. Participants will be invited to take part in informal and semi-structured interviews on a non-attributed (no names given) basis, which will be about 1 hour long. Interviews will be tape-recorded as a backup to notes I will take during the interview. This data will be confidential to me as the researcher, but due to peer review and academic accountability requirements one supervisor must also have access to the raw data. One of my supervisors, Cath Wallace, is involved in the fisheries management arena as an environmental lobbyist who 
attends many relevant forums. Access to interview data will therefore be restricted to my other supervisor, Richard Willis. My father, Martin Cawthorn, is a marine mammal biologist who frequently works as a consultant for various fishing industry groups. $\mathrm{He}$ will not have access to interview data except as used in research publications.

As a participant you are free not to answer any interview questions if you wish, and / or after the interview has taken place, to withdraw your participation at any time up until 31st December 2007. You can also request your identity to be obscured to the desired degree in the thesis and any derived presentations - for example you may choose to be identified only by sector (eg "a research provider").

During the interviews I will ask permission to acknowledge your contributions by putting your name and position in a dedicated "acknowledgements" section of the report, which of course you are free to decline.

A summary of the research findings will be sent to all participants so you can comment. The final thesis will be submitted to the School of Geography, Environment and Earth Sciences for marking, and will be deposited in the University Library. All tape recordings and transcriptions will be destroyed five years after publication. A copy of the thesis will also be given to the Ministry of Fisheries as an independent study. If given the opportunity, I may present my research at an academic or professional conference, and busmit articles based on it to academic journals.

Please feel free to contact me or my supervisors with any questions.

Thankyou for your time

Isabella Cawthorn — cawthoisab@ @student.vuw.ac.nz, or phone (04) 4635233 x8374 Cath Wallace: email cath.wallace@vuw.ac.nz (first words of subject line must be "Cawthorn study"), phone (04) 4635713 


\section{Appendix C}

\section{Interview scheme}

Interviews with participants will draw on the following themes:

- The role of science in natural resource management, and basic principles of science provision. Questions on this theme will address the position and role of science in managing natural resources (particularly those that are publicly- or state-owned), and issues of fisheries research purchasing.

- Risk and uncertainty in the Quota Management System (QMS). This theme will include questions about different groups' various perspectives on risk thresholds and acceptable levels of scientific uncertainty in fisheries generally and different fisheries, and about how risk is handled in the QMS and in New Zealand's fisheries management fora.

- Devolution of responsibility to the fishing industry and the relationship between industry and regulator, and the implications for fisheries science and management. This theme will look at the evolution of the relationship since the early 1980s and address any significant events or developments which may have sparked changes in the relationship.

- Institutional structure of the government's fisheries management and science organisations, and the implications of various structures for their performance. This theme will examine whether the restructuring of the Ministry of Agriculture and Fisheries (and its Fisheries Research Division) into the Ministry of Fisheries and NIWA has had any effect on the two bodies' interactions and performance.

- Contestability of research provision and the viability of the fisheries science provision market in New Zealand. Related to the previous theme, this one will address the issues of the extent to which competitive provider markets are functioning in New Zealand, the impact that the requirement for fisheries research 
contracts to be contestable has had on research provision, and the potential for industry involvement as a research provider for deep-water species

- The effect of section 10 of the Fisheries Act 1996 (the requirement that all management decisions be based on the best available information) on fisheries science and management - whether it has had any effect, and if so what effect and why

- The effect that cost-recovery has on science in the QMS and on the relationship between industry and regulator - if any effects exist, and why that might be the case, and what those effects are.

- The past and potential role of resource rentals, and how they fit into the existing climate of relationships between regulator and industry and into current guiding principles for fisheries management. This theme will address the topic of any influences that resource rentals had (when they were operating) on the relationship between government and industry, and what implications this might have for the relationship in the present and future. It will also look at how the issue of resource rentals, as an indicator of approaches to the concept of ownership of fisheries resources. 


\title{
Appendix D
}

\section{Human Ethics Forms}

\section{Consent form for participation in "Fishing in the Dark: Information Flows and the NZ Orange Roughy Fishery"}

\author{
Isabella Cawthorn \\ Institution: School of Geography, Environment and Earth Sciences, Victoria Univer- \\ sity of Wellington \\ Supervisors: Cath Wallace \\ Senior Lecturer, School of Government \\ Richard Willis \\ Senior Lecturer, School of Geography, Environment and Earth Sciences \\ Date: \\ I agree to take part in an informal, semi-structured interview with Isabella Cawthorn, \\ the researcher, as part of her thesis for a Masters of Environmental Studies at Victoria \\ University.
}

I have been informed of the objectives of this research. and I understand that the interview will cover topics relating to fisheries management and the provision of science on deep-water species, particularly orange roughy. I understand that the interviews and the resultant data will be confidential, and that I am free not to answer questions, or to withdraw at any time without consequence. My name and job title will not be used unless I wish to be acknowledged in the research. I can choose to nominate specific parts of my interview for different levels of non-attribution if I wish. Once the interview has taken place, I may withdraw my material from inclusion in the study at any time prior to 31st December 2007.

I am aware that the interview will be tape-recorded solely for the researcher's use for the purposes of this research, and that interview transcripts will only be seen by her and her supervisor and will be treated confidentially. I know that I can request the tape-recorder to be turned off at any point during the interview.

Before the thesis is submitted, I wish to be sent a summary of the findings of this 
research.

Name:

Date:

Signature:

Isabella Cawthorn: email cawthoisab@student.vuw.ac.nz phone (04) $4635233 \times 8374$

Cath Wallace: email cath.wallace@vuw.ac.nz (first words of subject line must be "Cawthorn study"), phone (04) 4635713 


\section{Waiver of Confidentiality}

I, [insert name here], have been interviewed by Isabella Cawthorn as part of the "Fishing in the Dark" research project. I have chosen that my identity will not remain confidential.

Isabella Cawthorn, of Victoria University of Wellington and any presentations and publications which use material from this project have my permission to publicly identify me by name by organisation (delete any which do not apply) by sector and to use any transcript of this interview as an accurate representation of what I have said. I acknowledge that the small nature of New Zealand's fisheries management community may make identification possible for those individuals familiar with the community, regardless of the level to which my identity is obscured.

I do / do not (delete one) wish to nominate part(s) of my interview to be more confidential than the rest. (If this option is chosen, please refer to "Additional Waiver of Confidentiality" sheet.)

Name:

Date:

Signature: 


\section{Additional Waiver of Confidentiality}

I, [insert name here], have been interviewed by Isabella Cawthorn as part of the "Fishing in the Dark" research project. I have chosen that my identity will not remain confidential, as documented on the "Waiver of Confidentiality" sheet.

I wish to nominate part(s) of my interview for a different level of confidentiality from the bulk of the interview.

For the section of my interview from dictophone timer reading [insert dictophone reading here] to dictophone timer reading [insert dictophone reading here], Isabella Cawthorn, of Victoria University of Wellington, and any presentations and publications which use material from this section have my permission to publicly identify me by name by organisation (delete any which do not apply) by sector and to use the transcript of this section as an accurate representation of what I have said.

Name:

Date:

Signature: 


\section{Employer's Consent Form}

To Whom It May Concern:

I hereby give consent for [insert name here] to be interviewed by Isabella Cawthorn as part of her Masters of Environmental Studies research.

Name:

Position:

Organisation:

Signature:

Date: 


\section{Acknowledgements}

The author is very grateful to the following people for their generosity in giving their time and assistance to this study. Particular thanks go to Anne Mackle for her superb transcription work, and to the Cawthorn family for being there, all the time.

The author is also very grateful to Cath Wallace and Richard Willis for their patience and assistance throughout this long journey.

Robin Allen Former Assistant Director-General, Fisheries Policy (Ministry of Agriculture and Fisheries)

John Annala Former Ministry of Fisheries scientist 1974-2004 (Chief Scientist 19952004)

George Clement CEO Clement and Associates (holds most orange roughy quota in New Zealand), Chair of the Deepwater Stakeholders' Group

Mike Baker Former skipper of Ministry of Agriculture and Fisheries' research vessel W. J. Scott

Jim Cornelius Former Senior Advisor (Fisheries Management), Ministry of Fisheries

Gary Courtney 40 years' New Zealand and international experience as middle depths and deep-water trawler skipper (both research and commercial trawling)

Chris Carey lifelong professional fisherman (trawler skipper). Runner-up in the World Wildlife Fund's 2006 "Smart Gear" competition

Stan Crothers Ministry of Fisheries since 1972, Deputy Chief Executive since 1998

Ian Hampton independent tender reviewer for Ministry of Fisheries 1998, reviewer of acoustic surveys for Ministry of Fisheries 2001, Co-director Fisheries Resource Surveys Ltd 2002 (provides acoustic survey services to the New Zealand fishing industry)

IP Fishing Industry Participant

Michael Harte Ministry for the Environment, Royal Forest and Bird Protection Society 1998—2003 New Zealand Seafood Industry Council

Ray Hilborn Professor, School of Aquatic and Fisheries Management, University of Washington (provides stock assessment advice to New Zealand fishing industry) 
John McKoy Director Fisheries Research, National Institute of Water and Atmospheric Research

Phil Major Fishing industry Board economic research officer, former Director Fisheries Policy, Ministry of Agriculture and Fisheries

Participant unaffiliated research participant

Don Robertson General Manager, Biodiversity and Biosecurity, National Institute of Water and Atmospheric Research

SF New Zealand Seafood Industry Council

Paul Starr Chief Scientist of New Zealand Seafood Industry Council

Kevin Stokes Chief Scientist (Stock Assessment), Ministry of Fisheries

Duncan Waugh Former Director, Fisheries Research Centre of Ministry of Agriculture and Fisheries

Barry Weeber Former Senior Researcher for Royal Forest and Bird Protection Society, currently spokesman for Environment and Conservation Organisations of Aotearoa New Zealand 


\section{Bibliography}

Aleshire, R. A. (1972). Power to the People: An Assessment of the Community Action and Model Cities Experience. Public Administration Review, 32(5):428-442.

Anderson, L. G. (1987). Expansion of the Fisheries Management Paradigm to Include Institutional Structure and Fuction. Transactions of the American Fisheries Society, 166:369-404.

Annala, J., Clark, M., Clement, G., and Cornelius, J. (2003). Management of New Zealand Orange Roughy Fisheries - A Deep Learning Curve. In Deep Sea 2003: Conference on the Governance and Management of Deep Sea Fisheries.

Anon (2004-2005). Attendance lists and minutes of meetings relating to deep water stocks in 2004 and 2005 (51 meetings).

Anscombe, E. (1978). On the Source of the Authority of the State. Ratio, 20(1):1-28.

Anthony, M. (2006). A Genealogy of the Western Rationalist Hegemony. Journal of Futures Studies, 10(4):25-38.

Arendt, H. (1958). The Human Condition. University of Chicago Press, Chicago.

Arnstein, S. (1969). A Ladder of Citizen Participation. Journal of the American Institute of Planners, 25:216-224.

Aron, W., Burke, W., and Freeman, M. (2002). Scientists Versus Whaling: Science, Advocacy, and Errors of Judgment. BioScience, 52(12):1137-1140.

Arrow, K. (1951). Social Choice and Individual Values. Wiley, New York.

Axelrod, R. (1984). The Evolution of Cooperation. Basic Books, New York.

Backman, K. and Kyngäs, H. A. (1999). Challenges of the Grounded Theory Approach to a Novice Researcher. Nursing and Health Sciences, 1:147-153.

Bailey, C. A. (2007). A Guide to Qualitative Field Research (2 Ed). Pine Forge, Thousand Oaks.

Barnes, B. (1995). The Elements of Social Theory. Princeton University Press, Princeton, New Jersey.

Barry, J. (2005). Debating the Earth: the Environmental Politics Reader. Oxford University Press, New York. 
Baumgartner, F. R. and Leech, B. L. (2001). Interest Niches and Policy Bandwagons: Patterns of Interest Group Involvement in National Politics. The Journal of Politics, 63(4):1191-1213.

Beck, U. (1992). Risk Society: Towards a New Modernity. Sage, London.

Beck, U. (1996). Risk Society and the Provident State. Sage Publications.

Bentham, J. (1776 (1948)). Fragments on Government and an Introduction to the Principles of Law and Legislation. Blackwell, Oxford.

Berger, P. L. and Luckmann, T. (1967). The Social Construction of Reality. Penguin, Harmondsworth.

Berkes, F. (1987). The Question of the Commons: the Culture and Ecology of Communal Resources. University of Arizona Press, Tucson.

Beverton, R. J. H. and Holt, S. J. (1957). On the Dynamics of Exploited Fish Populations. Fisheries Investigations Series 2, 19, United Kingdom Ministry of Agriculture and Fisheries.

Bhat, M. and Stamatiades, A. (2003). Institutions, Incentives, and Resource Use Conflicts: The case of Biscayne Bay, Florida. Population and Environment, 24(6):485509 .

Bloor, D. (1976). Knowledge and Social Imagery. University of Chicago Press, Chicago.

Boast, R. P. (1990). Treaty Rights or Aboriginal Rights? New Zealand Law Journal, 3:32-36.

Bobbio, N. (1987). The Future of Democracy. Polity, Cambridge.

Boston, J. and Pallot, J. (1997). Linking Strategy and Performance: Developments in the New Zealand Public Sector. Journal of Public Administration and Management, 16(3):383-404.

Boucher, D. and Kelly, P. (1994). The Social Contract from Hobbes to Rawls. Routlege, New York.

Bowen, B. K. (1997). Developing and Sustaining World Fisheries Resources: The State of Science and Management. CSIRO.

Boyd, R. O. and Dewees, C. M. (1992). Putting Theory into Practice: Individual Transferable Quotas in New Zealand's Fisheries. Society and Natural Resources, 5:179-198.

Bradford, D. F. (1975). Constraints of Government Investment Opportunities and the Choice of Discount Rate. American Economic Review, 65(5):887-899.

Brewer, G. D. (1999). The Challenges of Interdisciplinarity. Political Science, 32:327337. 
Bromley, D. (1991). Environment and Economy: Property Rights and Public Policy, chapter Property Rights and Property Regimes, pages 14-40. Blackwell, Oxford.

Broome, J. (1994). Discounting the Future. Philosophy and Public Affairs, 23:128143.

Brouha, P. (1993). The Emerging Science-based Advocacy Role of the American Fisheries Society. Journal of the North American Benthological Society, 12(2):215218.

Brown, D. A. (1995). Sustainable Development: Science, Ethics and Public Policy. Kluwer Academic Publishers, London.

Bruun, H., Hokkinen, J., Huuntoniemi, K., and Klein, J. T. (2005). Promoting Interdisciplinary Research: the Case of the Academy of Finland. Academy of Finland, Helsinki.

Bryan, H. (1984). Social Assessment and the Use of Analytic Induction. New Zealand Social Impact Assessment Newsletter, 5.

Bryman, A. (2001). Social Research Methods. Oxford University Press, Oxford.

Buchanan, J. (1980). Towards a Theory of the Rent-Seeking Society. Texas A \& M Press, College Station.

Buchanan, J. M. and Tullock, G. (1962). The Calculus of Consent. University of Michigan Press, Ann Arbor.

Burstall, B. (1998). Cat Among the Pigeons in Fishery Management Plan. New Zealand Herald, 15 December:A13.

Caddy, J. F. and Seijo, J. C. (2005). This is More Difficult Than We Thought! The Responsibility of Scientists, Managers and Stakeholders to Mitigate the Unsustainability Of Marine Fisheries. Philosophical transactions of the royal society B, 360:5975.

Caino, S. J. D. and Niemann, P. (2006). Equity Effects of Alternative Assignments of Global Environmental Rights. Ecological Economics, 56:546-559.

Callon, M. (1994). Is Science a Public Good? Fifth Mullins Lecture, Virginia Polytechnic Institute, 23 March 1993. Science, Technology and Human Values, 19(4):395-424.

Cameron, J. and Abouchar, J. (1991). The Precautionary Principle: A Fundamental Principle of Law and Policy For the Protection of the Environment. British Columbia International and Comparative Law Review, 14:1.

Campbell, H., Jnr, S. F. H., and Squires, D. (2000). The Role of Research in Fisheries Management: The Conservation of Dolphins in the Eastern Tropical Pacific and the Exploitation of Southern Bluefin Tuna in the Southern Ocean. Ocean Development and International Law, 31:347-375. 
Carpenter, S. R. and Gunderson, L. H. (2001). Coping with Collapse: Ecological and Social Dynamics in Ecosystem Management. BioScience, 51(6):451-457.

Cartner, M. and Bollinger, T. (1997). Science Policy Reforms: the New Zealand Experience. Social Studies of Science, 27(5):775-803.

Cartwright, I. (2003). Long-term Fisheries Management - the Australian Model. Maritime Studies, 131:10-19.

Charles, A. T. (1998). Living With Uncertainty in Fisheries: Analytical Methods, Management Priorities and the Canadian Groundfishery Experience. Fisheries Research, 37:37-50.

Charmaz, K. (2000). The Handbook of Qualitative Research. Sage Publications, Thousand Oaks.

Clark, I. N., Major, P. J., and Mollett, N. (1988). Development and Implementation of New Zealand's ITQ Management System. Marine Resource Economics, 5:325-349.

Clark, M. (2001). Are Deepwater Fisheries Sustainable? - the Example of Orange Roughy (hoplostethus atlanticus) in New Zealand. Fisheries Research, 51:123-135.

Clark, M. (2003). Counting Deepwater Fish: Challenges for Estimating the Abundance of Orange Roughy. In Deep Sea 2003: Conference on the Governance and Management of Deep Sea Fisheries, volume Part 1: Conference reports, Queenstown NZ. FAO.

Clark, R. H. H. (2007). Prime Minister's Statement. Parliament, Wellington.

Clement, G. (2000). The Orange Roughy Management Company Limited - A Positive Example of Fish Rights in Action. In Shotton, R., editor, FAO Fisheries Technical Paper 404/2 - Use of Property Rights in Fisheries Management, volume 404. Food and Agriculture Organisation (FAO), FAO.

Coase, R. (1960). The Problem of Social Cost. Journal of Law and Economics, 3:1-44.

Coffey, A. and Atkinson, P. (1996). Making Sense of Qualitative Data. Sage Publications, Thousand Oaks.

Corbin, J. and Strauss, A. (1990). Grounded Theory Research: Procedures, Canons, and Evaluative Criteria. Qualitative Sociology, 13(1):3-21.

Cresswell, J. W. (2007). Qualitative Inquiry and Research Design: Choosing Among Five Approaches ( 2 ed). Sage, Thousand Oaks, CA.

Cullen, R. and Memon, P. (1990). Impact of the Exclusive Economic Zone on the Management and Utilisation of the New Zealand Fishery Resources. Pacific Viewpoint, 31(1):44-62.

Dahl, R. A. (1966). Further Reflections on the Elitist Theory of Democracy. American Political Science Review, 60:296-305. 
Daly, H. and Farley, J. (2004). Ecological Economics: Principles and Applications. Island Press.

D'Amato, A., Brown-Weiss, E., and Gündling, L. (1990). "Agora": What Obligation Does Our Generation Owe to the Next? American Journal of International Law, 84:190-212.

Davidson, C. and Tolich, M. (2001). Social Science Research in New Zealand. Pearson, Auckland.

Dawes, R., McTavish, J., and Shaklee, H. (1977). Behavior, Communication, and Assumptions about Other People's Behavior in a Commons Situation. Journal of Personality and Social Psychology, 35(1):1-11.

Dayton, P. K. (1998). Reversal of the Burden of Proof in Fisheries Management. Science, 279(5352):821-822.

de Jasay, A. (1989). Social Contract, Free Ride. Clarendon Press, Oxford.

Degnbol, P., Gislasson, H., Hanna, S. L., Jentoft, S., Nielsen, J. R., and SverdrupJensen, S. (2006). Painting the Floor With a Hammer: Technical Fixes in Fisheries Management. Marine Policy, 30:534-543.

Demsetz, H. (1967). Towards a Theory of Property Rights. American Economic Review, 57:347-359.

Denhardt, R. and Denhardt, J. V. (2000). The New Public Service: Serving Rather Than Steering. Public Administration Review, 60(6):549-559.

Denzin, N. K. (1978). The Research Act. McGraw-Hill, New York.

Dewey, J. (1960). The Public and its Problems. H Holt, New York.

Dobson, A. (1996). Democracy and Green Political Thought. Routledge, London.

Doherty, B. and de Geus, M. (1996). Democracy and Green Political Thought. Routledge, London.

Downs, A. (1957). The Economic Theory of Democracy. Harper and Row, New York.

Dunn, K. (2005). Qualitative Research Methods in Human Geography (2nd Edition), chapter Inteviewing. Oxford University Press, Oxford.

Easton, B. H. (1989). How Commercial Should Science Be? NZ Science Review, 46(1-3):35-39.

Ebbin, S. A. (2004). Black Box Production of Paper Fish: An Examination of Knowledge Construction and Validation in Fisheries Management Institutions. International Environmental Agreements: Politics, Law and Economics, 4:143-159.

Eckstein, O. (1961). Public Finances: Needs, Sources and Utilization, chapter A Survey of the Theory of Public Expenditure Criteria. Princeton University Press, Princeton. 
Edmeades, D. C. (2004). Is The Commercial Model Appropriate For Science? New Zealand Science Review, 61(3-4):85.

Edwards, V. M. and Steins, N. A. (1999). Special Issue Introduction: The Importance of Context in Common Pool Resource Research. Journal of Environmental Policy and Planning, 1:195-204.

Ehrlich, P. R. and Ehrlich, A. H. (1996). Betrayal of Science and Reason. Island Press, Washington DC.

Émile Durkheim (1895 (1938)). Le Suicide: Étude de Sociologie (The Rules of Sociological Method). University of Chicago Press, Chicago.

Environment and Conservation Organisations of Aotearoa New Zealand (ECO) (1999). Submission on the Fisheries Act 1996 Amendment Bill1998.

Environment and Conservation Organisations of Aotearoa New Zealand (ECO) (2007). Submission on the Fisheries Act 1996 Amendment Bill 2007.

Feeny, D. (1994). Frameworks for understanding resource management on the commons. In Pomeroy, R. S., editor, Community management and common property of coastal fisheries in Asia and the Pacific: Concepts, Methods and Experience ICLARM Conference Proceedings 45, pages 20-33. International Centre for Living Aquatic Resources Management, Manila.

Fetterman, D. M. (1998). Ethnography Step By Step. Sage Publications, Thousand Oaks.

Feyerabend, P. (1975). Against Method: Outline of an Anarchistic Theory of Knowledge. Verso, London.

Fineman, M. L. and Opie, A. (1987). The Uses of Social Science Data in Legal Policymaking: Custody Determinations at Divorce. Wisconsin Law Review, 1:107-158.

Fisheries (2005). Offshore Options: Managing Environmental Effects in New Zealand's Exclusive Economic Zone (online version). Technical Report June 2005, Ref. ME603, Ministry of Fisheries. Available from: http://www.mfe.govt.nz/ publications/oceans/offshore-options-jun05/html/page3.html [cited 3.9.2006].

Fisheries Task Force (1992). Sustainable Fisheries - Tiakina Nga Tanga a Tangaroa: Report of the Fisheries Task Force to the Minister of Fisheries on the Review of Fisheries Legislation. Technical report, Ministry of Agriculture and Fisheries.

Flathman, R. (1966). The Public Interest. Wiley, New York.

Fleck, L. (1975). Genesis and Development of a Scientific Fact. University of Chicago Press, Chicago.

Flick, U. (2002). An Introduction to Qualitative Research (2 ed). Sage, London.

Flyvbjerg, B. (2001). Making Social Science Matter: Why Social Inquiry Fails and How it can Succeed Again. Cambridge University Press, Cambridge. 
Folke, C., Carpenter, S., and et al, T. E. (2002). Resilience and Sustainable Development: Building Adaptive Capacity in a World of Transformations - Scientific Background Paper on Resilience for the process of The World Summit on Sustainable Development on behalf of The Environmental Advisory Council to the Swedish Government. Technical report, The Environmental Advisory Council to the Swedish Government.

Foucault, M. (2000). Power: Essential Works of Foucault, 1954-1984. The New Press, New York.

Fox, W. (1990). Towards a Transpersonal Ecology: Developing New Foundations for Environmentalism. Shambhala, Boston.

Francis, R. C. (1980). Fisheries Science Now and in The Future: A Personal View. New Zealand Journal of Marine and Freshwater Research, 14(1):95-100.

Frankena, F. (1987). Citizen Participation in Environmental Decision Making: A Bibliography. Vance Bibliographies, Public Administration Series.

Fredrickson, H. G. (1994). Can Public Officials Correctly be Said to Have Obligations to Future Generations? Public Administration Review, 54(5):457-464.

Funder, M. (2005). Bias, Intimacy and Power in Qualitative Fieldwork Strategies. Journal of Transdisciplinary Environmental Studies, 4(1):1-9.

Funtowicz, S. O. and Ravets, J. R. (1990). Post-Normal Science: A New Science for New Times. Scientific European, 266:20-22.

Funtowicz, S. O. and Ravets, J. R. (1993). Science for the Post-Normal Age. Futures, 25:735-755.

Furlong, S. R. and Kerwin, C. M. (2004). Interest Group Participation in Rule Making: a Decade of Change. Journal of Public Administration Research and Theory, 15(3):353-370.

Garcia, S. M. (2005). Fishery Science and Decision-making: Dire Straits to Sustainability. Bulletin of Marine Science, 76(2):171-196.

Garrett-Jones, S., Turpin, T., Burns, P., and Diment, K. (2005). Common Purpose and Divided Loyalties: the Risks and Rewards of Cross-Sector Collaboration for Academic and Government Researchers. $R \& \&$ D Management, 5(5):535-544.

Gibbons, M., Limoge, C., Nowotny, H., Schwartzmann, S., Scott, P., and Trow, P. (1994). The Dynamics of Science and Research in Contemporary Societies, chapter The New Production of Knowledge. Sage, London.

Giddens, A. (1999). Risk and Responsibility. The Modern Law Review, 62(1):1-10.

Glaser, B. G. and Strauss, A. L. (1967). The Discovery of Grounded Theory. Aldine, Chicago.

Goble, D. D. (2006). Three Cases/Four Tales: Commons, Capture, the Public Trust, and Private Property in Land. Environmental Law, 35. 
Godfey-Smith, P. (2003). Theory and Reality: an Introduction to the Philosophy of Science. University of Chicago Press, Chicago.

Gold, R. (1969). Issues in Participant Observation, chapter Roles in Sociological Field Observation, pages 30-38. Addison-Wesley, Reading (MA).

Golden, M. M. (1998). Interest Groups in the Rule-Making Process: Who Participates? Whose Voices Get Heard? Journal of Public Administration Research and Theory, $8(2): 245-270$.

Goodin, R. E. (1982). Discounting Discounting. Journal of Public Policy, 2(1):53-72.

Goodland, R. and Daly, H. (1996). Environmental Sustainability: Universal and NonNegotiable. Ecological Applications, 6(4):1002-1017.

Gordon, H. S. (1954). The Economic Theory of a Common-Property Resource: The Fishery. Journal of Political Economy, 62:124-142.

Graham, M. (1935). Modern Theory of Exploiting a Fishery, and Application to North Sea Trawling. ICES Journal du Conseil International pour l'Exploration de la Mer, 10:264-274.

Grand, J. L. (1997). Knights, Knaves or Pawns? Human Behaviour and Social Policy. Journal of Social Policy, 26(2):149-169.

Greenpeace (2007). Submission on the Fisheries Act 1996 Amendment Bill 2007. Greenpeace NZ.

Gregory, R., Lichtenstein, S., and Slovic, P. (1993). Valuing Environmental Resources: A Constructive Approach. Journal of Risk and Uncertainty, 7(2):177-197.

Grillo, R. D. (1998). Pluralism and the Politics of Difference: State, Culture, and Ethnicity in Comparative Perspective. Clarendon Press, New York.

Grimble, R. (1998). Socio-Economic Methodologies - Best Practice Guidelines: Stakeholder Methodologies In Natural Resource Management. Technical report, Natural Resources Institute.

Gross, P. R. and Levitt, N. (1994). Higher Superstition: the Academic Left and its Quarrels with Science. Johns Hopkins University Press, Baltimore.

Grumbine, R. E. (1994). What is Ecosystem Management? Conservation Biology, 8:27-38.

Guerin, K. (2007). Adaptive Governance and Evolving Solutions to Natural Resource Conflicts. New Zealand Treasury Working Paper, New Zealand Treasury.

Guha, R. (2000). Environmentalism: A Global History. Oxford University Press, New Delhi.

Guth, H. K. (2001). Dividing the Catch: Natural Resource Reparations to Indigenous Peoples - Examining the Maori Fisheries Settlement. University of Hawaii Law Review, 2(24):179. 
Habermas, J. (1973). Legitimation Crisis. Beacon, Boston.

Habermas, J. (1987). The Theory of Communicative Action. Volume 2: A Critique of Functionalist Reason. Polity, Cambridge.

Hall, C. (1998). Institutional Solutions For Governing the Global Commons: Design Factors and Effectiveness. Journal of Environment \& Development, 7(2):86-115.

Hall, S. J. and Mainprize, B. (2003). Towards Ecosystem-Based Fisheries Management. Fish and Fisheries, 5(1):1-20.

Hammond, L. S. and Devine, S. D. (1994). The New Zealand Experience of a Comprehensive Fully Costed Science Funding System. Higher Education, 28(1):119-127.

Hapi, R. (2007). Aotearoa Fisheries Limited: Shared Fisheries Submission.

Hardin, G. (1968). The Tragedy of the Commons. Science, 162:1243-1248.

Harriss, J. (2002). The Case For Cross-Disciplinary Approaches in International Development. World Development, 30(3):487-496.

Harsanyi, J. C. (1985). Ethics and Economics. Basil Blackwell, Oxford.

Harte, M. (2001). Opportunities and Barriers for Industry-led Fisheries Research. Marine Policy, 25:159-167.

Heron, R. L., Rees, E., Massey, E., Bruges, M., and Thrush, S. (in press). Improving Fisheries Management in New Zealand: Developing Dialogue Between Fisheries Science and Management (FSM) And Ecosystem Science And Management (ESM). Geoforum.

Hilborn, R. (2006). Faith-Based Fisheries. Fisheries, 31(11):554-555.

Hile, R. (1936). Age and Growth of the Cisco, leucichthys artedi (le sueur), in the Lakes of the Northeastern Highlands, Wisconsin. US Bureau of Fisheries Bulletin, 48:211-237.

Hill, R. M. (1984). Establishing Value in the Social Sciences: An Empirical Evaluation. New Zealand Science Review, 40:4.

Hobbes, T. (1651(1968)). Leviathan. Penguin, Harmondsworth.

Hoggart, K. (2000). Citizen Responsive Government. JAI Press, New York.

Holdsworth, J. (2004). What is a Fisheries AMP? Available from: http://www . option4.co.nz/FAQs/faqamp0204.htm [cited 2007.09.14].

Holling, C. S. (1978). Adaptive Environmental Assessment and Management. International Series on Applied Systems Analysis. Wiley \& Sons, New York.

Holyoake, T. T. (2003). Choosing Battlegrounds: Interest Group Lobbying Across Multiple Venues. Political Research Quarterly, 59(3):325-366.

Howes, M. (2005). Politics and the Environment. Earthscan Publications. 
Hughes, T. P., Bellwood, D. R., Folke, C., Steneck, R. S., and Wilson, J. (2005). New Paradigms For Supporting the Resilience of Marine Ecosystems. Trends in Ecology and Evolution, 20(7):380-386.

Ihde, D. (2002). How Could We Ever Believe Science is Not Political? Technology in Society, 24:179-189.

Jacobs, G. (1970). The Participant Observer. George Brazillier, New York.

Jamal, T. (2004). Conflict in Natural Area Distinations: A Critique of Representation and 'Interest' in Participatory Processes. Tourism Geographies, 6(3):352-379.

James, B. (1991). Public Participation in Department of Conservation Management Planning. New Zealand Geographer, 47(2):51-59.

Jentoft, S. (1986). Fisheries Co-Operatives: Lessons Drawn From International Experience. Canadian Journal of Development Studies, 7:195-209.

Jentoft, S. (1999). Fisheries Comanagement: Delegating Government Responsibility to Fishermen's Organizations. Marine Policy, 23(2):137-154.

Jentoft, S. (2000). Legitimacy and Disappointment in Fisheries Management. Marine Policy, 24:141-148.

Jentoft, S. (2004). Institutions in Fisheries: What They Are, What They Do and How They Change. Marine Policy, 28:137-149.

Johnson, D. (2004). Hooked: The Story of the New Zealand Fishing Industry. Hazard Press, Christchurch (for the Fishing Industry Association).

Johnston, B. R. (1994). Who Pays the Price? The Sociocultural Context of Environmental Crisis. Island Press, Washington.

Kant, I. (1784(1965)). The Metaphysical Elements Of Justice. Library of Liberal Arts, Indianapolis.

Kerr, S., Newell, R., and Sanchirico, J. (2003). Evaluating The New Zealand Individual Transferable Quota Market For Fisheries Management. Technical Report Working Paper 2003-021, Motu Economic and Public Policy Research Trust.

King, C. S. and Stivers, C. (1998). Government Is Us: Public Administration in an Anti-Government Era. Sage, Thousand Oaks, CA.

King, D. M. (1994). Investing In Natural Capital: The Ecological Economics Approach to Sustainability. Island Press, Washington DC.

Kingdon, J. (1984). Agendas, Alternatives and Public Policies. Little, Brown \& Co, Boston.

Kiser, L. and Ostrom, E. (1982). Strategies of Political Action, chapter The Three Worlds of Action, pages 179-222. Sage, Beverly Hills. 
Klein, J. T. (2007). The Sage Handbook of Social Science Methodology. Sage Publications, Los Angeles.

Klein, U. (2000). Belief-Views on Nature - Western Environmental Ethics and Maori World Views. New Zealand Journal of Environmental Law, 4:81-119.

Knight, P. (2002). Oceans Policy and Property Rights: The Case for Common Property Regimes. New Zealand Surveyor, 292:19-26.

Kooiman, J. (2003). Governing as Governance. Sage Publications, London.

Kuhn, T. (1970). The Structure of Scientific Revolutions (2 ed). University of Chicago Press, Chicago.

Kysar, D. A. (2007). Discounting... On Stilts. University of Chicago Law Review, 74:119-143.

Lach, D., List, P., Steel, B., and Shindler, B. (2003). Advocacy and Credibility of Ecological Scientists in Resource Decisionmaking: a Regional Study. BioScience, 53(2):170-178.

Lakatos, I. (1976). Proofs \& Refutations. Cambridge University Press, Cambridge.

Landell-Mills, N. (2002). Developing Markets for Forest Environmental Services: an Opportunity for Promoting Equity while Securing Efficiency? Philsophical Transactions: Mathematical, Physical and Engineering Sciences, 360(1797):1817-1825.

Langbein, L. L. and Kerwin, C. M. (2000). Regulatory Negotiation: Claims, Counter Claims and Empirical Evidence. Journal of Public Administration Research and Theory, 10:599-632.

Larkin, P. A. (1977). An Epitaph For the Concept of Maximum Sustained Yield. Transactions of the American Fisheries Society, 106(1):1-11.

Lash, S., Szerszynski, B., and Wynne, B., editors (1996). Risk, Environment \& Modernity. Sage Publications.

Lattuca, L. R. (2001). Creating Interdisciplinarity: Interdisciplinary Research and Teaching Among College and University Faculty. Vanderbilt University Press, Nashville.

Leach, M., Mearns, R., and Scoones, I. (1999). Environmental Entitlements: Dynamics and Institutions in Community-Based Natural Resource Management. World Development, 27(2):225-247.

Leathwick, J., Julian, K., and Francis, M. (2006). Exploration of the Use of Reserve Planning Software to Identify Potential Marine Protected Areas in New Zealand's EEZ: Report Prepared for the Department of Conservation. Technical Report NIWA DOC06213, Department of Conservation.

Lee, K. N. (1993). Compass and Gyroscope: Integrating Science and Politics for the Environment. Island Press, Washington DC. 
Lemons, J. (1996). Scientific Uncertainty and Environmental Problem Solving. Blackwell Science, Oxford.

Lemons, J. (1998). Ecological Sustainability and Integrity: Concepts and Approaches. Kluwer, London.

Lévi-Strauss, C. (1966). The Savage Mind (La Pensée Sauvage). University of Chicago Press.

Levin, I. P., Gaeth, G. J., Schreiber, J., and Lauriola, M. (2002). A New Look at Framing Effects: Distribution of Effect Sizes, Individual Differences, and Independence of Types of Effects. Organizational Behavior and Human Decision Processes, 88(1):411-429.

Libecap, G. D. (2003). State Regulation of Open-access, Common-pool Resources. ICER working paper series 19/2003, International Centre for Economic Research.

Lindblom, C. E. (1959). The Science of Muddling Through. Public Administration Review, 19:79-88.

Link, J. S. (2002a). Concepts and Issues in Marine Ecosystem Management. Canadian Journal of Fisheries and Aquatic Sciences, 59:1329-1440.

Link, J. S. (2002b). What Does Ecosystem-Based Fisheries Management Mean? Fisheries, 27(4):18-21.

Locke, J. (1690(1994)). Two Treatises of Government. Cambridge University Press, Cambridge.

Longhurst, A. (2006). The Sustainability Myth. Fisheries Research, 81:107-112.

Longino, H. E. (1990). Science as Social Knowledge: Values and Objectivity in Scientific Inquiry. Princeton University Press, Princeton.

Longstaff, S. (1994). Ethics for the Public Sector: Education and Training, chapter Why Codes Fail, pages 237-246. Federation Press.

Ltd, S. (2007). Submission to the primary production committee on the fisheries act 1996 amendment bill precautionary approach.

Lubchenco, J. (1998). Entering the Century of the Environment: A New Social Contract for Science. Science, 279:491-497.

Mace, P. (2001). A New Role For MSY in Single-Species and Ecosystem Approaches to Fisheries Stock Assessment and Management. Fish and Fisheries, 2(1):2-32.

Malinowski, B. (1922). A Diary in the Strict Sense of the Term. Routlege and Kegan Paul, London.

Mansfield, B. (2004). Neoliberalism in the Oceans: "Rationalization", Property Rights, and the Commons Question. Geoforum, 35(3):313-326.

March, J. G. and Simon, H. (1958). Organizations. Wiley, New York. 
Marglin, S. (1963). The Social Rate of Discount and the Optimal Rate of Investment. Quarterly Journal of Economics, 77:95-111.

Marshall, C. and Rossman, G. B. (2006). Designing Qualititative Research (4 ed). Sage Publications, Thousand Oaks.

Martin, J. (2003). New Zealand Government \& Politics, chapter The Public Service, pages 135-147. Oxford University Press, Melbourne.

Marx, K. (1867 (1970)). Capital. Lawrence and Wishart, London.

Mason, M. (1999). Environmental Democracy. Earthscan Publications.

Maunder, M. N. and Starr, P. J. (2002). Industry Participation In Stock Assessment: The New Zealand SNA1 Snapper (pagrus auratus) Fishery. Marine Policy, 26:481492.

Mayumi, K. and Giampietro, M. (2006). The Epistemological Challenge of Selfmodifying Systems: Governance and Sustainability in the Post-normal Science Era. Ecological economics, 57(3):382-399.

McCarthy, J. and Zald, M. (1977). Resource Mobilization and Social Movements: A Partial Theory. American Journal of Sociology, 82:1212-1241.

McCay, B. J. (1980). A Fishermen's Cooperative, Limited: Indigenous Resource Management in a Complex Society. Anthropological Quarterly, 53:29-38.

McClurg, T. (2000). Return to the Nation: Resource Rentals and Cost Recovery. In Microbehavior and Macroresults: Proceedings of the Tenth Biennial Conference of the International Institute of Fisheries Economics and Trade.

McGlade, J. M. (1989). Mathematical Analysis of Fish Stock Dynamics, chapter Integrated Fisheries Management Models: Understanding the Limits to Marine Resource Exploitation, pages 139-165. American Fisheries society, Bethseda (MD).

McKean, R. (1965). The Unseen Hand in Government. American Economic Review, 55:496-505.

McKoy, J. (2006). Fisheries Resource Knowledge, Management and Opportunities: Has the Emperor Got No Clothes? In New Zealand's Ocean and its Future, Hilton Hotel, Princes Wharf, Auckland. The Royal Society of New Zealand, Paper for workshop session 2: New Zealand's Ocean and its Future: Knowledge, Opportunities and Management.

Meffe, G. K., Boersma, P. D., Murphy, D. D., Noon, B. R., Pulliam, H. R., Soule, M. E., and Waller, D. M. (1998). Independent Scientific Review in Natural Resource Management. Conservation Biology, 12(2):268-270.

Memon, P. A. and Cullen, R. C. (1996). Resources, Nations and Indigenous Peoples: Case Studies From Australasia, Melanesia and South-East Asia. Oxford University Press. 
Merton, R. K. (1973). The Sociology of Science. University of Chicago Press, Chicago.

Metzger, N. and Zare, R. N. (1999). Interdisciplinary Research: From Belief to Reality. Science, 283(5402):642-643.

Meyer, J. W. and Rowan, B. (1977). Institutional Organizations: Formal Structure as Myth and Ceremony. American Journal of Sociology, 83:340-363.

Meyer, W. J. (1975). Public Good and Political Authority. Kennikat Press Corp, Port Washington, New Jersey.

Mikalsen, K. H., Hernes, H.-K., and Jentoft, S. (2007). Leaning on User-Groups: the Role of Civil Society in Fisheries Governance. Marine Policy, 31:201-209.

Ministry of Fisheries (1996). Changing Course Towards Fisheries 2010. Technical report, Ministry of Fisheries.

Ministry of Fisheries (1997). Review of the Fisheries Cost Recovery Regime. Select Committee Briefing Paper.

Ministry of Fisheries (2001a). Policy Definition document: Section 12: Consultation.

Ministry of Fisheries (2001b). The Bite - Summer 2001-02.

Ministry of Fisheries (2004). Briefing for the Minister of Fisheries.

Ministry of Fisheries (2006a). Harvest Strategy Standard: Standards for Stocks Managed Under s13 of the Fisheries Act - Discussion Document.

Ministry of Fisheries (2006b). Letter to Stakeholders: Draft Fisheries Standards.

Ministry of Fisheries (2006c). Research Goals, Strategies and Objectives (in Strategic Framework and Directions for Fisheries).

Ministry of Fisheries (2006d). Statement of intent 2006-2011.

Ministry of Fisheries (2007a). "Fisheries At A Glance" page. Ministry website. Available from: http://www.fish.govt.nz/en-nz/SOF/default.htm [cited 2007.09.02].

Ministry of Fisheries (2007b). Initial Position Paper: Altering the Fisheries (Cost Recovery) Rules 2001 With Respect to the Benthic Protected Areas Accord.

Ministry of Fisheries (2007c). Policy definition document: Section 13 - total allowable catch.

Ministry of Fisheries (2007d). Policy definition: Section 8 - purpose of the fisheries act 1996.

Ministry of Fisheries (2007e). Press Release: Groundbreaking Initiative to Protect Underwater Habitats.

Ministry of Fisheries (2007f). “"Role of the Ministry” page. 
Ministry of Fisheries (2007g). Text of Accord Relating to Benthic Protection Areas Within New Zealand's Exclusive Economic Zone.

Ministry of Fisheries (2007h). "The Chatham-Challenger Project" page. 21.7.2007. Available from: http://www.fish.govt.nz/en-nz/info/contactus/Mediat Centre/Chatham+Challenger.htm [cited 21.7.2007].

Ministry of Research, Science and Technology (1992). Investing in Science for Our Future: a paper presenting the Government's Statement of Science Priorities for the Public Good Science Fund. Technical report, Ministry of Research, Science and Technology.

Mulgan, R. (2004). Politics in New Zealand. Auckland University Press, Auckland.

Mutter, L. R., Virden, R. J., and Cayer, N. J. (1999). Interest Group Influence in State Natural Resource Policymaking. Society and Natural Resources, 12:243-255.

Myers, N. (1997). The Scientific Enterprise. The Environmentalist, 17(3):149-151.

Myers, N. (1999). Environmental Scientists: Advocates as Well? Environmental Conservation, 26(3):163165.

Nash, R. F. (1989). The Rights of Nature: A History of Environmental Ethics, chapter Natural Rights to Rights of Nature. University of Wisconsin Press, Wisconsin.

Nelkin, D. (1996). The Science Wars: Response to a Marriage Failed. Social Text, 46(14):93-100.

New Zealand Seafood Industry Council (2007). Submission to the Primary Production Committee on the Fisheries Act 1996 Amendment Bill.

Newton, I. (1972). Philosophiae Naturalis Principia Mathematica (3 ed). Cambridge University Press, Cambridge.

Nightingale, T. (1992). White Collars and Gumboots: a History of the Ministry of Agriculture and Fisheries 1892-1992. The Dunmore Press.

Nola, R. and Sankey, H. (2007). Theories of Scientific Method: an Introduction. Acumen, Stocksfield.

Norgaard, R. B. (1992). Sustainability as Intergenerational Equity: Economic Theory and Environmental Planning. Environmental Impact Assessment Review, 12:85124.

Norgaard, R. B. (1994). Development Betrayed. The End of Progress and a Coevolutionary Revisioning of the Future. Routlege, New York.

Office of the Auditor-General (1999). Information Requirements for the Sustainable Management of Fisheries: 5th Report to Parliament. Technical report, Office of the Auditor-General. 
Office of the Auditor-General (2005). Follow-Up Report on the Information Requirements for the Sustainable Management of Fisheries. Technical report, Office of the Auditor-General.

Olson, M. (1965). The Logic of Collective Action: Public Goods and the Theory of Groups. Harvard University Press, Cambridge, Mass.

Opie, A. (2001). Thinking Teams / Thinking Clients: Knowledge-Based Team Work. Columbia University Press, Columbia.

Option4 (2007). Shared Fisheries Policy Development 2005 - 2007. Option4 website page. Available from: http://www.option4.co.nz/Fisheries_Mgmt/ sharedfisheries.htm [cited 2007.4.14].

Organization for Economic Cooperation and Development (2007). Environmental Performance Review: New Zealand. Technical report, Organization for Economic Cooperation and Development.

Ostrom, E. (1986). An Agenda for the Study of Institutions. Public Choice, 48(1):325.

Ostrom, E. (1990). Governing the Commons: the Evolution of Institutions for Collective Action. Cambridge University Press USA.

Ostrom, E. (1992). Crafting Institutions for Self Governing Irrigation Systems. Institute of Contemporary Studies Press, San Francisco.

Ostrom, E., Gardner, R., and Walker, J. (1994). Rules, Games and Common-Pool Resources. University of Michigan Press.

Parfit, D. (1983). Energy and the Future. Rowman \& Littlefield, Totowa, New Jersey.

Parfit, D. (1984). Reasons and Persons. Clarendon Press, Oxford.

Parsons, K. M. (2001). Drawing Out Leviathan: Dinosaurs and the Science Wars. Indiana University Press, Bloomington.

Parsons, T. (1982). Talcott Parsons on Institutions and Social Evolution: Selected Writings. University of Chicago Press, Chicago.

Pateman, C. (1976). Organizational Democracy: Participation and Self-Management. Sage, Beverly Hills, CA.

Patton, M. Q. (2002). Qualitative Research Evaluation Methods (3 ed). Sage Publications, Thousand Oaks.

Pearse, P. H. and Walters, C. J. (1992). Havesting Regulations Under Quota Management Systems for Ocean Fisheries: Decision Making in the Face of Natural Variability, Weak Information, Risks and Conflicting Incentives. Marine Policy, pages 167-182.

Peart, R. (2005). Looking Out To Sea: New Zealand as a Model for Ocean Governance. Environmental Defence Society. 
Peuhkuri, T. and Jokinen, P. (1999). The Role of Knowledge and Spatial Contexts in Biodiversity Policies: a Sociological Perspective. Biodiversity and Conservation, 8:133-147.

Pickitch, E. K., Santora, C., and et al, E. A. B. (2004). Ecosystem-Based Fishery Management. Science, 305:346-7.

Pigou, A. C. (1920). The Economics of Welfare. Macmillan, London.

Pinkerton, E., editor (1989). Cooperative Management of Local Fisheries: New Direction for Improved Management and Community Development. University of British Columbia Press, Vancouver.

Pitkin, H. F. (1972). The Concept of Representation. University of California Press, Berkeley.

Polanyi, M. (1958). Personal Knowledge: Towards a Post-Critical Philosophy. Routledge \& Kegan Paul, London.

Polanyi, M. (1962). The Republic of Science: its Political and Economic Theory. Minerva, 1:54-74.

Pollitt, C. (2000). Institutional Amnesia: A Paradox of the 'Information Age'? Prometheus, 18(1):5-16.

Popper, K. (1959). The Logic of Scientific Discovery. Hutchison \& Co, London.

Posner, R. A. (1977). Economic Analysis of Law. Little Brown, Boston.

Prugh, T. (1995). Natural Capital and Human Economic Survival. International Society for Ecological Economics.

Ravetz, J. J. (1979). Scientific Knowledge and its Social Problems. Oxford University Press, Oxford.

Ravetz, J. J. (1990). The Merger of Knowledge with Power: Essays in Critical Science. Mansell, London.

Rawls, J. (1971). A Theory of Justice. Oxford University Press, Oxford.

Regan, T. and Singer, P., editors (1989). Animal Rights and Human Obligations. Prentice Hall, Englewood Cliffs.

Ricardo, D. (1821). On the Principles of Political Economy and Taxation (3 Ed). John Murray, London.

Ricker, W. E. (1954). Stock and Recruitment. Journal of the Fisheries Research Board of Canada, 11:559-623.

Riley, P. (1982). Will and Political Legitimacy: A Critical Exposition of Social Contract Theory in Hobbes, Locke, Rousseau, Kant and Hegel. Harvard University Press, Cambridge, Massachusetts. 
Rochefort, D. A. and Cobb, R. W. (1993). Policy Evaluation. Edward Elgar Publishing, Aldershot.

Roll-Hansen, N. (1994). Science, Politics and the Mass Media: on Biased Communication of Environmental Issues. Science, Technology and Human Values, 19(3):324341.

Rousseau, J.-J. (1762(1968)). The Social Contract. Penguin, London. Maurice Cranston (trans).

Routley, R. and Routley, V. (1995). Environmental Ethics. Oxford University Press, Oxford.

Royal Forest and Bird Protection Society (2004). "Unsustainable Hoki" - media release. Available from: www.forestandbird.org.nz/mediarelease/2004/ 0523_unsustainablehoki.asp.

Russell, F. S. (1931). Some Theoretical Considerations on the "Overfishing" Problem. ICES Journal du Conseil International pour l'Exploration de la Mer, 6:3-27.

Sabatier, P. A. (1988). An Advocacy Coalition Framework of Policy Change and the Role of Policy-Oriented Learning Therein. Policy Sciences, 21:129-168.

Sagoff, M. (1988). The Economy of the Earth. Cambridge University Press, New York.

Salwasser, H. (1993). Sustainability Needs More Than Better Science. Ecological Applications, 3(4):587-589.

Sampford, C. (1994). Ethics for the Public Sector: Education and Training. Wm Gaunt \& Sons.

Sands, P. (1995). Principles of International Environmental Law Volume I: Frameworks, Standards and Implementation. Manchester University Press, Manchester.

Sartorius, R. (1981). Political Authority and Political Obligation. Virginia Law Review, 67(1):3-17.

Saward, M. J. (2006). Political Theory and the Ecological Challenge, chapter Representation. Cambridge University Press, Cambridge.

Schaefer, M. B. (1954). Some Aspects of the Dynamics of Populations Important to the Management of the Commercial Marine Fisheries. Inter-American Tropical Tuna Commission Bulletin, 1(1956.II.B.1):25-56.

Schlager, E. and Ostrom, E. (1992). Property-Rights Regimes and Natural Resources: A Conceptual Analysis. Land Economics, 68(3):249-262.

Scott, A. (1955). The Fishery: The Objectives of Sole Ownership. The Journal of Political Economy, 63(2):116-124.

Scott, A. and Coustalin, G. (1995). The Evolution of Water Rights. Natural Resources Journal, 35(4):821-979. 
Scott, W. R. (1987). The Adolescence of Institutional Theory. Administrative Science Quarterly, 32(4):493-511.

Scott, W. R. (1995). Institutions and Organizations. Sage Publications, Newbury Park, California.

Selznick, P. (1957). Leadership in Administration. Harper \& Row, New York.

Sen, S. and Nielsen, J. R. (1996). Fisheries Co-Management: A Comparative Analysis. Marine Policy, 20(5):405-418.

Senkowsky, S. (2004). A Tale of Two Commissions: Scientists Seek to Broaden Constituency for Changing US Oceans Policy. Bioscience, 54(6):495-499.

Sethi, R. and Somanathan, E. (2001). Norm Compliance and Strong Reciprocity. In Bowles, S., Boyd, R., Fehr, E., and Gintis, H., editors, Workshop on The Structure and Evolution of Strong Reciprocity. Santa Fe Institute.

Sharp, B. M. H. (1997). From Regulated Access To Transferable Harvesting Rights: Policy Insights From New Zealand. Marine Policy, 21(6):501-517.

Sharples, P. and Turia, T. (2007). Press release: 'MMP can work for Maori' Says Maori Party Over Fisheries Bill Delay. Last accessed 28.8.2007. Available from: http://www.scoop.co.nz/stories/PA0705/S00603.htm.

Shaw, R. and Eichbaum, C. (2005). Public Policy in New Zealand: Institutions, Processes and Outcomes. Pearson Education New Zealand, Auckland.

Shrader-Frechette, K. (2006). Scientific Uncertainty and Environmental Problem Solving. Blackwell Science, Oxford.

Silber, J. F. (1995). Space, Fields, Boundaries: The Rise of Spatial Metaphors in Contemporary Sociological Theory. Social Research, 62:323-355.

Simberloff, D. (1998). Flagships, Umbrellas and Keystones: Is Single-Species Management Passe in the Landscape Era? Biological Conservation, 83:247-257.

Singleton, S. (2000). Co-operation or Capture? The Paradox of Co-management and Community Participation in Natural Resource Management and Environmental Policy-Making. Environmental Politics, 9(2):1-21.

Sinner, J. and Fenemor, A. (2005). The Adoption of ITQ for New Zealand's Inshore Fisheries. Research Report 4, Ecologic.

Sissenwine, M. P. and Mace, P. M. (1992). ITQs In New Zealand: The Era of Fixed Quota in Perpetuity. Fishery Bulletin, 90(1):147-160.

Smith, A. (1776 (1937)). The Wealth of Nations. Random House, New York.

Smith, G. (1993). Impact Assessment and Sustainable Resource Management. Longman, New York. 
Smith, T. D. and Link, J. S. (2005). Autopsy Your Dead ... and Living: A Proposal For Fisheries Science, Fisheries Management and Fisheries. Fish and Fisheries, 6:73-87.

Smith, V. (1968). Economics of Production From Renewable Natural Resources. American Economic Review, 58:409-431.

Soboil, M. and Craig, T. (2006). Growing Pains of the QMS. Technical report, Aotearoa Fisheries Ltd.

Sokal, A. and Bricmont, J. (1998). Fashionable Nonsense: Postmodern Intellectuals' Abuse of Science. Picador, New York.

Spiller, P. T. (1990). Politicians, Interest Groups, and Regulators: a Multiple-Principals Agency Theory of Regulation, or "Let them be bribed". Journal of Law and Economics, 33(1):65-101.

Sprague, R. K. (1962). Plato. London.

Starr, P., Annala, J. H., and Hilborn, R. (1998). Contested Stock Assessment: Two Case Studies. Canadian Journal of Fisheries and Aquatic Sciences, 55:529-537.

State Services Commission (2007). State Sector Code of Conduct. (online version). Available from: www.ssc.govt.nz/display/document.asp?navid=296 [cited 2008.11.17].

Stathakis, Y. and Vaggi, G., editors (2006). Economic Development and Social Change. Routledge, London.

Stigler, G. (1971). The Theory of Economic Regulation. Bell Journal of Economics and Management Sciences, 2:3-21.

Stokes, K., Gibbs, N., and Holland, D. (2006). New Zealand's Cost-Recovery Regime for Fishery Research Services: an Industry Perspective. Bulletin of Marine Science, 78(3):467-485.

Stone, D. A. (1989). Causal Stories and the Formation of Policy Agendas. Political Science Review, 104:281-300.

Straker, G., Kerr, S., and Hendy, J. (2002). A Regulatory History of New Zealand's QMS. Technical report, Motu Economic and Public Policy Research Trust.

Suppe, F. (1977). The Structure of Scientific Theories (2 ed). University of Illinois Press, Urbana.

Tacconi, L. and Bennett, J. (1995). Economic Implications of Intergenerational Equity. Ecological economics, 12:209-233.

Taylor, B. (2004). Illuminated or Blinded by Science? Issues raised in a Discussion Paper on the Role of Science in Environmental Policy and Decision-making. New Zealand Science Review, 60(4):126-129. 
Taylor, P. (1998). An Ecological Approach to International Law - Responding to the Challenges of Climate Change. Routledge, London.

The Hon. Pete Hodgson (2000). Managing Our Oceans - Address to the New Zealand Marine Sciences Society Conference, Waikato University, Hamilton.

The Rt Hon Jim Anderton (2007). Benthic Protection Accord.

Tietenberg, T. (2000). Environmental and Natural Resource Economics (5 ed). Addison-Wesley, New York.

Tirole, J. (1986). Hierarchies and Bureaucracies: On the Role of Collusion in Organizations. Journal of Law, Economics and Organizations, 2:181-214.

Tress, B., Gunther, R., and Fry, G. (2006). From Landscape Research to Landscape Planning - Aspects of Integration, Education and Application, chapter Defining Concepts and the Process of Knowledge Production in Integrative Research, pages 13-26. Wagenen UR Frontis Series 12.

Turei, M. (2007). Press release: Sustainable Fisheries Absolute Necessity - Greens. Last accessed 3.9.2007. Available from: http://www.scoop.co.nz/stories/ PA0705/S00392.htm.

Turvey, R. (1964). Optimization and Suboptimization in Fishery Regulation. The American Economic Review, 54(2):64-76.

Tversky, A. and Kahneman, D. (1981). The Framing of Decisions and the Psychology of Choice. Science, 211:453-458.

Ubel, P. A., DeKay, M. L., Baron, J., and Asc, D. A. (1996). Cost-Effectiveness Analysis in a Setting of Budget Constraints - Is It Equitable? The New England Journal of Medicine, 334(18):1174-1177.

Urbinati, N. (2006). Representative Democracy: Principles and Genealogy. University of Chicago Press, Chicago.

VanderZwaag, D. (2002). The Precautionary Principle and Marine Environmental Protection: Slippery Shores, Rough Seas, and Rising Normative Tides. Ocean Development and International Law, 33:165-188.

Vatn, A. (2005). Institutions and the Environment. Elgar, Cheltenham.

Veblen, T. B. (1906). The Place of Science in Modern Civilisation. The American Journal of Sociology, 11(5):585-609.

Vedsmand, T. and Nielsen, J. R. (1995). Devolved Fisheries Management Systems: A Discussion on Implementation of Alternative Fisheries Co-Management Models in Denmark. In Devolved and Regional Managment Systems for Fisheries, volume International Council for the Exploration of the Seas (ICES) C.M. 1995 S:1. European Union.

von Hayek, F. (1960). The Constitution of Liberty. Routlege and Kegan Paul, London. 
Wagner, F. H. (2001). Freeing Agency Research from Policy Pressures: a Need and an Approach. BioScience, 51(6):445-450.

Wald, P. (1985). Negotiation of Environmental Disputes: A New Role for the Courts? Columbia Journal of Environmental Law, 10(1):1-33.

Wallace, C. and Weeber, B. (2003). The Devil and the Deep Sea - Economics, Institutions and Incentives: the Theory and the NZ Quota Management Experience in the Deep Sea. In Deep Sea Conference 2003 1-5 December Queenstown NZ.

Walters, C. J. (1986). Adaptive Management of Renewable Resources. MacMillan, New York.

Weber, J. R. and Word, C. S. (2001). The Communication Process as Evaluative Context: What do Nonscientists Hear When Scientists Speak? BioScience, 51:487-495.

Weber, M. (1922 (1947)). The Theory of Social and Economic Organization. Oxford University Press, New York.

Weber, M. (1948). From Max Weber: Essays in Sociology. Routlege and Kegan Paul, London.

Weeber, B. (1998). Ecosystem Management Principles: New Zealand's Marine Legal Framework. In Wallace, C., Weeber, B. R., and Buchanan, J., editors, Proceedings of the February 1998 SeaViews conference. Environment and Conservation Organisations of Aotearoa New Zealand (ECO).

Weeks, P. and Packard, J. M. (1997). Acceptance of Scientific Management by Natural Resource Dependent Communities. Conservation Biology, 11(1):236-245.

Weible, C., Sabatier, P. A., and Lubell, M. (2004). A Comparison of a Collaborative and Top-down Approach to the Use of Science in Policy: Establishing Marine Protected Areas in California. The Policy Studies Journal, 32(2):187-207.

West, I. F., Molloy, J., Donoghue, M. F., and Pugsley, C. (1999). Seabird and Marine Mammal Bycatch Reduction through Fishing Industry Funded Research: the New Zealand Conservation Services Levy Program. Marine Technology Society Journal, 33(2):13-18.

Wildavsky, A. (1987). Choosing Preferences by Constructing Institutions: a Cultural Theory of Preference Formation. American Political Science Review, 81:3-22.

Williams, M. (1978). Obligations to Future Generations, chapter Discounting versus Maximum Sustainable Yield. Temple University Press, Philadelphia.

Winterton, N. (2003). Science and Sustainability: Who Knows Best? Clean Technology and Environmental Policy, 5:154-166.

Wright, R. (2004). A Short History of Progress. Text Publishing, Melbourne. 
Wyatt, N. (2000). Why Recover Costs? Cost Recovery and Property Rights in New Zealand. In Shotton, R., editor, FAO Fisheries Technical Paper 404/2 - Use of Property Rights in Fisheries Management. Food and Agriculture Organisation (FAO), FAO.

Wynne, B. (1991). Knowledges in Context. Science, Technology and Human Values, 16(1):111-121.

Wynne, B. (1992). Social Theories of Risk. Praeger, Westport CT.

Yager, R. E. (1996). Science / Technology / Society as Reform in Science Education. University of New York Press, New York.

Yandle, T. (2001). Market-Based Natural Resource Management: An Institutional Analysis of Individual Tradable Quota in New Zealand's Commercial Fisheries. $\mathrm{PhD}$ thesis, Department of Political Science, Indiana University.

Yandle, T. (2003). The Challenge of Building Successful Stakeholder Organizations: New Zealand's Experience in Developing a Fisheries Co-Management Regime. $\mathrm{Ma}$ rine Policy, 27:179-192.

Young, H. P. (1988). Condorcet's Theory of Voting. The American Political Science Review, 82(4):1231-1244.

Young, M. D., Gunningham, N., Elix, J., Lambert, J., Howard, B., Grabosky, P., and McCrone, E. (1996). Reimbursing the Future: Biodiversity Paper 9, Vol. 1. Biodiversity Unit, Department of the Environment, Sport and Territories, Canberra.

Younger, P. L., Coulton, R. H., and Froggatt, E. C. (2005). The Contribution of Science to Risk-based Decision-making: Lessons from the Development of Full-scale Treatment Measures for Acidic Mine Waters at Wheal Jane, UK. Science of the Total Environment, 338:137-154.

Yudkowsky, E. (2008). Global Catastrophic Risks, chapter Cognitive Biases Potentially Affecting Judgement of Global Risks. Oxford University Press. 